WMP-27397

Revision 1

\title{
Evaluation of Vadose \\ Zone Treatment \\ Technologies to \\ Immobilize Technetium-99
}

Prepared for the U.S. Department of Energy

Assistant Secretary for Environmental Management

Project Hanford Management Contractor for the

U.S. Department of Energy under Contract DE-AC06-96RL13200

\section{FLUOR.}

P.O. Box 1000

Richland, Washington 


\section{Evaluation of Vadose Zone Treatment Technologies to Immobilize Technetium-99}

Document Type: TI

D. S. Kaback

Geomatrix Consultants, Inc.

M. H. Young

Desert Research Institute

T. W. Fogwell

S.W. Petersen

Fluor Hanford, Inc.

M. D. Ankeny

Idaho National Laboratory

Date Published

February 2006

Prepared for the U.S. Department of Energy

Assistant Secretary for Environmental Management

Project Hanford Management Contractor for the

U.S. Department of Energy under Contract DE-AC06-96RL13200

\section{FLUOR.}

P.O. Box 1000

Richland, Washington
Program/Project: WMP

J. M. H. Hendrickx

New Mexico Institute of Technology

B. B. Looney

Savannah River National Laboratory

E. P. Weeks

U. S. Geological Survey

S. E. Silliman

University of Notre Dame 
Page 5 of 93 of DA02161933

WMP-27397

Revision 1

APPROVAL PAGE

Title: $\quad$ Evaluation of Vadose Zone Treatment Technologies to Immobilize Technetium -99

Approvals: $\quad$ T. W. Fogwell

Manager, Integration and Assessment, Groundwater Remediation Project

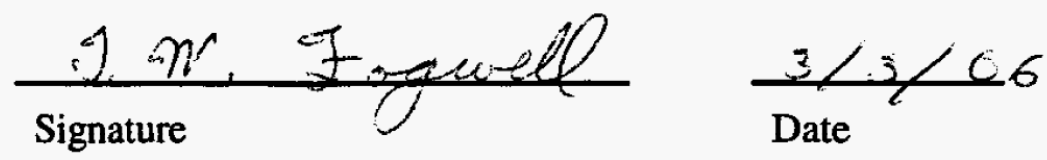

J. G. Riddelle

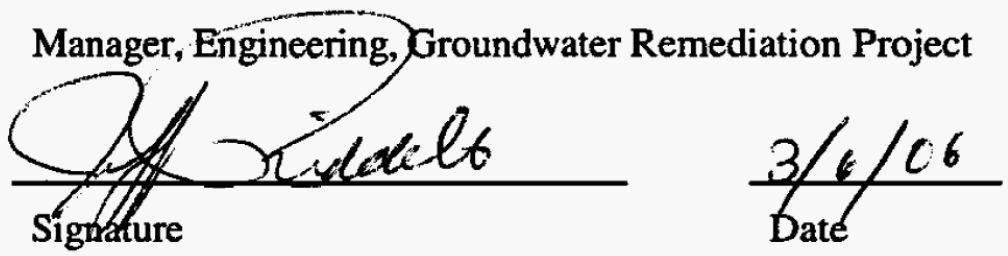

J. A. Winterhalder

Environmental Compliance Officer, Groundwater Remediation Project

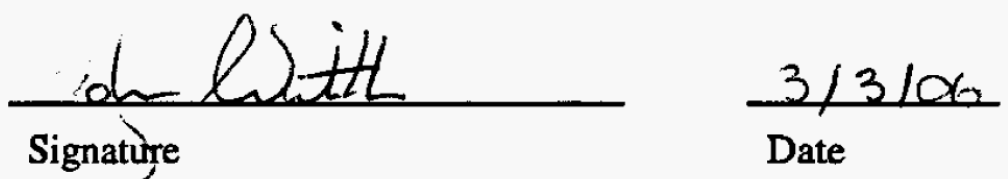

S. W. Petersen

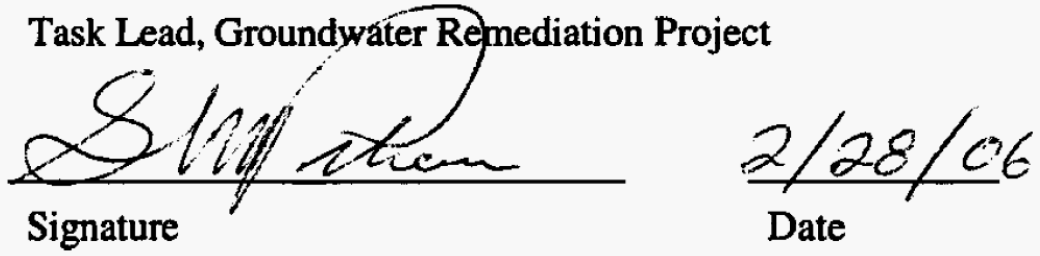

i 
Page 6 of 93 of DA02161933

WMP-27397

Revision 1

This page intentionally left blank 
WMP-27397

Revision 1

\section{TABLE OF CONTENTS}

EXECUTIVE SUMMARY ............................................................................................................ vi

1.0 INTRODUCTION................................................................................................................. 1-1

1.1 Background .......................................................................................... 1-1

1.2 Goal/Objectives................................................................................... 1-1

1.3 Approach ........................................................................................ 1-1

2.0 HANFORD 200-AREA VADOSE-ZONE CONCEPTUAL MODEL ........... 2-1

2.1 Key Elements of the Current Conceptual Model ............................................... 2-1

2.2 Linking the Conceptual Model to an Evaluation of Deep Vadose-Zone Treatment Options

2.3 Developing Consistent and Diagnostic Monitoring Tools and Decision Criteria2-2

\subsection{UNCERTAINTIES RELATED TO DEEP VADOSE-ZONE} REMEDIATION

3.1 Uncertainties Related to Current Subsurface Conditions (the BC Cribs and Trenches Example) 3-1

3.1.1 Extent of Vertical Migration of the Contaminant Plume(s).......................... 3-1

3.1.2 Continuity/Interconnectivity of Sediment Layers......................................... 3-1

3.2 Uncertainties Regarding Impact of Technologies............................................... 3-3

3.2.1 Delivery of Fluids ........................................................................................ 3-3

3.2.2 Change in Subsurface Pressure Distribution................................................. 3-3

3.2.3 Geochemical Impacts.................................................................................. 3-3

3.2.4 Physical Effects................................................................................. 3-6

3.2.5 Unintended Impact of Technology ............................................................ 3-6

3.3 Uncertainties Related to Episodic or Extreme Events ..................................... 3-6

\subsection{REVIEW OF TECHNOLOGIES FOR MINIMIZING DOWNWARD} TRANSPORT OF DEEP VADOSE-ZONE CONTAMINATION .................. 4-1

4.1 Introduction....................................................................................... 4-1

4.2 Evaluation of Alternatives to Minimize Contaminant Migration in the Deep Vadose

Zone .............................................................................................................4-1

4.2.1 In Situ Gaseous Reduction.......................................................................... 4-1

4.2.2 Vadose-Zone Bioreduction ....................................................................... 4-2

4.2.3 Vadose-Zone Permeable Reactive Barrier.................................................. 4-2

4.2.4 Saturated-Zone In Situ Redox Manipulation Permeable Reactive Barrier. 4-3

4.2.5 Vadose-Zone In Situ Grouting .................................................................... 4-3

4.2.6 Vadose-Zone Desiccation ........................................................................ 4-4

4.2.7 Surface Infiltration Control ..................................................................... 4-8 
4.2.8 Soil Flushing 4-11

4.2.9 Perturbation Geochemistry 4-13

4.2.10 Energy-Based Methods 4-14

4.3 Priority Technologies

4.3.1 Surface Infiltration Control

4.3.2 Desiccation

\subsection{GENERAL RECOMMENDATIONS}

5.1 The Decision Tree

5.2 Site Conceptual Model Refinements

5.2.1 Delineation of Current Extent of Plume and Its Interaction with Lithology5-3

5.2.2 Modeling Based Upon Known Lithologic Structure and Incorporating Random Preferential Pathways. 5-3

5.2.3 Linking the Conceptual Model to Evaluate Deep Vadose-Zone Treatment Options

5.3 Modeling of Surface Infiltration Control ...................................................... 5-4

5.4 Evaluation of the Effects of Desiccation .......................................................5-5

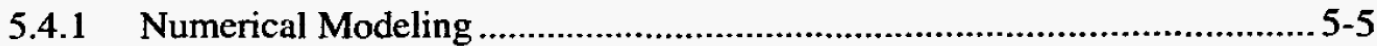



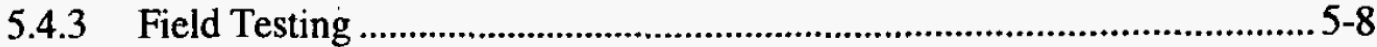

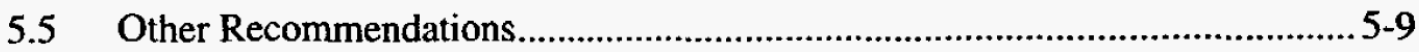

\subsection{RECOMMENDATIONS FOR TESTING, DEMONSTRATING, AND DEPLOYING TECHNOLOGIES AT THE BC CRIBS AND TRENCHES6-1}

6.1 Conceptual Model of the Vadose Zone Beneath BC Cribs and Trenches ........ 6-1

6.1.1 Key Elements of the Current Conceptual Model ......................................6-1

6.1.2 Vertical Penetration of Contaminants at the BC Cribs and Trenches......... 6-5

6.1.3 Linking the BC Cribs and Trenches Conceptual Model to Evaluate Deep Vadose-Zone Treatment Options

6.2 Recommendations for Site Conceptual Model Refinements, BC Cribs and Trenches

Example 6-6

6.2.1 Delineation of Current Extent of Plume and Its Interaction with Lithology6-6

6.2.2 Modeling Based Upon Known Lithologic Structure and Incorporating Random Preferential Pathways. 6-7

6.3 Modeling of Surface Infiltration Control 6-7

6.4 Evaluation of the Effects of Desiccation

REFERENCES. 7-1

Appendix A: Workshop Agenda. A-1

Appendix B: ${ }^{99}$ Te Chemistry. 
WMP-27397

Revision 1

Appendix C: Desiccation Calculations............................................................................... C-2

C.1 Equations Relating Well Discharge to Permeability ...................................... C-2

C.2 Permeability Estimate ..............................................................................

Appendix D: Further Desiccation Analysis .................................................................. D-2

D.1 Motivation for Desiccation in the Deep Vadose Zone................................... D-2

D.2 How Much Water Must be Removed for Desiccation to Work?...................... D-2

D.3 Desiccation under Transient Flow Conditions................................................ D-2

Appendix E: Perturbation Geochemistry ..........................................................................E-2

E.1 Perturbation of Carbonate Systems...............................................................2

E.2 Perturbation of Silicate Systems ....................................................................

\section{LIST OF FIGURES}

Figure ES-1. Recommended Decision Process for Deep Vadose-Zone Remediation............. x

Figure 1. Simplified Geometry of a Contaminant Plume Emanating from a Waste Site ..... 2-3

Figure 2. Exposure of Subsurface Sediments at Hanford's 200 East Area (Ward et al., 2004)

Figure 3. Simplified "Redox Ladder" for ${ }^{99} \mathrm{Tc}$ and a Few Key Co-Disposed Constituents at the BC Cribs and Trenches

Figure 4. Perturbation Geochemistry, Gas-Phase Vadose-Zone Treatments

Figure 5. Schematic of Impact of Infiltration Control on Recharge Rate at the Hanford Site

(Ward, et al., 2004)

Figure 6. Recommended Decision Process for Deep Vadose-Zone Remediation.

Figure 7. Map of BC Cribs and Trenches (not to scale) (Rucker and Sweeney, 2005)....... 6-1

Figure 8. Geologic Profile, ${ }^{99}$ Tc Activity, and Water Content from Borehole C4191, BC

Cribs/Trenches (Rucker and Sweeney, 2005).

Figure 9. Recent High-Resolution Resistivity Geophysics Indicating the Presence of Residual Wastes in the Intermediate Vadose Zone (Rucker and Sweeney, 2005)

Figure 10. Recent High-Resolution Resistivity Geophysics Indicating Possible Penetration of Wastes Deeper in the Vadose Zone at the BC Cribs (Rucker and Sweeney, 2005).. 6-4

Figure 11. Proposed Borehole/Monitoring Well Locations Near the BC Cribs 
WMP-27397

Revision 1

\section{EXECUTIVE SUMMARY}

\section{Introduction}

The Hanford Site End State Vision document (DOE/RL-2003-59) states: "There should be an aggressive plan to develop technology for remediation of the contamination that could get to the groundwater (particularly the technetium [ $\left.{ }^{99} \mathrm{Tc}\right]$ )." In addition, there is strong support from the public and regulatory agencies for the above statement, with emphasis on investigation of treatment alternatives. In July 2004, PNNL completed a preliminary evaluation of remediation technologies with respect to their effectiveness and implementability for immobilization of ${ }^{99} \mathrm{Tc}$ beneath the BC Cribs in the 200 West Area (Truex, 2004). As a result of this evaluation, PNNL recommended treatability testing of in situ soil desiccation, because it has the least uncertainty of those technologies evaluated in July 2004 (Treatability Test Outline, September 30, 2004).

In 2005, DOE-RL and Fluor Hanford convened an independent technical panel to review alternative remediation technologies, including desiccation, at a three-day workshop in Richland, Washington. The panel was composed of experts in vadose-zone transport, infiltration control, hydrology, geochemistry, environmental engineering, and geology. Their backgrounds include employment in academia, government laboratories, industry, and consulting. Their review, presented in this document, is based upon written reports from Hanford, oral presentations from Hanford staff, and each panel members' years of experience in their particular field of expertise.

The purpose of this report is to document the panel's evaluation of various treatment alternatives with potential for minimizing contaminant migration in the deep vadose zone at the Department of Energy Hanford Site. The panel was tasked with assessing the most viable and practical approach and making recommendations for testing. The evaluation of vadosezone treatment alternatives was conducted to be broadly applicable at a variety of locations at Hanford. However, because of limitations of time, the panel was asked to focus on one example, ${ }^{99} \mathrm{Tc}$ contamination below the BC Cribs and Trenches. It is well recognized that conditions at BC Cribs and Trenches are not the same as those at other Hanford locations, but it was selected so that the panel could develop an understanding of site conditions at one location. The recommendations in this report are not intended to address the regulatory decision process for this site.

\section{Evaluation Approach}

The implementability, effectiveness, and cost of technologies that have potential to remediate deep vadose-zone contaminants strongly depend upon subsurface conditions, history of disposal, and the resulting contaminant and moisture distribution. The panel generally agreed with the conclusions of Truex (2004, PNNL Letter Report: Evaluation of In Situ Technologies for Immobilization of Technetium Beneath the BC Cribs), but evaluated other options and also performed a detailed evaluation of Truex's "preferred option," desiccation. Truex noted that the following features must be considered when implementing any of the treatment technologies:

- amount of water introduced to the subsurface; 
WMP-27397

\section{Revision 1}

- impact on water distribution in the subsurface, if hydraulic conductivity is changed;

- contrasts in permeability at multiple intervals within and immediately below the contaminated zone; and,

- thickness and areal extent (i.e., volume) of the contaminated zone.

Another critical document reviewed by the panel is the report entitled "Vadose Zone Contamimant Fate-and-Transport Analysis for the 216-B-26 Trench" by Ward et al. (2004), which produced a conceptual model for the 216-B-26 Trench to support evaluation of remediation alternatives. Modeling was conducted for two remedial alternatives: no action and capping. The capping alternative was also included in the panel's evaluation.

\section{Uncertainties Related to Deep Vadose-Zone Remediation}

Prior to review of individual technologies for minimizing downward transport of deep vadose-zone contamination, the panel identified a number of uncertainties that must be considered during the analysis. Uncertainties were classified as related to 1) current subsurface conditions, using data from BC Cribs and Trenches as an example, 2) impact of technologies, and 3) episodic or extreme events.

Because data on subsurface conditions at Hanford are somewhat limited, due to the high cost of characterization, the panel recognizes that there is significant uncertainty regarding the extent of vertical migration of many of the contaminant plumes. For example, at BC Cribs and Trenches, borehole data throughout the vadose zone is available from only one borehole. At Hanford, typically there is also limited information on continuity and interconnectivity of sediment layers and horizontal extent of contaminants. This is true at BC Cribs and Trenches, although the recent surface high-resolution resistivitiy (HRR) geophysical survey has produced promising results in better characterizing subsurface contaminant distribution. Borehole information is now required to validate the geophysical data. If its performance is confirmed with borehole data, HRR may prove to be a cost-effective volumetric method to characterize contaminant distribution in the subsurface at Hanford where high-salt aqueous wastes were introduced. In order to determine the maximum extent of penetration of radionuclides, such as ${ }^{99} \mathrm{Tc}$, HRR surveys will have to target the entire thickness of the vadose zone.

Uncertainties associated with the impact of technologies implemented as a remedial action include: delivery of fluids, changes in subsurface pressure distribution, geochemical impacts, and unintended impacts (such as improper well installation).

Uncertainties associated with episodic or extreme events (both short-term, such as floods or earthquakes, and long-term, such as climate change) are discussed in terms of the requirement for robustness of any technologies selected for implementation. 
WMP-27397

Revision 1

\section{Review of Technologies for Minimizing Downward Transport of Deep Vadose Zone Contamination}

The panel reviewed ten technology alternatives, six of which had been reviewed by Truex (2004) and one of which had been reviewed by Ward et al. (2004). Those technologies that had been evaluated by Truex (2004) include: in situ gaseous reduction, vadose-zone bioreduction, vadose-zone permeable reactive barrier, saturated zone in situ redox manipulation permeable reactive barrier, in situ grouting, and vadose-zone desiccation. Ward et al. (2004) reviewed surface infiltration control with engineered barriers. Additional technologies reviewed by the panel include: soil flushing, perturbation geochemistry, and energy-based (e.g., thermal) enhancements. As a result of the technical review, priority technologies, as described below, were recommended for further consideration.

The panel generally agreed with the conclusions of Truex (2004), whose preliminary evaluation described vadose-zone desiccation with the least uncertainty of the six technologies. Technologies that require injection or extraction of fluids, particularly liquids, in the subsurface are impacted by significant uncertainties, due to our limited knowledge of subsurface heterogeneities and our ability to access contaminants in finer-grained layers within the section. Gas-phase injection (e.g., desiccation) is somewhat less impacted by these uncertainties. In addition, technologies that rely upon redox manipulation present concerns related to the ability to maintain reducing conditions over an extended period of time and the inefficiency of the reduction due to the presence of oxygen and cocontaminants, such as nitrate and sulfate, which significantly increase the mass of reductant required to produce and maintain reducing conditions.

\section{Recommendations for Deep Vadose-Zone Remediation}

To evaluate options for deep vadose-zone remediation at the Hanford Site, the panel recommends focus on contaminant flux as a key to success. Each of the options should then be evaluated within that context.

An overarching recommendation by the panel is implementation of surface infiltration control as a surface barrier at sites with vadose-zone contamination that has potential to or already has impacted the aquifer. The surface barrier is likely to provide significant benefit towards minimizing further downward transport of contaminants already present in the deep vadose zone. It must also include a monitoring system that will be operated until the peak solute flux has passed. The time-scale of the monitoring may well span several hundreds of years or longer.

Because PNNL recommended further study of desiccation, the technical panel conducted a more extensive review. As such, the panel concluded that factors previously unidentified require that modeling and laboratory/field testing be conducted to determine the viability of the technology. A number of issues, such as vadose-zone heterogeneity, energy balance, geochemical effects, osmotic effects, and implementation issues (e.g., installation of a large number of wells) may impact the effectiveness, implementability, and cost of desiccation and should thus be further examined. The panel also recommended that modeling be conducted to investigate the viability of thermal enhancements to desiccation, although significant issues with implementation likely exist. 
As requested by Fluor Hanford, the panel developed a flow chart (Figure ES-1) to describe the recommended path forward for investigating remedial alternatives for deep vadose-zone remediation at the Hanford Site. Figure ES-1 calls for evaluation of the effectiveness of desiccation for potential application at numerous sites at Hanford. Concurrent with this evaluation for the overall Hanford Site, specific-site activities that include 1) reduction of uncertainty about contaminant location and 2) modeling effectiveness of surface infiltration reduction at that particular site should proceed. 


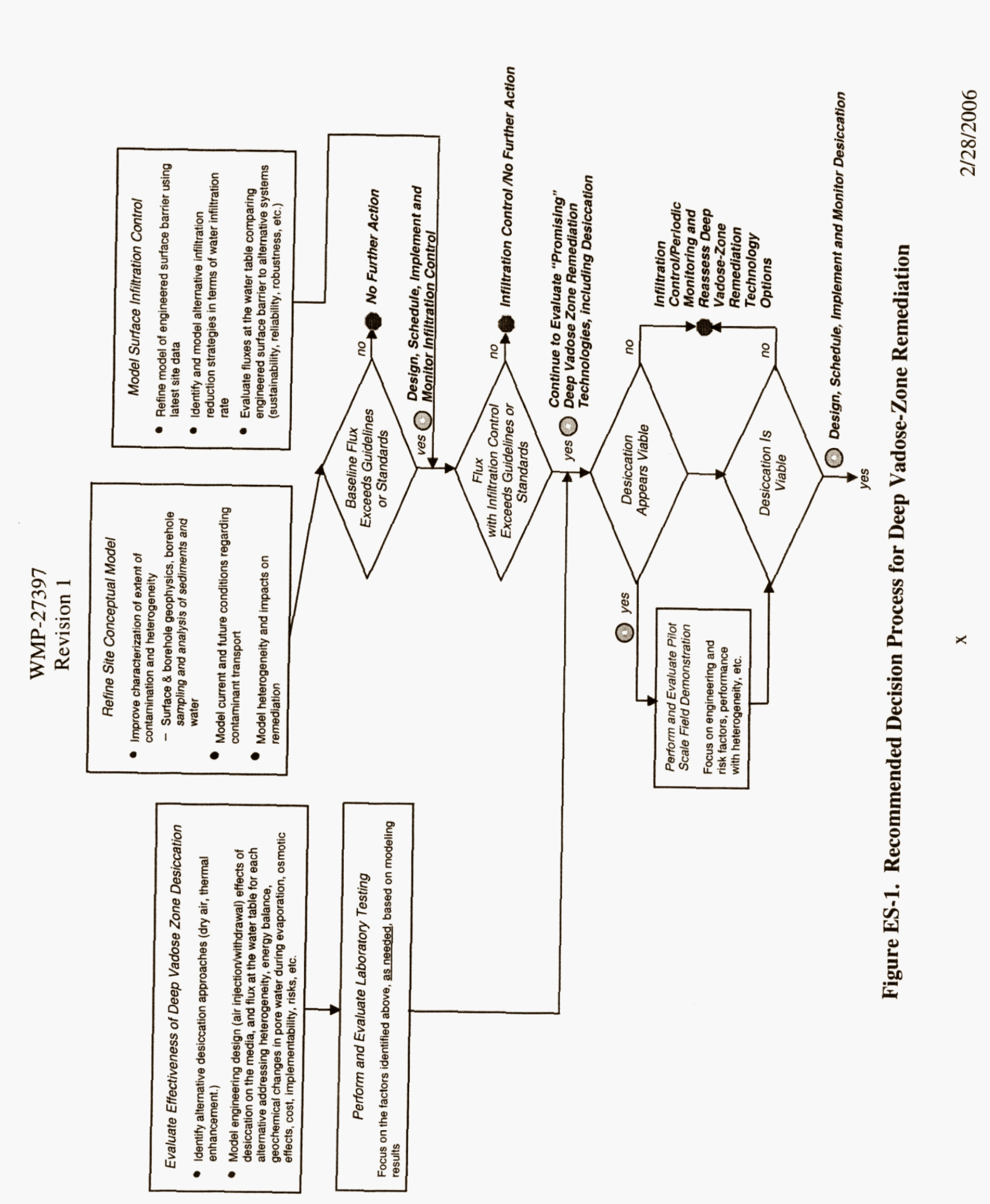

证

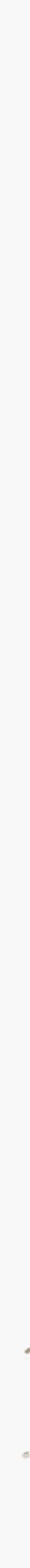


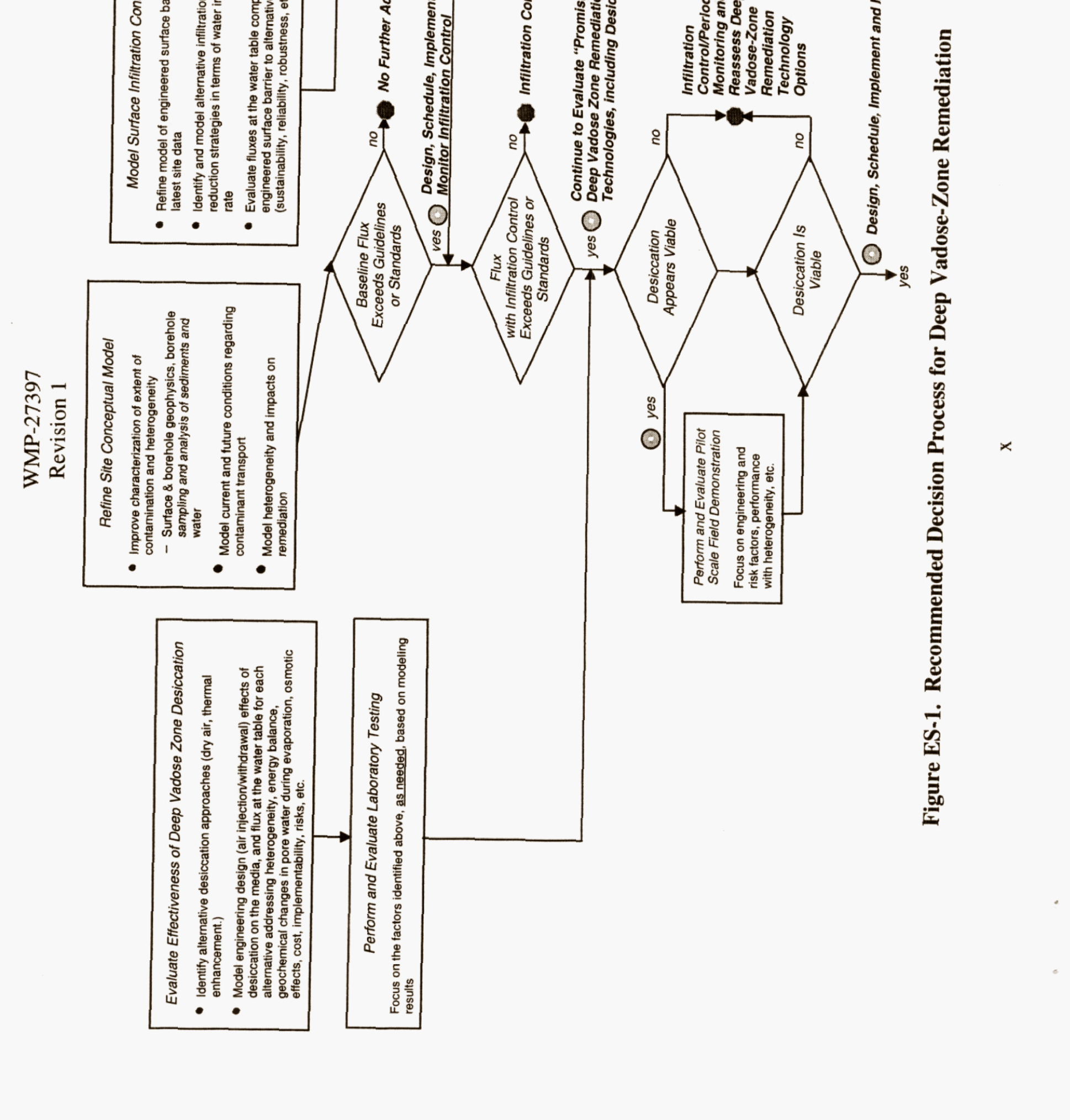
WMP-27397

\section{Revision 1}

For a specific site, after completion of site investigations and modeling of effectiveness of infiltration control, a go/no-go decision should be made. If the baseline flux (no infiltration control) is found to exceed guidelines or standards, surface infiltration control is recommended. The panel strongly recommends this be the first line of attack for vadosezone control. If the modeling shows that flux with surface infiltration control still exceeds guidelines or standards, further work to evaluate promising deep vadose-zone remediation technologies is recommended.

Because the problem of contamination in the deep vadose zone is widespread at the Hanford Site, modeling and testing of the effectiveness of desiccation as a potential remediation technology should be conducted immediately so that results can be incorporated into remedial alternative evaluations at specific sites. The first step in the evaluation of the effectiveness of desiccation involves modeling ${ }^{99} \mathrm{Tc}$ fluxes at the water table, with consideration of heterogeneity (building upon the latest site characterization data), energy balance, geochemical changes in pore water during evaporation, osmotic effects, implementation, risks, and cost.

Based on the modeling results, laboratory studies of desiccation effectiveness should be conducted to answer key questions, focusing on the factors identified above. At the conclusion of both modeling and laboratory studies, there is a key decision point regarding potential viability of desiccation at the Hanford Site (Figure ES-1).

If desiccation is determined to be not viable at a particular site, periodic monitoring of the infiltration control and reassessment of deep vadose-zone technologies are recommended. If desiccation appears to be viable, the panel recommends a pilot-scale field demonstration that focuses on the identified engineering and risk factors in a real-world setting. If the pilotscale field demonstration of desiccation is performed, another go/no-go decision is required after its completion. If it is determined to be a viable alternative, the full-scale system should be designed based upon the results of the demonstration, built, and implemented with both performance and long-term monitoring as a system component.

\section{BC Cribs and Trenches Site Conceptual Model}

The panel was asked to provide specific recommendations regarding remediation of ${ }^{99} \mathrm{Tc}$ below the BC Cribs and Trenches. As such, the panel reviewed the conceptual models of Truex (2004) and Ward et al. (2004). Based upon these models and new site characterization data, the panel described the vadose-zone conceptual model beneath the BC Cribs and Trenches in terms of 1) known facts, 2) inferences, and 3) uncertainties.

- Known facts relate to the physical size of the facility, period of operation, approximate quantity and chemistry of waste disposed, and available subsurface characterization data (e.g., Borehole C4191).

- Inferences relate to the depth of waste penetration based upon high-resolution resisitivity (HRR) data recently collected across the entire site, likely subsurface chemistry, and driving forces for migration.

- Uncertainties relate to the total depth of migration of mobile contaminants across the site, effectiveness of the proposed remedial technologies, and lithologic controls (i.e., heterogeneity). 
WMP-27397

Revision 1

The panel recommends that performance metrics for minimizing ${ }^{99} \mathrm{Tc}$ migration in the vadose zone must be formulated in terms of reduction of mass flux, which could potentially be accomplished through 1) improving the ability of the vadose zone to retain contamination and buffer its release or 2) decreasing the infiltration rate that controls long-term steady-state outputs of both water and contaminants, or 3) reducing ${ }^{99} \mathrm{Tc}$ mass through in situ removal. The first approach includes chemical stabilization and water-removal methods. The second involves decreasing infiltration, which impacts long-term flux from the accumulation zone. The third involves treatment that results in removal of ${ }^{99} \mathrm{Tc}$ from the vadose zone, e.g., in situ soil flushing.

\section{Recommendations for Testing, Demonstrating, and Deploying Technologies at the BC Cribs and Trenches}

The panel recommends that $\mathrm{DOE}$ and the regulatory agencies establish an effective regulatory path forward for the BC Cribs and Trenches, which includes an early assessment of the effectiveness of surface infiltration control, refining the work by Ward et al. (2004) through use of new site characterization data followed by establishment of a ROD for the surface infiltration control, while including later assessment of alternative enhancements, such as desiccation, pending the results of laboratory and field testing. The panel also recommends further characterization to reduce uncertainty regarding the vertical distribution of ${ }^{99} \mathrm{Tc}$ and subsurface heterogeneity in the target volume prior to the later assessment of alternative enhancements.

Refinement of Ward et al.'s (2004) modeling should be conducted to: 1) include the recently collected HRR and borehole data collected for HRR validation; 2) identify alternative infiltration-control strategies, and 3) examine ${ }^{99} \mathrm{Tc}$ fluxes at the water table in terms of sustainability, reliability, and robustness to extreme events and compare to the no-action alternative.

A decision regarding implementation of active subsurface remediation must take into account the current distribution of ${ }^{99} \mathrm{Tc}$ at the site. As such, the panel recommends the following characterization activities at $\mathrm{BC}$ Cribs and Trenches.

- Perform an additional HRR survey to target greater depths in the vadose zone (i.e., to the water table), thus providing information on the limits of vertical penetration of ${ }^{99} \mathrm{Tc}$;

- Drill additional boreholes to collect depth-discrete data (e.g., ${ }^{99} \mathrm{Tc}$, nitrate, moisture content, geology, porosity, bulk density) throughout the vadose zone in areas of suspected deep penetration, i.e. Cribs; data shall be collected from both discrete core samples and downhole geophysical logging tools (pulsed neutron for porosity and dual gamma for density); data will also be used to validate the additional HRR survey;

- Install additional monitoring wells and collect groundwater samples underlying and downgradient of the Cribs (utilizing the new boreholes if possible); and,

- Perform comprehensive 3-D data analysis to better characterize subsurface heterogeneity within the deep vadose zone. 
WMP-27397

Revision 1

\subsection{INTRODUCTION}

\subsection{Background}

The Hanford Site End State Vision document (DOE/RL-2003-59) states, in Alternative (Variance) 3: "There should be an aggressive plan to develop technology for remediation of the contamination that could get to the groundwater (particularly the technetium $\left[{ }^{99} \mathrm{Tc}\right]$ )." In addition, comments from the public workshops for the End State Vision concluded that Variance 3 strongly supported the above statement. Currently, regulatory agency interest in deep vadose-zone treatment is high. Both the U.S. Environmental Protection Agency and Washington State Department of Ecology have urged Department of Energy Richland (DOE$\mathrm{RL})$ to investigate treatment alternatives.

In 2004, a preliminary technology assessment was conducted by Pacific Northwest National Laboratory (PNNL) (Truex, 2004) to evaluate a number of remediation technology alternatives. In addition, Ward et al. (2004) analyzed fate and transport of vadose-zone contaminants, comparing no action to capping as a remedial alternative. As a result of this work, Truex recommend further testing of vadose-zone desiccation as a potential remedial method for minimizing migration of mobile contaminants in the vadose zone, thus enhancing groundwater protection. The next step proposed by DOE-RL and Fluor Hanford was to convene an independent technical panel to review a number of alternatives, including desiccation, based upon their specific experience and the work completed to-date at Hanford.

\subsection{Goal/Objectives}

The purpose of this project was to evaluate various treatment alternatives targeted to minimize contaminant migration in the deep vadose zone at the DOE Hanford Site in Washington (WA). The evaluation was completed by an independent technical panel tasked with assessing the most viable and practical approach and providing recommendations regarding testing required, before the preferred alternative can be applied at specific locations at the Hanford Site. Although the evaluation of alternatives is broadly focused on application at a variety of locations at the Hanford Site, the panel was also asked to provide specific recommendations regarding remediation/fixation of ${ }^{99} \mathrm{Tc}$ currently located at depth in the vadose zone below the BC Cribs and Trenches in the 200 East Area.

\subsection{Approach}

In early 2004, Fluor Hanford identified a number of technical experts from academia, national laboratories, industry, and the federal government to participate as a technical panel for the review of alternatives. The experts have significant experience in a number of fields, including vadose-zone fluid migration, hydrogeology, aqueous geochemistry, numerical modeling, and environmental engineering. Panel participants include: Dr. Mark Ankeny, Idaho National Laboratory, Dr. Jan Hendrickx, New Mexico Institute of Technology, Dr. Dawn Kaback, Geomatrix Consultants, Inc., Dr. Brian Looney, Savannah River National Laboratory, Dr. Stephen Silliman, University of Notre Dame, Mr. Edwin Weeks, United States Geological Survey, and Dr. Michael Young, Desert Research Institute. The panel participated in a three-day workshop in Richland WA the week of April 25, 2005. The workshop agenda is provided in Appendix A. On the first day, presentations on historical 
operations and the PNNL technology evaluation and modeling efforts were made by staff from Fluor Hanford, CH2MHill, and PNNL. The panel also attended a tour of the PNNL laboratory facility where laboratory testing on various aspects of vadose-zone transport is being conducted. The remainder of the workshop involved internal panel discussions and an outbriefing to the broad stakeholder group at the conclusion of the workshop. After the workshop, the panel prepared this report to document their findings and recommendations.

Section 1.0 of the report provides introductory information such as background, goal/objectives of the project, and approach. Section 2.0 provides a brief description of the Hanford Site vadose-zone conceptual model regarding fate and transport of mobile radionuclides. Section 3.0 identifies general issues related to deep vadose-zone remediation. Section 4.0 provides the evaluation of alternatives, which is targeted broadly towards application at any of the waste management units at the Hanford Site. Technologies were evaluated as to whether they could reduce mass flux of contaminants or delay arrival of contaminants at the water table, and remain insensitive to uncertainties in field conditions, including potential extreme events. Technologies showing promising long-term performance, while minimizing contaminant flux, are preferred. Section 5.0 provides recommendations for deep vadose-zone remediation at Hanford, while Section 6.0 presents the BC Cribs and Trenches conceptual model and recommendations for testing, demonstrating, and deploying technologies at that site. 
WMP-27397

\section{Revision 1}

\subsection{HANFORD 200-AREA VADOSE-ZONE CONCEPTUAL MODEL}

\subsection{Key Elements of the Current Conceptual Model}

The 200 Area at the Hanford Site has a significant historical record of liquid waste disposal. Because of the large size of the site and the complexity of waste disposal operations, the panel was asked to concentrate on the BC Cribs and Trenches in the 200 West Area as an example site. A more detailed conceptual model of the BC Cribs and Trenches is provided in Section 6. Here we describe basic conditions that may be present at numerous waste sites in the 200 Area of the Hanford Reservation; however, significant differences exist site by site.

The following highlights key elements of the 200-Area vadose-zone conceptual model; these elements are organized into categories based on the approximate level of certainty or uncertainty.

\section{What We Know}

- Millions of gallons of liquid wastes, many of which were brines containing radionuclides, were disposed to the subsurface at numerous locations at Hanford.

- Some mobile contaminants (e.g.. ${ }^{99} \mathrm{Tc}, \mathrm{NO}_{3}$ ) have migrated to depth, reaching the water table in some locations and not in others. Because of its extended half-life and high mobility, ${ }^{99} \mathrm{Tc}$ is a priority contaminant for remedial strategy development. Appendix A contains information on ${ }^{99} \mathrm{Tc}$ chemistry.

- In the 200 Area, the depth to the water table is approximately 65-100 meters.

- The vadose zone at Hanford consists of unconsolidated fluvial sediments, primarily sands, gravels, and cobbles, with thin layers of silts.

- The current moisture profile in the vadose zone varies widely from $<2$ to 15 weight percent, with higher values associated with finer grained layers.

What We Suspect

- Heterogeneity is impacting subsurface migration pathways and rates. Preferential pathways that accelerated transport of contaminants to great depths in the vadose zone and even to the water table are believed to exist, but are difficult to predict.

- Surface geophysical methods (high-resolution resisitivity [HRR]) may be able to map contaminant plumes due to their high salt content.

What Is Unclear

- Total depth of migration of mobile contaminants (e.g., $\left.{ }^{99} \mathrm{Tc}, \mathrm{NO}_{3}\right)$ is not known at every waste site.

- Effectiveness of proposed remedial technologies has significant uncertainties.

- Lithologic controls (e.g., thickness and continuity of silty zones and the role in focusing water flow, and the role of coarse zones in forming capillary barriers or in facilitating waste penetration) are not well understood at this site. 


\section{Revision 1}

- Geochemical conditions (impact of waste brines and their interaction with subsurface minerals) must be considered during any evaluation.

- Impacts of variable methods of wastewater discharge complicate the situation.

\subsection{Linking the Conceptual Model to an Evaluation of Deep Vadose-Zone Treatment Options}

The implementability, effectiveness, and cost of technologies that target deep vadose-zone contaminants strongly depend on subsurface conditions, the history of disposal, and the resulting contaminant and moisture distribution. Such technologies require the ability to deliver amendments to or remove moisture or contaminants from target zones.

The panel generally concurred with the criteria developed by Truex (2004) in his feasibility study evaluation for the BC Cribs. Specifically, Truex noted that the following features must be considered in the implementation of any in-situ treatment technology:

- amount of water introduced to the subsurface;

- impact on water distribution in the subsurface, if the hydraulic conductivity is changed by the in situ technology;

- contrasts in permeability at multiple intervals within and immediately below the contaminated zone; the layers of finer-grained material are typically very thin ( $\mathrm{mm}$ to $15 \mathrm{~cm}$ ); layers identified as generally coarse may be laminated by very thin lenses of finer-grained material;

- depth and thickness of the contaminated zone in the subsurface;

- areal extent of contamination.

Truex (2004) opted not to consider technologies that required flushing or addition of large volumes of liquid reagents. In reviewing the feasibility study, the panel conditionally accepted this as an appropriate conclusion. To confirm this preliminary assumption, additional analysis (documented later in this report) was performed.

Notably, because Truex (2004) focused exclusively on in situ treatment technologies, the work did not include evaluation of the performance of infiltration control as a long-term remedy nor potential synergies to be considered if infiltration control were combined with any of the proposed in situ methods. However, Ward et al. (2004) evaluated the impact of surface infiltration control as engineered barriers.

\subsection{Developing Consistent and Diagnostic Monitoring Tools and Decision Criteria}

The ultimate goal of remedial activities is to reduce contaminant release and flux to the groundwater. Thus, the panel recommends the measures of the success for such actions should specifically target and quantify flux-reduction performance, and modeling and decision tools that support these measures also focus on flux reduction. The importance of this concept was highlighted during discussions of vadose-zone desiccation as a remedial alternative, because desiccation may increase contaminant maximum point-concentrations, while decreasing overall flux. Because flux is difficult to directly measure, conceptualize, and compare to regulatory standards, the panel recommends use of a flux-averaged concentration for modeling, interpretation of field monitoring data, and decision making. 
The simplest method for calculating a flux-averaged concentration is based upon a standard geometry for groundwater monitoring wells, as shown in Figure 1. Looney and Falta (2000) present a discussion of this concept for a site at Brookhaven National Laboratory. A projected contaminant concentration in a standard well geometry is correlated with the flux to groundwater. The maximum calculated concentration is predicted at the down-gradient edge of the area where the subject waste was released to the water table.

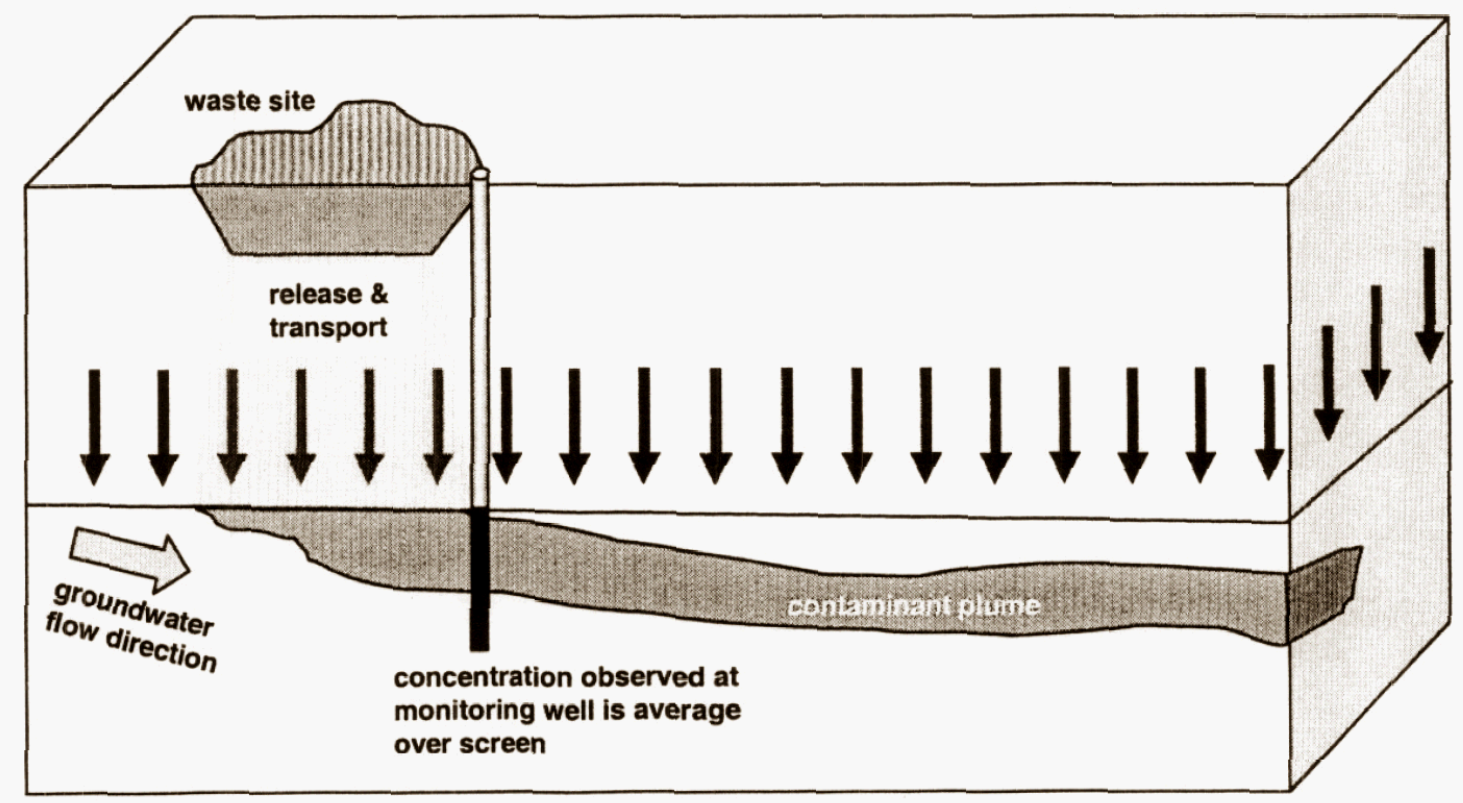

Figure 1. Simplified Geometry of a Contaminant Plume Emanating from a Waste Site

As an example, if a remediation, such as desiccation, results in doubling of the maximum point concentration, but reduces the flow to less than half, the calculated groundwater concentration in the well will reflect the net change in flux (and be in units of concentration that are traditional to regulatory decision-making). If the plume is thinner than the length of the well-screen, then the composite maximum point concentration is reduced proportionally by the water drawn in from the "clean" screen interval. If the contaminated interval is thicker than the length of the well screen, then the undiluted, composite maximum-point concentration will be measured by the well.

Another interesting feature of this approach is the projected vertical trajectory of the plume after it leaves the footprint of the waste-disposal area. This behavior suggests a strategy of monitoring plumes in three dimensions and that the vertical flow component be considered when designing and installing such monitoring wells (through selection of an appropriate standard screen length and shifting the vertical positions of the screens as distance from the subject waste site increases). Consistent application of the recommended approach throughout the plume will minimize potential problems associated with interpretation of data across a site. 
WMP-27397

Revision 1

The panel recommends that Hanford consider implementing this or an equivalent monitoring approach on a site-wide basis to develop consistent remediation decisions across the site and aid in communication with regulators and stakeholders. Currently, Hanford uses this approach for some (e.g., the down-gradient well), but not all, modeling calculations. 
WMP-27397

Revision 1

\subsection{UNCERTAINTIES RELATED TO DEEP VADOSE-ZONE REMEDIATION}

The panel recognized that significant uncertainties regarding the contaminant problem and possible solutions remain, and that they must be strongly considered when evaluating alternatives for minimizing contaminant migration in the deep vadose zone. Critical to the deliberations of the panel was the recognition that significant uncertainties remain with respect to: (1) current subsurface conditions (geology, spatial distribution of moisture content and contaminants, subsurface geochemistry and mineralogy, etc.), (2) long-term impact of the various possible technologies with current and future subsurface conditions, and (3) possible future changes in the natural or anthropogenic environments that might impact the efficacy of the technologies. As a result, the panel considered possible impacts of these uncertainties as an important component in the selection and design of priority technologies. It is noted, however, that the time limitations placed upon the panel made it impossible for the panel to thoroughly assess any of the uncertainties / extremes. Thus, a critical recommendation (Section 5) calls for detailed modeling to consider the potential impact of these uncertainties / extremes to be performed. This uncertainty analysis was targeted towards conditions at the BC Cribs and Trenches as an example, but should be specifically applied during a similar analysis at other appropriate locations at the Hanford Site.

\subsection{Uncertainties Related to Current Subsurface Conditions (the BC Cribs and Trenches Example)}

Uncertainties related to subsurface conditions are described in terms of the BC Cribs and Trenches example, further discussed in Section 6.0. Uncertainties would often be similar from site to site across the Hanford Site.

\subsubsection{Extent of Vertical Migration of the Contaminant Plume(s)}

A maximum depth of penetration of contaminants cannot often be determined due to limited subsurface data. As an example, at BC Cribs and Trenches there are data available from only one borehole that extends throughout the vadose zone. A recent surface HRR survey (Rucker and Sweeney, 2005) indicates that, in the areas of the Cribs in the northeastern portion of the site, contamination may have extended well beyond 50 meters depth, as observed near the trenches in the one borehole. This example illustrates the uncertainty associated with determining the maximum depth of penetration. Complicating the picture is the fact that the current HRR surveys did not target greater depths and thus cannot define the base of the contaminant plume across the entire site.

This uncertainty clearly impacts all proposed technologies that require targeting zones of current contamination (either through reduction in moisture content or stabilization of the contaminants through geochemical means) and may also impact the timing required for technologies reliant upon interception of the contaminant through groundwater capture and treatment.

\subsubsection{Continuity/Interconnectivity of Sediment Layers}

Subsurface heterogeneity, known to be present at the BC Cribs and Trenches and other subsurface locations at the Hanford Site, appears to affect flow and transport of contaminants and will have similar effects on injection or extraction of fluids as part of an active 


\section{WMP-27397}

\section{Revision 1}

remediation system. The presence of highly heterogeneous layering at the BC Cribs and Trenches is indicated in Figure 2 (Ward et al., 2004).

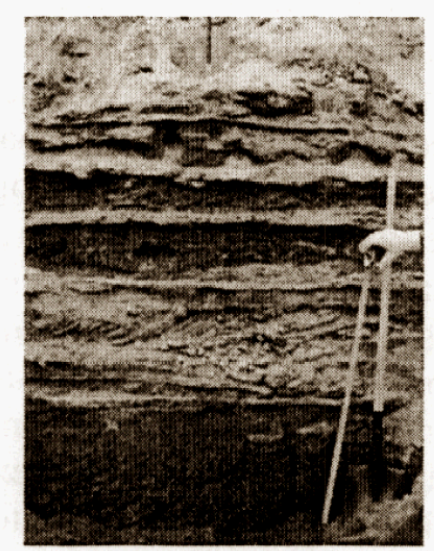

Figure 2. Exposure of Subsurface Sediments at Hanford's 200 East Area (Ward et al., 2004)

Flow in unsaturated porous media is extremely sensitive to the continuity and interconnectivity of fine-grained sediments of variable grain size. Fine-grained sediments can hold more moisture at a given soil-water potential than can most coarse sediments. Further, the hydraulic conductivity is strongly dependent upon moisture content, such that hydraulic conductivity at saturation tends to be significantly higher for coarse-grained sediments than fine-grained sediments, but this relationship reverses as the moisture content decreases (Hillel, 1998, Figure 8.5). Without detailed characterization of the relationship between sediment type, conductivity, and moisture content, it is difficult to estimate which sediment type will dominate fluid-flux distribution in the vadose zone. In addition, this fluidflux distribution among sediment types will vary as the mean moisture content varies in space or time. The conductivity versus percent-moisture relationship varies most significantly for coarse sediments, and as such, can change dramatically if moisture is removed or added to the subsurface. In a relatively dry setting like Hanford, fine-grained sediments may have lower resistance to partially saturated flow (higher relative permeability) than coarse-grained sediments, but an evaluation of soil hydraulic properties would be needed to ascertain how the resistance changes with water content.

Knowledge of the location, continuity and interconnectivity among layers of fine- and coarse-grained sediments is critical to understanding both current fluid fluxes and potential changes in fluxes related to application of various remediation technologies. The fact that borehole data for the entire vadose-zone interval exist for only one location at the $\mathrm{BC}$ Cribs and Trenches introduces significant uncertainty regarding lateral continuity of the finer grained layers identified in C4191. As a result, this uncertainty must be applied to analyses of potential flow pathways for both fluids and gases that might be introduced or extracted during an active remedial action. 
WMP-27397

Revision 1

\subsection{Uncertainties Regarding Impact of Technologies}

In addition to uncertainties related to current conditions in the subsurface, there are a number of uncertainties related to proposed remediation / stabilization technologies and their impact on the subsurface. Many of these are discussed in Truex (2004) and are further described here.

\subsubsection{Delivery of Fluids}

Most of the methods investigated to minimize the movement of contaminants from their current location in the vadose zone to the water table involve source treatment or barrier development/treatment by the injection and/or removal of fluids, either gas or liquid. Hence, for problems involving areally extensive contamination, successful implementation of active treatment will require nearly complete volumetric coverage to be achieved.

The presence of subsurface heterogeneity can lead to substantial difficulty in achieving such coverage. Specifically, flow tends to follow preferential pathways that are defined by the distribution of particle size and initial distribution of moisture content. For example, finegrained sediments with high relative moisture content will tend to have far higher resistance to the movement of a gas than will coarse-grained sediments with low relative moisture content. For such problems, bypass zones remain essentially untreated, due both to well placement and vadose-zone heterogeneity. Experience gained by the petroleum extraction industry during enhanced recovery operations and the in situ solution mining industry can shed substantial light on the issues of bypass flow and well placement. The impact of physical heterogeneity on formation of bypass zones remains an active topic of research.

When the invading fluid is a liquid (e.g., water, gel, etc.), this problem is exacerbated by the fact that movement of liquids in the vadose zone tends to be dominated by gravity, such that horizontal migration away from a point source is usually quite minimal (the primary mean direction of motion tends to be vertically downward). Hence, distributing fluids horizontally without creating substantial vertical flux of the invading liquid is usually problematic.

Finally, because problems of transport and delivery are scale dependent, bypass flow may be much less significant for treatment of localized contamination. Thus, proposed methods that may be rejected for deployment at the BC Cribs and Trenches might be suitable for small sites of point-source contamination. Because of this scale issue, treatment options should be considered for each site separately.

\subsubsection{Change in Subsurface Pressure Distribution}

Technologies that involve injection or withdrawal of fluids (liquids or gases) will necessarily change subsurface pressure conditions (in both the soil liquid and soil gas phases). Such changes could alter distribution of flow in the subsurface (again, both liquid and gas), including the possibility that a change in driving force may cause migration of contaminated fluids.

\subsubsection{Geochemical Impacts}

The ${ }^{99} \mathrm{Tc}$ plume is associated with extremely high loadings of other contaminants including nitrate, sulfate, and sodium. These high loadings combined with uncertainty of the local mineralogy, make it difficult to predict geochemical interactions likely to occur under either natural conditions or the influence of technologies that directly or indirectly impact such 
factors as mean moisture content or redox state. These uncertainties impact, to varying degrees, all potential remediation technologies

Due to the complexity of the contaminants present in many of the sites contaminated in the deep vadose zone, hydraulic and/or chemical manipulation of the contaminated regions may lead to complex chemical interactions and reactions, including precipitation and/or dissolution of mineral phases, creation of colloidal materials, and changes in oxidation state of various constituents. It is not clear that the complex geochemical changes that may occur in association with many of the potential remediation technologies have been adequately modeled, particularly under field conditions. As a result, significant uncertainty exists with respect to the magnitude of remediation effort required, impacts of the remediation, the time period over which remediation might occur, or the long-term sustainability of the remediation effort.

As a specific example, that of desiccation, changes in pore water chemistry occurring as a result of the intended remedial action will require significant additional study and consideration. These potential changes were not sufficiently addressed in the Truex (2004) feasibility study or in the PNNL draft treatability test plan (PNNL, 2004). The evaporation of pore water may increase contaminant concentrations and may affect mobility through: 1) chemical changes that promote enhanced adsorption of contaminants, including more available sites due to precipitation of high-surface area phases; and, 2) co-precipitation of mineral phases with contaminants as saturation is exceeded, occluding contaminants from interaction with pore water and preventing their continued migration, and 3) possible chemical reactions that change vadose-zone transport properties.

It was noted further that precipitation and adsorption are strongly influenced by $\mathrm{pH}$ variations. In acidic plumes, $\mathrm{pH}$ is controlled by interactions with mineral phases. These include pH buffering by dissolution of minerals and sorption of acid to mineral surfaces. Pore water in the vadose zone is under the influence of carbon dioxide partial pressures that exceed atmospheric ( $\mathrm{P}_{\mathrm{CO} 2}=10^{-3.5} \mathrm{~atm}$.) (Karberg et al., 2005). If air is used to dry the vadose zone, then the $\mathrm{P}_{\mathrm{CO} 2}$ of the system will be reduced to $10^{-3.5} \mathrm{~atm}$. and $\mathrm{pH}$ will rise by a corresponding amount. This may result in enhanced adsorption of metals and radionuclides, as well as contribute to precipitation of mineral phases.

Although redox-based stabilization is a widely proposed approach for treatment of redoxsensitive contaminants, such as metals and some radionuclides (e.g., ${ }^{99} \mathrm{Tc}$ ), the biggest uncertainty lies with maintenance of reducing conditions in the subsurface within a normally oxidizing target volume. The amount of reductant and the need for repeated treatment, due to the continuing presence of the contaminant, are major questions as to the viability of the process. When assessing the viability of this process, co-contaminants (such as nitrate and sulfate), must be considered in terms of requirements for producing and maintaining reducing conditions, as well as the potential side effects of their reduction. Current proposals for redox manipulation rely on chemical reagents and/or on microbial metal reduction. Gasphase chemical reduction has been studied by various investigators (Thornton, et al., 1999 and 2003). Chemical reduction by aqueous solutions of sodium dithionite has also been studied and implemented full-scale at the Hanford Site (e.g. Amonette et al., 1994; Williams et al., 2000). Other aqueous solutions such as those containing $\mathrm{Fe}$ (II), $\mathrm{Cu}$ (I), or $\mathrm{Sn}$ (II) may also reduce ${ }^{99} \mathrm{Tc}$. The Natural and Accelerated Bioremediation (NABIR) program of DOE 


\section{Revision 1}

has funded several projects to microbially reduce ${ }^{99} \mathrm{Tc}$. Examples can be found on the NABIR website http://www.lbl.gov/NABIR.

Another factor that contributes to the inapplicability of vadose-zone redox manipulation at Hanford is the extreme quantities of co-disposed competing electron acceptors, particularly nitrate. Figure 3 shows a redox ladder, which demonstrates that the "tons" of nitrate codisposed with the ${ }^{99} \mathrm{Tc}$ would compete for electrons and inhibit the effectiveness of redox manipulation until almost the entire nitrate pool is depleted. In the 100-D Area where in situ redox manipulation has been deployed to treat chromium through injection of liquid sodium dithionite, calculations have shown that more than $97 \%$ of the reductant is utilized removing nitrate and oxygen from the system and less than $3 \%$ targets the contaminant of concern, i.e. chromium. These chemical challenges were not fully considered in the Truex (2004) feasibility study, and as such, provide additional and compelling reasons why redox manipulation is not appropriate for many sites at Hanford, including the BC Cribs and Trenches.

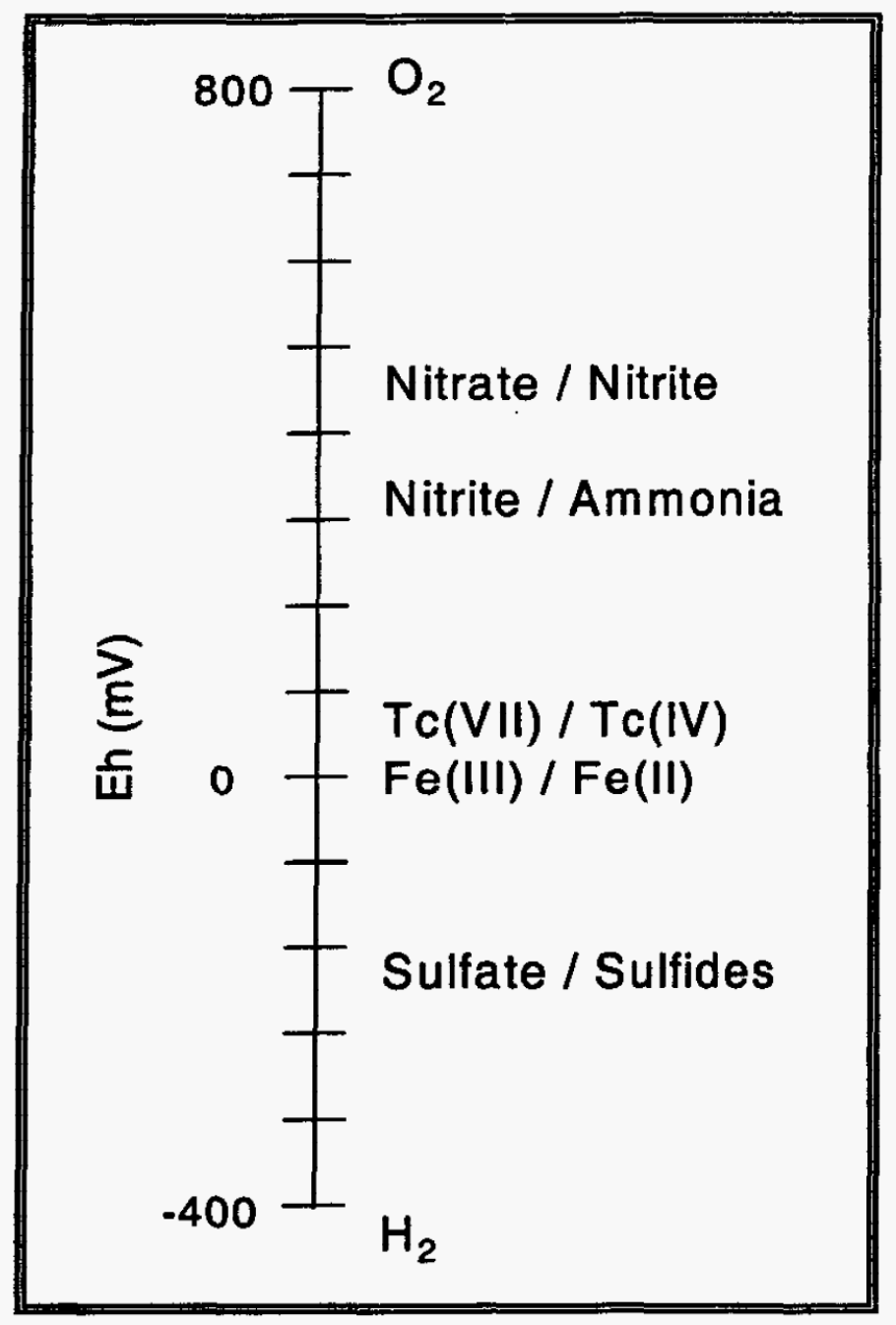

Figure 3. Simplified "Redox Ladder" for ${ }^{99} \mathrm{Tc}$ and a Few Key Co-Disposed Constituents at the BC Cribs and Trenches 
WMP-27397

\section{Revision 1}

\subsubsection{Physical Effects}

Physical effects of soil desiccation may include an increase in soil surface area due to microfracturing after rewetting of the soil. Micro-fracturing may cut across finer-grained layers that are current retaining the contaminants, thus potentially promoting further downward migration of contaminants remaining in the vadose zone.

\subsubsection{Unintended Impact of Technology}

In addition to the hydraulic and geochemical uncertainties associated with developing technologies for remediation of the deep vadose zone, the installation of the equipment required by these technologies provides additional uncertainties. In particular, any permanent intrusion into the subsurface (e.g., well casing, tubing, etc.) creates a potential preferential pathway (along the line of the intrusion) for migration of excess fluid into the deep vadose zone. Such preferential flow can create new point sources of water, thus changing the flow dynamics in the vadose zone and potentially driving existent contaminants deeper. One extreme event associated with a variance in procedures for installation of a well could introduce significant quantities of a fluid phase into the vadose zone. While such an event is extremely unlikely in the short term (e.g., the next 100 years), the potential for such an event may increase over time.

\subsection{Uncertainties Related to Episodic or Extreme Events}

In addition to the uncertainties in current conditions and impact of technology, uncertainty enters the analysis of potential technologies via possible extreme events (e.g., floods, earthquakes, extreme weather patterns) or long-term changes in climate (e.g., increase in mean annual precipitation).

As outlined in Sections 1 and 2 of this report and discussed in further detail in Section 4, when considering long timeframes, the primary driver moving contamination towards the water table is net recharge. Hence, one category of extremes of concern in selecting appropriate technologies involves resistance of a proposed technology to short-term infiltration extremes as well as long-term increase in the differential between annual precipitation and evapotranspiration, both of which could lead to an increase in net recharge to the deep vadose zone.

Short-term extremes might include a combination of events, such as a late-Autumn fire that destroys most vegetation (including desiccation of the root zone), followed by a warm winter period with heavy (e.g., one meter) snow, and followed by an advancing warm front with heavy rain. This event would lead to substantial excess surface water (due to the snow melt and additional rain) and minimization of evapotranspiration. Thus, potential for infiltration, and thereby potential for increased recharge to the deep vadose zone, is substantially increased.

Long-term extremes would include change of weather patterns leading to an increase in mean annual precipitation, while maintaining or decreasing evapotranspiration. Estimates for such changes in climate, including observations of historical increases in precipitation and predictions of future increases of mean annual precipitation for the Pacific Northwest, can be found in the reports by other authors, including Mote (2003) and Mote et al. (1999). 


\section{WMP-27397}

\section{Revision 1}

In considering natural extremes, it quickly becomes apparent that a number of scenarios can be imagined which, in the correct combination, could lead to failure of many remediation technologies that leave the ${ }^{99} \mathrm{Tc}$ in the subsurface, if no surface infiltration control were implemented. Further, prediction of the impact of these events is highly sensitive both to the postulated event and to the existing surface and subsurface conditions at the time of the event. Hence, there is uncertainty in predicting either the probability or the impact of such extremes.

Rather than attempt to directly model a number of extreme scenarios, the panel suggests that each technology seriously considered for implementation be assessed for the degree to which it is robust to a number of classes of extremes without reference to a particular extreme scenario. 
WMP-27397

Revision 1

\subsection{REVIEW OF TECHNOLOGIES FOR MINIMIZING DOWNWARD TRANSPORT OF DEEP VADOSE-ZONE CONTAMINATION}

\subsection{Introduction}

This section provides information on the panel's review of various technologies for minimizing transport of deep vadose-zone contamination at the Hanford Site. As mentioned previously, the review attempts to consider technologies for deployment at any site at Hanford where deep vadose-zone contamination is known to be present. The panel began by reviewing the evaluations completed by Truex (2004) and Ward et al. (2004). The panel reviewed the Truex preferred alternative, desiccation, in greater detail and also assessed a few additional alternatives. This report does not attempt to repeat the conclusions of the Truex or Ward et al. reports, but provides information on key points that are either distinct from the Truex report or that we believe need to be further emphasized.

\subsection{Evaluation of Alternatives to Minimize Contaminant Migration in the Deep Vadose Zone}

Truex (2004) performed a preliminary screening and identified six active remediation technologies for application to the deep vadose zone at the BC Cribs. Ward et al. (2004) evaluated one active remediation technology as compared to the no-action alternative. Each of these seven technologies is further discussed in this section and information on additional technologies that the panel evaluated is also provided. The focus in this section is on key issues and recommendations, which have been described by Truex and Ward et al. regarding implementation at Hanford.

\subsubsection{In Situ Gaseous Reduction}

In situ gaseous reduction (ISGR) was demonstrated by PNNL at the White Sands Missile Range in New Mexico in 1998 to treat chromate-contaminated soils (Thornton et al., 1999 and 2003). Hydrogen-sulfide gas (200 ppm) was injected into a single injection well at depths of 1-6 meters for 76 days. This well was surrounded by six extraction wells (at a radius of 10 meters), which were operated as soil vapor extraction units to optimize flow of gas through the vadose zone.

Conclusions of the demonstration include the following.

- Seventy percent of the chromate at the site was reduced to $\mathrm{Cr}^{+3}$ thus verifying the effectiveness of the approach.

- The effectiveness of ISGR was limited by subsurface heterogeneities, with channeling of the injected gases in the most permeable sands. The deeper, less permeable sands were bypassed by the injected gases.

- The amount of hydrogen sulfide used during the test exceeded the amount predicted by the laboratory treatability study.

As discussed in Truex (2004), the gas-phase variant appears to be the most promising variant that might be applicable to this target contaminated zone. Unfortunately, the chemical conditions in much of Hanford's deep vadose zone are poorly suited to the necessary redox manipulation. 
WMP-27397

Revision 1

Panel concerns include the following.

- Subsurface heterogeneity may serious impact the effectiveness of gaseous injection into the vadose zone at the Hanford Site. The finer-grained layers that contain more ${ }^{99} \mathrm{Tc}$ and water may be difficult to treat, based on the BC Cribs and Trenches example.

- The limited capacity of the treated zone to maintain anoxic conditions may limit ISGR effectiveness. The presence of co-contaminants, such as nitrate and iron, and the influx of oxygen will require significant amounts of reductant to maintain anoxic conditions. For example, the sodium dithionite injected into the 100-D aquifer to reduce chromate, utilized $97 \%$ of the injected reductant to reduce oxygen and cocontaminants and only $3 \%$ was utilized to reduce the chromate.

As a result of the above concerns, the panel does not recommend gaseous reduction for vadose-zone treatment as a practicable option for most Hanford waste sites, especially larger sites like the BC Cribs and Trenches.

\subsubsection{Vadose-Zone Bioreduction}

Vadose-zone bioreduction requires addition of a microbial substrate to the subsurface to stimulate indigenous microorganisms that can produce anoxic conditions, thus reducing the ${ }^{99} \mathrm{Tc}$ to a less mobile form. If the microbial substrate is added as a gas, the same issues as ISGR (heterogeneity of the subsurface and maintenance of anoxic conditions) are applicable. In addition, there is additional concern regarding whether sufficient indigenous microbial biomass is present in the vadose zone with the desired metabolism. Laboratory experiments have shown ${ }^{99} \mathrm{Tc}$ reduction by microorganisms, but other studies have shown populations that limit the applicability of this method. Injection of gaseous substrates for microbial reduction has been demonstrated only in the laboratory, thus adding further uncertainty to this altemative.

If liquid amendments were required (this was not considered by Truex), significant issues as described in the section on Soil Flushing (Section 4.2.8) would apply. The panel recommends that this alternative not be further considered for this application.

\subsubsection{Vadose-Zone Permeable Reactive Barrier}

Creation of a vadose-zone permeable reactive barrier is a variation on a theme that the ISGR and the vadose-zone bioreduction presented in the previous two sections. It simply calls for a smaller volume to be treated, but requires improved knowledge of contaminant transport rates in the vadose zone, so that the barrier is active when the contaminants migrate through it. The uncertainty associated with when to implement such a technology makes it an impractical choice. In addition, the concerns already mentioned above apply to this option as well.

- The requirement to maintain anoxic conditions for a very long period of time introduces a significant uncertainty and would require continuing treatment and monitoring.

- The presence of the co-contaminants identified above (e.g., nitrate and iron), as well as oxygen, make it difficult and costly to maintain anoxic conditions. 
WMP-27397

Revision 1

\subsubsection{Saturated-Zone In Situ Redox Manipulation Permeable Reactive Barrier}

In situ redox manipulation (ISRM), which involves injection of a reducing liquid (dithionite) into the aquifer through wells, has been demonstrated and deployed at the Hanford Site in the 100-D Area (Amonette et al., 1994; Williams et al., 2000). ISRM has effectively reduced chromate to $\mathrm{Cr}+3$ in all of the injection wells. However, a number of the wells have shown breakthrough, with rising chromate concentrations, within three years after injection. The dithionite injections were originally predicted to maintain anoxic conditions for 23 years and thus have not been as effective as predicted. Some of the reasons for this change in technology effectiveness include 1) subsurface heterogeneity causing preferential pathways, which may be deficient of iron required to maintain reducing conditions, and 2) the presence of co-contaminants, such as nitrate, not originally included in the estimate of longevity.

The panel does not support this alternative, in large part because it requires the contaminants to reach the water table prior to treatment. Specific issues include the following.

- The actual time required for the ${ }^{99} \mathrm{Tc}$ to travel to the water table is highly uncertain and so the timing of implementation of this alternative would also be highly uncertain.

- The requirement to maintain anoxic conditions for a very long period to time introduces a significant uncertainty and would require continuing treatment and monitoring.

- The ability to treat a continuous volume of aquifer is highly uncertain due to our limited knowledge of subsurface heterogeneity.

- The presence of the co-contaminants identified above make it difficult to maintain anoxic conditions.

\subsubsection{Vadose-Zone In Situ Grouting}

Small demonstrations of in situ grouting to contain waste in place have occurred at several DOE sites: 1) Viscous Liquid Barrier at Brookhaven National Laboratory, and 2) a waxbased grout demonstration at Sandia National Laboratories in New Mexico. Remedial actions using in situ grouting have been completed at Oak Ridge National Laboratory in 1996, Idaho National Laboratory (INL) in 1997, Brookhaven National Laboratory in 1999, and Savannah River Site in 2000. After completion of an evaluation of in situ grouting methods for mixed radioactive waste landfills (Armstrong et al., 2002), wax-based grout was deployed as a non-time critical removal action at INL to stabilize beryllium reflector blocks and outer shim control cylinders buried in soil vaults and trenches at the Subsurface Disposal Area in the Radioactive Waste Management Complex (Lopez et al., 2005). In situ grouting was also evaluated as a remedial option for Pit 9 at Los Alamos National Laboratory TA-54 Site. Major issues with use of this technology include delivery of the grouting fluid (i.e. requires closely space injection ports) and validation of the effectiveness of the delivery (DOE, 2004).

- The number of boreholes required to ensure complete coverage of the grout would be very large and extremely costly, because of the cost of drilling at the Hanford Site and because of the large volume of investigative-derived waste (IDW) that would result. 


\section{WMP-27397 \\ Revision 1}

- Due to the depth of the contamination in the 200 Area, direct-push technology that could minimize the amount of IDW or large-diameter augers are likely to be unsuccessful. Thus, costs of drilling would be extremely high.

- Effectiveness of delivery depends upon subsurface heterogeneity, which could impact the effectiveness of the grout.

- Validation and monitoring of the performance of the continuous volume of grout would be extremely difficult.

The panel does not believe that in situ grouting of the vadose zone is a practicable approach for the Hanford vadose zone.

\subsubsection{Vadose-Zone Desiccation}

Vadose-zone desiccation is described as the injection of dry (dried) air, accompanied by the withdrawal of an equal volume of wet air in an array of wells. The particular application for this study was to immobilize ${ }^{99} \mathrm{Tc}$, but it may be applicable for: other radionuclides, such as tritium and iodine-129; metals, such as chromium; and nitrate. Because Truex's (2004) evaluation showed vadose-zone desiccation to have the least uncertainty among the active remediation technologies and because the panel believes it is worthy of further consideration, a discussion follows. Further details are provided in Appendix $\mathbf{C}$.

In 2001, a field demonstration of desiccation was performed as part of the Hanford Subsurface Air Flow and Extraction (SAFE) Project (Cameron et al., 2002). Results include extraction of $\sim 1000$ gallons of water during a two-week test. However, this volume includes both water present in the vadose zone and in the injected air, as there was no dehumidification of air prior to injection.

Because Truex's evaluation was sceening level, it did not provide details on how the technology could be applied, potential strengths and weaknesses, or how the geology might affect the technology performance, both short and long-term. Many questions remain unanswered and must be evaluated before a decision to implement desiccation at Hanford should be made. The panel identified the following findings and concerns regarding implementation of desiccation as an active remedial action at the Hanford Site.

\subsubsection{Uncertainty Regarding Quantity of Water to Be Removed by Desiccation}

A major uncertainty regarding the feasibility of desiccation concerns the amount of water that should be removed. Our assumption is that desiccation should remove excess water that includes both water added to the vadose zone by waste-disposal activities and excess recharge that occurred as a result of removal of vegetation.

To assess the potential requirements of desiccation, we considered the effective depth of water that must be removed from the subsurface by desiccation. As noted in Section 2.0, we suspect that wastewater may have penetrated to greater depths at some locations compared to others. However, for this evaluation, we considered average conditions over a proposed treatment area, because more detailed information was not available. If we assume that wastewater was evenly discharged over the disposal area, we can estimate the mean depth of water to be removed by desiccation. For the BC Cribs and Trenches example, the panel calculated that an average effective depth of $\sim 1.3$ meters of contaminated water was 
introduced to the vadose zone. Because vegetation was removed in preparation for waste disposal, recharge was likely enhanced both during and after operations. If the additional recharge is assumed to have averaged about $25 \mathrm{~mm} /$ year for 40 years, an additional one meter of water, not in equilibrium with the long-term recharge of about one $\mathrm{mm} / \mathrm{year}$, would have infiltrated. Thus, to effectively remove most of the excess recharge, deșiccation may require removal of an effective thickness of more than 2 meters of excess recharge across the entire BC Cribs and Trenches site (22 acres). Considering disposal operations, effective thickness of excess recharge could be significantly greater immediately beneath the waste disposal facilities. However, using the average value for the site and assuming a volumetric moisture content of 0.1 , the zone to be desiccated would be approximately 20 meters thick.

In Appendix D, Section D-2, it is explained that the effect of desiccation depends not only on total volume of water removed, but also on initial water content. For example, in a loamy sand, a decrease in water content from 0.41 to 0.40 decreases the solute flux from $3.5 \times 10^{6}$ to $2.8 \times 10^{6} \mathrm{mg} /$ day- $\mathrm{m}^{2}$ which is a decrease of 20 percent. However, a decrease in water content from 0.072 to 0.062 decreases the solute flux from 23.7 to $0.221 \mathrm{mg} /$ day $-\mathrm{m}^{2}$ which is a decrease of two orders of magnitude. This means that the removal of a small amount of water in a relatively dry soil may have a large impact on solute flux.

\subsubsection{General Limitations on Rate of Water Removal}

The performance of the desiccation system will be determined by the following:

- injection/withdrawal rate

- temperature and moisture of the dry injected air

- temperature and moisture of the exhaust air.

Further, the injection/extraction rate for air will be limited by the horizontal permeability to air of the unsaturated sediments at their prevailing moisture content, and to a lesser extent, by well spacing and the diameter of the wells. As described in Appendix C, the withdrawal rate per unit length of well screen is limited by the need to maintain the exhaust pressure above that of a perfect vacuum. For a 40-meter well spacing, the maximum withdrawal rate is about $200 \mathrm{~m}^{3} / \mathrm{m} / \mathrm{d} / \mathrm{Darcy}$ of permeability. Field tests to determine air permeability of proposed injection zones are required prior to final assessment of the feasibility of desiccation. These data can then be used to determine the maximum feasible injection/withdrawal rate.

However, a rough estimate of the air permeability of Hanford sediments can be made from the existing data set, as described in Appendix C. A reasonable estimate of horizontal permeability to air for Hanford vadose-zone sediments is about 100 Darcies. For such a permeability, the maximum withdrawal rate per unit screen length would be $\sim 20,000$ $\mathrm{m}^{3} / \mathrm{m} / \mathrm{d}$. For scoping calculations, it will also be assumed that the injection and withdrawal wells will be screened over a 10-meter interval, so that each will have a production rate of $200,000 \mathrm{~m}^{3} / \mathrm{d}$, or $2.3 \mathrm{~m}^{3} / \mathrm{second}$. For high production rates, sizing of the wells to avoid excessive pressure loss between the well screen and land surface, termed "well loss," becomes an important engineering consideration. This is particularly true when substantial vacuum is being produced at the well screen. Based upon an equation to compute well losses developed for the natural gas industry (Katz, 1959, p. 306, Eq.7.37), pumping air at a rate of 


\section{Revision 1}

200,000 standard $\left(15^{\circ} \mathrm{C}\right.$ and $1 \mathrm{~atm}$.) $\mathrm{m}^{3} / \mathrm{d}$ would require an extraction-well diameter of 0.25 $\mathrm{m}$ to avoid excessive well loss.

The net amount of water removed per unit volume of injected air is controlled by the saturated water vapor density, $\rho_{\mathrm{vs}}$, of the removed air at its prevailing temperature minus the vapor density of the injected air. At the start of desiccation, the temperature of the removed air will be equal to the formation temperature, which is about $15^{\circ} \mathrm{C}$ at the Hanford Site, and $\rho_{v s}$ at that temperature is about $13 \mathrm{~g} / \mathrm{m}^{3}$. For desiccation to be practical, the injected air would require dehumidification, which can be accomplished using commercially available dehumidification units. For scoping calculations, we assumed that the air is passed through a desiccant-based dehumidifier prior to injection that reduces its $\rho_{\mathrm{v}}$ (vapor density) to $2 \mathrm{~g} / \mathrm{m}^{3}$ (dew point $-10^{\circ} \mathrm{C}$ ). Based on these assumptions, each meter of exhaust air will initially remove $11 \mathrm{~g}$ of water net. Although the initial drying rate will be limited by energy balance considerations as desiccation continues, this estimate may be used to obtain a best-case estimate of the time required to obtain maximum areal coverage of the drying front.

The maximum extent of the desiccation drying front in a standard five-spot injection/withdrawal operation will be achieved when the injected dried air breaks through to the withdrawal well. To obtain an initial estimate of the rate of advance of the desiccation drying front, we rely upon concepts developed by the petroleum industry to evaluate waterflood operations. While we recognize that sweep efficiency will need to be be determined specifically for desiccation, we provide order-of-magnitude estimates of time of breakthrough of the injected fluid by using the sweep efficiency of $72 \%$, computed using an analytical equation developed by Collins $(1961, \mathrm{p}$. 186). For the 40-m spacing of alternating injection and extraction wells (Cameron et al., 2002), each extraction well will affect an area of $3200 \mathrm{~m}^{2}$. The volume of water contained in a $1-\mathrm{m}$ thick slab of this area, assuming a volumetric moisture content of 0.1 , is $320 \mathrm{~m}^{3}$. Removal of $72 \%$ of that mass, with a net vapor extraction rate of $11 \mathrm{~g} / \mathrm{m}^{3}$, would require the injection of $2.1 \times 10^{7} \mathrm{~m}^{3}$ of air. Based on the maximum allowable extraction rate of $20,000 \mathrm{~m}^{3} / \mathrm{m} / \mathrm{d}$ given above, breakthrough might be reached in about 2.9 years if energy-balance considerations are ignored. Note that this injection/withdrawal rate is about 14 times that used during the Hanford SAFE Project of $1,440 \mathrm{~m}^{3} / \mathrm{d} / \mathrm{m}$ (Cameron et al., 2002). At that injection rate, breakthrough would occur after approximately 40 years.

\subsection{Energy Limitations on Volume of Water Removed}

After considering energy-balance effects, the panel believes that the dried air would advance more slowly than computed above. About 2,500 $\mathrm{J}$ (joules) of energy are required to evaporate one gram of water. This energy must be derived either from the injected air or from the porous medium through which the air passes. Moreover, as shown in the following paragraphs, the energy available by cooling the formation is limited, and would be depleted in a relatively short time. Thus, as a first approximation, the rate of vapor extraction will depend on the energy available from the injected air.

Repeating the calculations above, but considering only the energy available from the injected air, dried air injected at the mean annual temperature for Hanford of $15^{\circ} \mathrm{C}$ will become water-vapor saturated (at approximately $7 \mathrm{~g} / \mathrm{m}^{3}$ ) at its wet-bulb temperature of $5.5^{\circ} \mathrm{C}$. Thus, 
WMP-27397

\section{Revision 1}

energy limitations restrict the long-term net extraction rate within the air phase to $5 \mathrm{~g} / \mathrm{m}^{3}$, rather than the $11 \mathrm{~g} / \mathrm{m}^{3}$ previously calculated. For these conditions, breakthrough would be predicted to require approximately 6.4 years, rather than 2.9 years computed assuming that vapor extraction occurs at formation temperature throughout the period of desiccation.

These calculations are based on the assumption that the formation will provide little of the energy required to evaporate the pore water. This assumption is verified by considering the energy available for evaporation of water within each meter depth of the porous medium (and assuming minimal conduction of thermal energy from above or below the zone of desiccation). Cooling $1 \mathrm{~m}^{3}$ of formation by $9.5^{\circ} \mathrm{C}$ (the difference between the formation temperature of $15^{\circ} \mathrm{C}$ and the wet-bulb temperature of the injected air of $5.5^{\circ} \mathrm{C}$ ) releases $1.9 \times 10^{7} \mathrm{~J}$ of energy, enough to evaporate $7,600 \mathrm{~g}$ of water, or $7.6 \mathrm{~mm}$ of water depth per meter thickness of the desiccated zone. Thus, the formation would contribute only approximately $8 \%$ of the evaporation required for complete desiccation. Further estimates by the panel led to the conclusion that the energy stored in the formation would impact the desiccation process only during the first approximately 100-200 days of injection of dry air, after which time further evaporation of water would be dependent solely on the energy available in the air phase.

Additional energy for evaporation of water would be available by heat conduction from zones above, below, and in front of the cooling front. Computations based on analytical solutions for heat conduction indicate that the heat flux from these areas would be no more than a few per cent of the heat flux derived from cooling the zone within the cooling front, however, and can be ignored for this first cut at understanding the impact of energy balance considerations on the feasibility of the desiccation treatment.

The above computations assume that the injected air will be dried by desiccant cooling to a $\rho_{\mathrm{v}}$ of $2 \mathrm{~g} / \mathrm{m}^{3}$, but will be injected at the mean annual temperature. (Note: The efficiency of the desiccation operation will vary as ambient vapor density changes, but will generally be substantially less if the air is not dried; modeling using historical temperature and humidity data should be performed to assess long-term desiccation efficiency.) One approach to minimize energy-balance issues would be to heat the dried air to a temperature at which its wet-bulb temperature is equal to the formation temperature. For air injected at a dew-point temperature of $-10^{\circ} \mathrm{C}$, this temperature would be about $37^{\circ} \mathrm{C}$. An alternate approach would be to limit injection to, say, April-October. Assuming that vadose-zone dessication, on the basis of these rough calculations, is considered to be viable, various options concerning injected air temperatures should be tested by computer simulation.

\subsubsection{Osmotic Effects on Volume of Water Removed}

Because brine is present in the vadose zone at many Hanford waste sites, saturated watervapor pressure equilibrium with the gas phase will be lower than if no brine were present. [Wheeting (1925), Kelly and Selker (2001), and Weisbrod et al. (2003)]. This reduced vapor pressure would: 1) impact the early dynamics of the desiccation process, and 2) ultimately further reduce the efficiency and rate of desiccation. In the early stages of desiccation, moisture will be most rapidly removed from the cleanest areas and most slowly from contaminated areas containing waste brine; in fact, it is possible for water to be moved from clean areas and deposited into brine areas until the drying front moves past. When the brine 
WMP-27397

Revision 1

area begins to desiccate, the pore water will become more and more concentrated, further reducing vapor pressure and slowing the rate of drying. This osmotic effect would compound the energy limitations described above and result in desiccation time frames that are likely to be significantly longer than those estimated solely through consideration of the carrying capacity of the air at formation temperature.

\subsubsection{Chemical Effects of Desiccation}

Desiccation, in theory, results in the delay of the arrival of contaminants at the water table. However, as evaporation occurs within the vadose zone, concentrations of contaminants remaining will increase. Hence, a secondary, non-conservative impact of desiccation may occur related to remobilization of these contaminants after drying. Rewetting and remobilization, should they occur, may cause a temporary increase in peak concentrations and mass flux of contaminants reaching groundwater. The processes impacting mass flux and peak concentration are complex, as indicated above, and remobilization should be modeled under field conditions to determine potential impacts of desiccation on timing and duration of arrival of contaminants at the water table (Appendix D).

\subsubsection{Installation of Injection/Extraction Wells}

The panel is concerned about desiccation performance related to both areal and volumetric coverage. As mentioned above, if a five-spot array is not effective in $28 \%$ of the area, significant moisture, potentially containing ${ }^{99} \mathrm{Tc}$, would be retained after breakthrough of dried air. In addition, finer-grained layers, containing higher moisture content and likely ${ }^{99} \mathrm{Tc}$, would be bypassed due to air-flow blockage.

The PNNL proposed test plan suggests that the problem of bypass can be ameliorated by reversing flow between the injection and exhaust wells. However, air-flow reversal would result in wet air being drawn into previously desiccated zones, where water vapor could recondense, and the degree of improvement in desiccation performance would be uncertain. Reasonably complete volumetric coverage may require substantially closer well spacing or the use of additional wells left idle during the initial drying phase and then activated after breakthrough of drier air in the primary wells.

In addition, desiccation would likely require a large number of injection and extraction wells through potentially contaminated geologic media. Several concerns related to installation of a large number of wells must be considered before a decision to pursue an active remedial action: 1) the potential for downward migration of contaminants due to drilling and well installation could be significant, as this is likely to have occurred at Hanford in the past; 2) a significant volume of IDW requiring waste disposal will be generated; and 3) the cost of installation of wells at designed spacing will likely add significantly to overall project cost.

\subsubsection{Surface Infiltration Control}

This section describes recharge conditions through three periods of time: prior to waste disposal, during waste disposal, and after waste disposal to analyze recharge through time and predict the impact of such an action into the future. 


\section{Revision 1}

\subsubsection{Prior to Waste Disposal}

It is reasonable to assume that prior to the liquid waste disposal at many Hanford waste sites, including BC Cribs and Trenches, the water-content profile was in a state of dynamic equilibrium with the

- soil hydraulic properties,

- depth to the water table, and

- deep percolation rate.

The soil hydraulic properties, of course, can be considered static in time. The depth to the water table is $>100 \mathrm{~m}$, so we can safely assume that upward capillary movement from the water table will not affect shallower recharge processes. The deep percolation rate (or flux), however, will be very important, because that rate will affect the long-term, steady-state water content and hydraulic conductivity profiles in the porous material.

To understand how the fluxes affect water content and hydraulic conductivity, the Richards Equation shows that the driving force for water movement is from gradients in soil-water potential and gradients in gravity, and that the two forces are additive. Stephens (1995) stated that gradients in soil-water potential during infiltration events tend toward zero close to ground surface (maybe several meters below ground surface), leading to a condition where gravity becomes the dominating force. This is known as the unit-gradient condition and it shows that deep water flux equals the hydraulic conductivity. Or, said a different way, the hydraulic conductivity and water-content profiles will adjust themselves to the long-term flux at ground surface.

In a non-uniform profile like at the BC Cribs and Trenches site, the water content and soilwater potential will vary depending on the texture of the porous material and the flux placed upon the system. The hydraulic conductivity will also vary locally and with changes in moisture content. During periods of large changes in recharge, the distribution of moisture and conductivity can be quite complex and the unit-gradient assumption may not apply, especially when viewed on the local scale (tens of centimeters). However, when the flow system is viewed more globally and over a time scale that averages across transients in recharge, the hydraulic system will eventually approach steady state in a horizontally layered system, where discharge rates at the base of the profile will approach recharge rates near the ground surface. Local-scale heterogeneities might cause lateral flow, but as long as the recharge rate does not exceed the local-scale hydraulic conductivity for any layer, we can expect predominantly vertical flow.

\subsubsection{During and After Waste Disposal}

During the time period when liquid waste was disposed, the steady-state flux and water conditions in the vadose-zone profile were altered. At the BC Cribs and Trenches example, liquid disposal in the cribs and trenches was intermittent, sometimes occurring in sudden and large pulses. Though rapid pulses of fluids into unsaturated porous material could lead to preferential flow, layering in the soil eventually will dampen out these pulses, and, at some depth, soil water flow rates will become more uniform and less susceptible to preferential flow (Young et al., 1999); though supporting documents indicate that soil layering created potential preferential flow paths and increased lateral flow, from a broad context, water 


\section{Revision 1}

moved downward. As the liquid waste percolated deeper into the profile, water content in the porous material increased to a level that was consistent with a "new" time-averaged flux (natural recharge plus the liquid waste-disposition rate), which decreases over time.

Below the wetting front, the vadose-zone water-content profile corresponds to the "old" recharge rate compatible with natural recharge only. This can be seen clearly in the vicinity of Borehole C4191 (Figure 8), where water contents towards the bottom of the hole are significantly less than in the upper portion of the borehole. In fact, a cursory analysis of the data indicates a distinct decline in water content between 170 and $194 \mathrm{ft} \mathrm{bgs,} \mathrm{from} \sim 6.5 \%$ to $\sim 2 \%$ by weight. Hence, below $194 \mathrm{ft}$ bgs, unit-gradient conditions likely exist, with a watercontent range that corresponds to pre-disposal (natural) activity recharge rates. Soil-moisture conditions in the interval between 170 and $194 \mathrm{ft}$ bgs appear to be subject to re-equilibration (see Section 4.2.7.3), impacted both by gravity and local gradients in soil-water potential, thus allowing the possibility of relatively complex flow patterns at these depths. It is less clear, and requires further clarification through field characterization and modeling, as to the behavior of the vadose zone above 170 feet, which could be undergoing internal drainage from the disposal practice and recharge from ground surface. Thus, one possible interpretation of the observed water contents at these shallower depths is that this portion of the vadose zone remains in a period of re-equilibration. A second possible interpretation, and one which we consider to be more likely, is that this region has come to equilibrium with the new rate of recharge and is therefore again well approximated by unit-gradient conditions.

Further characterization and modeling is required to more fully understand the current moisture distribution in the subsurface both in terms of spatial variation in the depth of penetration of higher moisture contents (expected to exceed $194 \mathrm{ft}$ bgs in regions near the Cribs) and in defining the current state of water flux in the shallow portion of the vadose zone. These efforts will be important in the design of any active remediation strategy, such as selection of a target interval for desiccation, particularly as it appears that the majority of the ${ }^{99} \mathrm{Tc}$ contamination is associated with depths shallower than the depth of maximum penetration of increased moisture content.

\subsubsection{Analysis of Recharge Through Time}

For the BC Cribs and Trenches example, we identified three distinct recharge periods, and briefly discuss their influence on pore-water velocity and ${ }^{99} \mathrm{Tc}$ migration rates.

- The first period, the Baseline Condition, corresponds to the ambient recharge rates with natural vegetation, or prior to site activities. As described by Ward et al. (2004), and through the voluminous research already conducted at the Hanford Site by PNNL, long-term recharge is estimated to be in the $1-3.5 \mathrm{~mm} / \mathrm{yr}$ range depending on vegetation and other environmental factors.

- The second period, Waste Disposal, corresponds to the time of active liquid waste disposal. In this period, the panel estimated the recharge rate at $1.3 \mathrm{~m}$ of liquid disposed across the 22-acre site, or approximately $650 \mathrm{~mm} / \mathrm{yr}$ for a 2-year operational period, plus ambient recharge through a bare soil surface ( 50 to $100 \mathrm{~mm} / \mathrm{year}$ ), or a total of approximately 700 to $750 \mathrm{~mm} / \mathrm{yr}$ during waste disposal operations. 
WMP-27397

\section{Revision 1}

- The third period, Equilibration, corresponds to the current recharge rate, ambient recharge through a disturbed site with mostly bare soil conditions, or $25 \mathrm{~mm} / \mathrm{yr}$ (Ward et al., 2004, Table 4.1).

Changes in these fluxes will influence water and contaminant migration rates. For example, average pore water velocity is equal to flux divided by water content, so reducing the flux at a rate greater than the water content will lead to a lower pore-water velocity, and hence to a reduction in ${ }^{99} \mathrm{Tc}$ migration rates.

Hillel (1998) also describes, for homogeneous media, the redistribution process and shows that internal drainage of water will redistribute water from wetter intervals higher in the vadose-zone profile, and move it toward drier intervals deeper in the profile. Within layered media, this concept must be recast into one where drainage will redistribute water from regions of relatively high potential (higher in the vadose-zone profile) to regions of lower potential. In either case, two changes to vadose-zone water conditions occur. First, the loss of water at shallow depths leads to soil drying and a lower hydraulic conductivity; thus, the flux decreases in those layers. Second, at each depth increment where the redistribution is occurring, this internal drainage rate represents a higher-than-ambient flux, and the soil consequently will absorb water until the relative permeability of the local sediments corresponds to the new flux rate (i.e., the soil-water deficit of the sediments will decrease). Eventually, the excess water will be absorbed by the sediments and the water content gradients will diminish. Therefore, field activities that reduce water fluxes entering the vadose-zone profile at ground surface or that reduce the excess liquid in the vadose zone will slow the downward migration of the wetting front and slow the migration of ${ }^{99} \mathrm{Tc}$.

The recent predictive modeling by Ward et al. (2004) illustrates this point very clearly, as they compared placement of a cover to reduce infiltration to a no-action scenario. Figures $5.2-5.5$ of Ward's report show that reduction of the surface flux leads to a significant lengthening of time before the ${ }^{99} \mathrm{Tc}$ plume reaches $110 \mathrm{~m}$ depth, with no other remediation technology being considered. At fluxes equal to $25 \mathrm{~mm} / \mathrm{yr}$ (perhaps with a very sparse vegetative cover), the plume appears after $\sim 100$ years. At flux equal to $0.5 \mathrm{~mm} / \mathrm{yr}$, the first arrival of the plume is delayed about 35 years, but the time of exceeding the maximum contaminant level (MCL) is delayed approximately 100 years. It is clear from the example of Ward et al. that re-establishing the natural recharge rate will reduce the driver required to flush the existing high-water content interval in the profile to greater depth, thus effectively reducing the potential for further downward migration of the contaminants present at depth. Ward's analysis showed that the contamination will continue to "drain," albeit at a slower rate, even if recharge is eliminated entirely.

Also, minimization of infiltration will reduce the sensitivity of other remedial measures to uncertainties in subsurface conditions. Therefore, other technologies that may be considered for implementation can benefit synergistically by including infiltration control at the surface.

\subsubsection{Soil Flushing}

Soil flushing is the in situ extraction of contaminants from the soil using water, an aqueous solution, or an organic solvent. It is applicable to a broad range of contaminants, including radionuclides. The extraction solution is infiltrated, sprayed, or injected into the contaminated soil zone followed by the down-gradient collection of the elutriate (flushing 


\section{Revision 1}

solution mixed with the contaminants). Typically, the elutriate is pumped to the surface for removal, recirculation, on-site treatment, and reinjection. This summary is based on reports by the Ground Water Remediation Technologies Analysis Center (Roote, 1997 and 1998) and the Environmental Protection Agency (U.S. EPA, 1997). The use of soil flushing to remediate contaminants at the BC Cribs and Trenches, though not considered by Truex (2004), is discussed here briefly for completeness.

The hydraulic conductivity at the site, as well as its vertical and lateral variability, is the most important factor for the successful implementation of a flushing remediation project. Hydraulic conductivities greater than $10^{-3} \mathrm{~cm} /$ second allow the flushing solutions to flow through the solid media in a reasonable period of time, but it may be applied at sites with lower conductivities, from $10^{-5}$ to $10^{-3} \mathrm{~cm} / \mathrm{s}$. Comparison of these numbers with the hydraulic conductivity range from about $6 \times 10^{-3}$ to $4 \times 10^{-5} \mathrm{~cm} / \mathrm{second}$ at the Hanford Site (Ward et al., 2004) indicates that the geological setting at Hanford is not ideal for soil flushing, but also does not make it entirely impossible.

The main obstacle for in situ soil flushing appears to be the great heterogeneity of the sediments at Hanford, not only with depth, but also in lateral directions. Fine-textured lenses with a low vertical hydraulic conductivity often have a relatively high horizontal conductivity, because of higher clay content. Paleosols and other fine-textured layers have been found to result in lateral spreading of crib effluent over ranges of about 100 meters (Ward et al., 2004). The anisotropy of unsaturated hydraulic conductivity has been demonstrated in the laboratory (Palmquist and Johnson, 1962; Stephens and Heemann, 1988) and in the field (McCord et al., 1991). A theoretical analysis revealed that the degree of anisotropy increases when the soil dries out (Yeh et al., 1985a, 1985b). This finding has been corroborated by measurements in the laboratory (Stephens and Heemann, 1988) and in the field (McCord et al, 1991). When the fine-textured layers overlaying coarse layers are inclined, lateral water flow is increased substantially (Hendrickx and Flury, 2001; Kung $1990 \mathrm{a}$ and 1990b), in a phenomenon known as funnel flow; it seems to be most distinctive under dry conditions (Ju and Kung, 1993; Kung, 1993), which indicates that vadose zones in semi-arid regions have a higher propensity for such flow than those in more humid environments. Dissolution pipes are a common feature in indurated calcic horizons in the arid southwestern U.S. (Rodriguez-Marin, 2001; Rodriguez-Marin et al., 2005). A simulation study demonstrated that these pipes may increase the areal deep downward flux in the vadose zone threefold from 3 to $9 \mathrm{~mm} /$ year, while fluxes through the pipes vary from 24$95 \mathrm{~mm}$ /year (Rodriguez-Marin et al., 2003).

The above studies, together with observations at the Hanford Site, indicate that large (10-100 $\mathrm{m}$ ) and small-scale (0.1-10 m) lateral variability of the sediments will cause complex flow paths. The implications of such extreme heterogeneity for the implementation of in situ soil flushing are twofold. First, the heterogeneous nature of the vadose zone will cause channeling of the extraction solution and uneven treatment that will decrease the reliability of the remediation. Secondly, even with a reliable high-resolution geophysical survey of the subsurface, it will be difficult to precisely predict the multiple flow paths of the extraction solution. As a result, the flushed contaminants and the elutriate cannot be contained and may cause impairment of uncontaminated volumes of the vadose zone and aquifer. As a matter of fact, persons responsible for implementing or regulating current in situ flushing projects have major concerns with containment, because it often can not be proven that all infiltrated water 
WMP-27397

Revision 1

will be recaptured (Roote, 1998). Given the thick vadose zones at Hanford, the infiltrated water may not fully drain for long periods of time, requiring an on-site presence and active groundwater pumping program for the foreseeable future. Therefore, the panel concludes that, at this time, in situ soil flushing is not a viable remediation strategy for the Hanford deep vadose zone.

\subsubsection{Perturbation Geochemistry}

Perturbation geochemistry is an innovative concept that is a variation on several technologies, such as ISRM, ISGR, and soil flushing. It involves changing either or both Eh or $\mathrm{pH}$ conditions through addition of liquids or gases, so that contaminants precipitate as or are incorporated into a less soluble or less mobile solid phase. The range of possible chemical changes is broadened beyond those upon which ISRM, ISGR, and soil flushing are based. Because metals and radionuclides are often associated with exchange sites in clay minerals or are bound in the near surfaces of minerals, such as oxides or organic matter, they are typically not in equilibrium with the vadose-zone media, and thus, can be relatively easily changed to make them less available for transport (Figure 4).



Figure 4. Perturbation Geochemistry, Gas-Phase Vadose-Zone Treatments

Specific examples of possible chemical changes that could be induced include:

- increasing $\mathrm{CO}_{2}$ gas partial pressures in the vadose zone to dissolve and reprecipitate calcite with the intent of sequestering contaminants,

- addition of ammonia gas to increase $\mathrm{pH}$ of the vadose zone to dissolve and reprecipitate silica to sequester contaminants,

- addition of a reducing gas in the vadose zone to reduce ferric to ferrous iron, which may reprecipitate with greater effective surface area and sorptive capabilities.

As shown in Figure 4, the system returns to ambient conditions after the perturbation (assumed in the figure to be an oxidized carbonate-buffered system). In most cases, return to ambient conditions cannot be economically avoided. Eh and $\mathrm{pH}$ perturbations can potentially be combined.

The application of perturbation geochemistry may be of use for metals and radionuclides at Hanford, but it would require significant testing in the laboratory and the field. More 
WMP-27397

Revision 1

information about perturbation geochemistry, including discussions on both carbonate and silicate systems, is included in Appendix E.

\subsubsection{Energy-Based Methods}

Various energy-based methods (or energy-based enhancements for desiccation) are theoretically applicable to contaminants in the deep vadose zone (Jarosch and Looney, 1999). These include various types of heating, as well as electroosmosis or electrokinetic methods. In the case of the Hanford deep vadose zone, these methods might be considered to facilitate vapor-phase water removal (or to induce the movement of liquid water and/or contaminants towards a collection system). Various broad classes of energy-based technology are summarized below, along with key recommendations, uncertainties, and limitations. In general, these methods will require extensive subsurface access and extremely close well spacing, which may likely preclude applicability at Hanford, especially at large sites like the BC Cribs and Trenches.

\subsubsection{Radiant/Conductive Heating (ISTD)}

This technology uses standard resistive heaters deployed in wells/boreholes to generate heat, which is applied using a radiant high-temperature surface $\left(250^{\circ} \mathrm{C}\right.$ to $\left.>500^{\circ} \mathrm{C}\right)$ in contact with the soil. As a result, thermal conduction and convection occur in the bulk of the soil volume. Field data suggest that thermal conduction accounts for more than $80 \%$ of the heat transfer. ISTD is typically used to remove soil moisture and to remove/destroy some classes of contaminants (to date it has primarily been applied to volatile and semi-volatile contaminants such as organics and mercury).

Several commercial ISTD applications have used a five-spot pattern with a central heat only borehole surrounded by heated vapor extraction wells (www.terratherm.com). Typical well spacing has been on the order of 2 to $10 \mathrm{~m}$. Radiant/conductive heating would assist in overcoming potential energy-balance limitations and provide deployment geometry options that are not available when using only dried air.

\subsubsection{Other Energy-Based Methods}

For completeness, there are several other energy-based methods that are worth describing. These include electroosmosis and electrokinetic remediation, joule heating, steam heating, and radiofrequency (RF) heating. In general these are less promising for the deep vadose zone than the radiant/conductive heating summarized above.

Electroosmosis (for drying or dewatering) and electrokinetic remediation (for contaminant extraction) exploit phenomena in which contaminants and water move in response to a direct current (DC) electric field. Electroosmosis in porous media, such as clays, is possible, because of the structured electrical double layer of negative and positive ions formed at typical solid-liquid interfaces. For soil particles, the double layer consists of a fixed layer of negative charges associated with the solid phase and a diffuse aqueous layer of positive ions. Application of an electric potential on the double layer results in a driving force for displacement of the two layers toward the respective electrodes; i.e., the positively charged layer to the cathode and the negatively charged layer to the anode. Because the particles in the soils are immobile, the fixed layer of the negative ions is unable to move. However, the positive ions can move within the diffuse layer and drag water toward the cathode (US EPA, 
1990). While the basics of this technology are well established from industrial applications in dewatering and clay consolidation, reliable performance for remediation applications, especially at complex sites like Hanford, has yet to be established. Furthermore, electroosmosis based-drying (or dewatering) only works effectively in clays or shales, and as such would not be effective at Hanford.

Electrokinetics was developed by Casagrande in the 1930's, and has received little attention in the USA, but has been applied for remedial applications at a number of sites in Europe. The concept is well described in Mitchell (1993). Because at Hanford, the contaminant of interest, ${ }^{99} \mathrm{Tc}$, is an anion, residual waste brine is also present, and the geologic column is primarily sands and gravels, electrokinetic remediation would not be likely to be effectively applied.

Joule heating technology (also known as "six-phase" or "three-phase" heating) directly "injects" AC power into the subsurface to heat the soil through a self-resistive heating. The ground itself acts in a manner analogous to a heating element. Six-phase heating was developed by PNNL and has been licensed for commercial implementation. While the interbedded silts in the Hanford vadose zone are suited to Joule heating, implementation would be difficult and expensive. Because electrical contact must be maintained, Joule heating requires some moisture in the heated zone. Because the area immediately adjacent to the electrodes heats faster than the overall treatment zone, injection of water or electrolyte solution is typically required to allow the ground to be heated to temperatures with a practical limit of 90 to $100^{\circ} \mathrm{C}$. A requirement for injection of fluid into the site to support a remediation process aimed at removing fluid is counterproductive (see section on soil flushing) and makes this technology less desirable than radiant/conductive heating.

Steam heating uses steam to enhance remediation - typically to deliver heat and sweep residual organic solvent from the subsurface. While steam efficiently carries and delivers a significant amount of energy, use of a fluid (some of which will condense in the target zone) may be substantively counterproductive to a site where the aim of the remediation process is to remove fluid. There are several commercial variants of steam heating, including the licensees of the Lawrence Livermore National Laboratory (LLNL) developed steam remediation processes. In virtually all variants of in situ steam treatment, the steam is injected at high pressures and spreads rapidly through premeable formations. Heat is transferred to the formation and the steam front expands as the treatment zone reaches target temperatures near the boiling point of water. The rapid expansion of the steam zone decreases the required number of access points compared to some of the alternative heating technologies, such as six-phase heating or radiant/conductive heating.

$R F$-heating is an electromagnetic technique that induces molecular vibfrations in the subsurface media, resulting in higher temperatures. RF heating works initially through interaction with the pore water and waters of hydration, but the method is capable of continued heating to temperatures above 100 degrees Celsius by interaction with the minerals. Typical frequencies applicable to soils are in the range of 1 to $100 \mathrm{MHz}$, which is the frequency band set aside by the Federal Communications Commission for industrial, scientific and medical use. The technology has been studied for enhanced oil recovery and successfully deployed for a pilot solvent source treatment demonstration (Jarosch and Looney, 1999). 


\section{Revision 1}

Different applicator configurations are possible. The two most common are a dipole for application in a borehole, and a "triplate array" for treatment of a fixed volume block. RF heating was developed primarily by researchers from the Illinois Institute of Technology Research Institute. Because of the cost of the RF generator and matching network, and poor efficiency with respect to the original power source $(<70 \%), R F$ heating has not had as much commercial success as Joule heating. This technology has limited case-study experience and has no advantage over radiant/conductive heating.

\subsubsection{General Recommendations, Uncertainties and Issues for Energy-Based Technologies}

Truex's evaluation did not assess energy-based technologies. Many questions remain unanswered and must be evaluated before a decision to implement such enhancements at Hanford could be made. Based on available data, the panel considers radiant/conductive heating to be a possible enhancement to desiccation for consideration at Hanford. This evaluation could be conducted through modeling by coupling with modeling of unheated desiccation. If the modeling of thermal enhancement is promising, additional modeling (using STOMP or a similar tool) might also assist in design and operation of the remediation system. By extension, most of the issues and concerns associated with unheated desiccation apply to a thermally enhanced desiccation. Further, based on the real-world case study experience, large numbers of wells and close well spacing would be a major drawback to this method in a contaminated setting. If the technology were to be deployed using a 15-foot well spacing, more than 3500 boreholes would be needed at the BC Cribs and Trenches.

\subsection{Priority Technologies}

Discussion of priority technologies is focused on three primary considerations:

(1) potential of the technology to reliably reduce mass flux of ${ }^{99} \mathrm{Tc}$ across the water table,

(2) potential of the technology to reliably delay arrival of ${ }^{99} \mathrm{Tc}$ at the water table, and

(3) robustness of the technology to uncertainties, including incomplete knowledge of the challenges faced in field implementation, incomplete analysis of pertinent processes impacting efficacy, and potential impact of extreme events.

These considerations are discussed within the context of the overall goal of identifying priority technologies based on:

- long-term effectiveness and permanence

- reduction of toxicity, mobility or volume

- short-term effectiveness

- implementability

- cost.

As noted previously, the panel concurs with much of the analysis and many of the conclusions contained in Truex (2004) and Ward et al. (2004). Review of these prior studies, with additional analysis by the panel, leads to the conclusion that chemical reduction 
WMP-27397

Revision 1

technologies are not recommended as priority technologies for treatment of ${ }^{99} \mathrm{Tc}$ in the Hanford vadose zone. This conclusion is based on the substantial uncertainties identified in Truex (2004) and our discussion above regarding:

(1) uncertainty regarding uniform distribution of treatment gases within the treatment volume,

(2) long-term stability of the treatment methodology due to the potential for re-oxidation of the treatment zone, and

(3) incomplete knowledge of the geochemical reactions occurring within the treatment zone (particularly the interference of competing compounds during the reduction process).

It is noted further that the effectiveness of these technologies may be affected by changes in recharge, such as might occur as a result of climate change or meteorological extremes.

In contrast, the panel recommends that technologies designed to reduce groundwater flux may provide a better choice to delay the arrival of, and thus reduce mass flux of, ${ }^{99} \mathrm{Tc}$ to the water table. It is suggested that substantial delay in arrival time of ${ }^{99} \mathrm{Tc}$ at the water table, reduction in mass flux of ${ }^{99} \mathrm{Tc}$ across the water table, and robustness to extremes may be best realized through a combination of technologies.

As discussed below, the panel concludes that surface infiltration control is a necessity. Further, the panel believes that desiccation deserves further analysis as a possible complementary technology with a number of potential benefits, but also a number of uncertainties related both to its application to the deep vadose zone at Hanford and its longterm impacts. Additional study is therefore required prior to adoption of desiccation as a remedial alternative.

\subsubsection{Surface Infiltration Control}

As discussed by Ward et al. (2004), shown in Figure 5, infiltration control has the potential to significantly delay the time of arrival of ${ }^{99} \mathrm{Tc}$ at the water table and, after its initial arrival, reduce the mass flux of ${ }^{99} \mathrm{Tc}$ across the water table. Specifically, infiltration reduction decreases the vertical driving force as well as reduces the mean moisture content (and therefore relative permeability) throughout the vadose zone, thus leading to lower rates of vertical migration. Hence, infiltration control, implemented as a surface barrier, is considered a viable and applicable technology for many sites containing vadose-zone contamination at Hanford. This surface barrier will, to a significant degree, replicate natural conditions similar to the shrub steppe ecosystem observed at the site prior to initial construction of the waste-disposal facilities. This recharge control is expected to substantially reduce the rate of recharge through enhancement of evapotranspiration at the surface, and thereby, reduce the rate of fluid migration through the deep vadose zone.

The panel recommends serious evaluation of surface infiltration control at all Hanford sites with deep vadose-zone contamination. Specifically at the BC Cribs and Trenches, the panel recommends construction of a surface barrier (e.g., an ET barrier planted with native vegetation) whether or not additional remediation is performed. 
WMP-27397

Revision 1

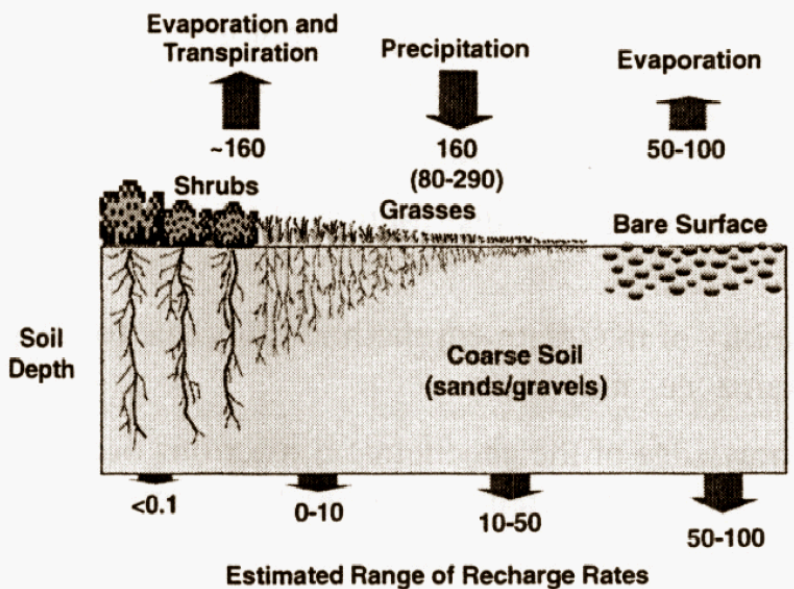
Figure 5. Schematic of Impact of Infiltration Control on Recharge Rate
at the Hanford Site (Ward, et al., 2004)

With proper construction, it is anticipated that the infiltration rate can be reduced to less than 1 to $10 \mathrm{~mm} / \mathrm{yr}$ (Gee et al., 1989 as described by Ward et al., 2004) under a fully developed infiltration control structure. Ward et al. (2004) used a range of infiltration rates and chose $3.5 \mathrm{~mm} /$ year as equivalent to pre-disposal surface conditions.

Infiltration control meets the criteria outlined above for priority technologies, as follows.

- Long-term effectiveness and permanence. Assuming no catastrophic breaches of the infiltration control due to anthropogenic interference or tectonic activity, this technology should remain stable over extremely long time periods. The technology also allows adaptation to both short-term extremes and long-term climate changes. With respect to short-term extremes, the storage capacity of the soil layers combined with surface runoff that may occur to off-site will provide substantial short-term resilience to meteorological extremes. The one exception would be an extreme occurrence in which the vegetation was first eliminated (e.g., through fire, insects, and other pests) and a precipitation extreme were to follow. In this case, however, increased recharge would occur only over a limited time span with vegetation becoming reestablished through replanting and/or natural processes. Further, appropriate initial design could allow for resistance to this sort of natural extreme (the panel understands that such design considerations have been included in prior work at Hanford). With respect to climate change, natural vegetation allows the technology to adapt naturally to changes in climate (i.e., an increase in mean annual precipitation would be counterbalanced by an increase in evapotranspiration), thus reducing the impact of any reasonable changes in precipitation patterns.

- Reduction of toxicity, mobility or volume. This technology directly reduces the mobility of the ${ }^{99} \mathrm{Tc}$ and associated chemicals through reduction in water flux through the deep vadose zone.

- Short-term effectiveness. While the infiltration control would not remove the excess water currently within the system, the panel hypothesizes that the mean rate of flux through the deep vadose zone would adapt to the new rate of recharge at the surface. 


\section{Revision 1}

Although existing contaminated pore water will be transport downward under gravitational forces for some time, infiltration control would provide a relatively rapid reduction in the mean rate of vertical migration.

- Implementability. Infiltration control is a common technology that can be performed at this site with minimal disturbance of the existing subsurface.

- Cost. Although cost figures have not been calculated for this option, the elimination of a need to drill wells (either clean or through contaminated regions), as well as the elimination of surface operations, would result in this option being relatively inexpensive.

\subsubsection{Desiccation}

Desiccation enables a number of conditions attractive for application in the deep vadose zone at Hanford. Its primary attribute is the removal of excess moisture from the subsurface, thereby reducing relative permeability in the target volume currently containing ${ }^{99} \mathrm{Tc}$. It is anticipated that this would, in turn, reduce the mean rate of downward migration of the contaminant, although this hypothesis should be verified through numerical modeling.

Through empirical argument and professional judgment, the panel has determined that the primary target zone for desiccation (in order to achieve a reduction in vertical migration of the contamination) would be the depths at which the moisture content is currently elevated and the contamination is currently present. Based upon data from the example site, BC Cribs and Trenches, the likely desiccation interval would be range between approximately 20 and 50 meters within the deep vadose zone. As such, the cost estimates presented in the Truex report would need to be significantly increased.

Desiccation, without infiltration control, would not be an effective approach, in part, due to the fact that the long-term mean rate of vertical migration of the ${ }^{99} \mathrm{Tc}$ and other contaminants towards the water table is controlled, to a large degree, by the rate of recharge at the surface, rather than by current moisture conditions at depth.

While the panel views desiccation as a possible companion technology to infiltration control, there are a significant number of issues that must be addressed, before it can be accepted as an effective means to contribute to minimization of contaminant migration in the vadose zone. Some of the issues related to desiccation, already discussed in Section 4.2.6, include:

- uncertainty regarding energy requirements to effectively evaporate significant quantities of water from the subsurface through injection of gas (e.g., air) via wells;

- changing chemistry during desiccation, including precipitation, possible formation of colloidal materials (that could be transported in the air or water phases), and rewetting of this zone after desiccation through uptake of water from the soil atmosphere by the salt phase;

- impact of desiccation on the biological population (although this is not considered significant as bioreduction is believed to play a minimal role at this site);

- appropriate depth intervals and injection/withdrawal strategies necessary to optimize removal of moisture and overcome difficulties related to preferential flow of air in the dry, coarse sediments;

- the technology will not likely allow fine control over moisture content; specifically, the technology will not allow the operators to "dial in" a particular moisture content 
and then stop evaporation at that moisture content; rather, the evaporation in the drier zones will continue until there is a balance between water removed by evaporation and water gained by rewetting; it is anticipated that, during the period of active desiccation, extremely low moisture contents behind the drying front will result.

As a result of concerns over these issues, the panel recommends that desiccation be considered as a possible companion technology to infiltration control, but that additional study be conducted prior to making a decision regarding its full-scale use at the Hanford Site (Section 5.0); recommendations specific to BC Cribs and Trenches are provided in Section 6.

In assessing the criteria outlined above, there is substantial uncertainty regarding the ability of desiccation technology to meet these criteria. Specifically:

- Long-term effectiveness and permanence. Desiccation provides both potential resilience to extremes and climate change; however, it leaves significant questions regarding long-term efficacy. Desiccation will result in a moisture deficit within the drying zone. As a result, the zone of desiccation will draw water from surrounding regions (particularly above the desiccation zone), thus significantly reducing vertical migration of pore fluid from this region (at least until the soil-water deficit is satisfied). Further, the zone of desiccation may act as a capillary barrier (due to the extremely low moisture contents that will be present) until partial rewetting occurs, thus reducing substantially vertical migration of water and contaminants. Desiccation may also provide a natural resilience to extreme recharge events, as the soil moisture deficit provides for storage of water within the zone of desiccation. Finally, there is a possibility that desiccation may result in formation of mineral species that entrap the ${ }^{99} \mathrm{Tc}$ and may be resistant to dissolution upon increase in moisture content. From these arguments, desiccation has a number of positive features with respect to longterm effectiveness and permanence.

At the same time, desiccation may lead to select subsurface behaviors that could be detrimental to long-term effectiveness. First, through reduction in moisture content without reduction in the mass of dissolved constituents, desiccation leads to a significant increase in the concentration of the dissolved constituents. During the long-term post-closure period, infiltration will become the dominant process of water re-entry into the contaminated zone. If the desiccation process were to significantly increase the pore-water concentration, and if the infiltrate were to displace the contaminated pore water, then we hypothesize that a situation could be created in which not only the concentration, but also the mass flux of ${ }^{99} \mathrm{Tc}$, would increase at the water table for a period of time dependent upon the infiltration rate and the hydrodynamic and transport characteristics of the contaminants (Appendix D). This hypothesis requires conceptual model testing to verify and bound. Conceptual model testing should also include effects of increased air pressure on the vertical gradient in the water phase and possible creation of a capillary barrier, that will hold moisture until a point of breakthrough (preferential flow path) is established.

There is a final, long-term concern with the use of desiccation. Specifically, as outlined in Truex (2004), a large number of wells will need to be drilled across the treatment zone. Should these wells be drilled after installation of the permanent infiltration control and/or should these wells be left in place (without plugging) 


\section{Revision 1}

following completion of the desiccation effort, each well will represent a possible preferential pathway for migration of recharge waters into the deep vadose zone. This would be particularly of concern should the analysis of extreme hydrologic events indicate a possibility for ponding at the surface. We suggest that, should desiccation be applied, a temporary infiltration control strategy be used during the period of desiccation with the permanent infiltration control constructed after completion of desiccation operations and sealing (preferably after removal of surface casing) of all boreholes used in the desiccation process.

- Reduction of toxicity, mobility or volume. This technology, when used in conjunction with infiltration control, has the potential to reduce both volume and mass flux of water / contaminants at the water table. Overall, it reduces the total volume of contaminated water in the deep vadose zone (while, at the same time, increasing the mean contaminant concentration in the water remaining in this zone). As noted above, use of this technology in the absence of infiltration control may have a deleterious effect leading to increased mass flux of contaminants at the water table.

Of minor concern, the possibility for formation of colloids capable of being transported in the gas phase (during desiccation) should be considered. Should colloids be formed and mobilized, there is potential both to spread the contamination (horizontally) within the deep vadose zone and to produce contaminated air at the extraction wells.

- Short-term effectiveness. Desiccation provides two distinct advantages with respect to short-term effectiveness. First, if successful, it will provide a means for removal of some of the excess water derived from waste-disposal operations. Secondly, because it is based on movement of the vapor phase and will lead to overall lowering of the mean moisture content in the target zone, it is likely that desiccation will be relatively robust to heterogeneity in the subsurface and may specifically provide the ability to reduce the relative permeability of pathways that are preferential for vertical liquid migration (e.g., locally connected layers of fine-grained sediments). The ability of desiccation to minimize the impact of heterogeneity should be studied through numerical modeling.

- Implementability. Technologies for soil vapor extraction have been discussed by many authors (e.g., Chai and Miura, 2004; Nobre and Nobre, 2004; Shan et al., 1992; Falta et al., 1993 and many others). Further, Cameron et al. (2002) have designed and conducted a field test for injection and withdrawal of a gas phase through the Hanford sediments. Hence, the technology is readily available.

Of greater concern is the design of the well layout and determination of the working parameters required to achieve the desired level of moisture removal within a realistic time frame. A number of issues remain to be resolved prior to identifying the final field design and, therefore, the degree to which this technology may be implemented at Hanford.

- Cost. Initial cost estimates are contained in Truex (2004). It is noted that Truex provided an uncertainty of $-50 \%-+500 \%$. There is concem that the initial estimates have substantially underestimated the true cost of application of this technology. Reliable cost estimates for this technology cannot, however, be determined until a 



\subsection{GENERAL RECOMMENDATIONS}

\subsection{The Decision Tree}

The panel recommends that for any site containing deep vadose-zone contamination at Hanford, the site conceptual model be refined and a minimum of two potential technologies be evaluated through a multiple-stage decision process (Figure 6). This process would involve, primarily, three levels of analysis and decision: 1) rigorous site characterization and modeling of current hydrogeologic conditions, including distribution of excess soil moisture and contaminants, to fully assess the need for technologies to enhance long-term stabilization of the contaminants of concern, 2) if this characterization indicates a need for stabilization, modeling of the impact of surface infiltration control should be pursued in an effort to determine potential benefits relative to contaminant migration, and 3) if the analysis of surface infiltration control indicates further need for technology, desiccation should be fully assessed to determine its potential to contribute to long-term stabilization of the contaminants of concern.

This section focuses on steps required to reduce uncertainties in the site conceptual model and evaluation of surface infiltration control and desiccation technologies for minimizing contaminant migration in the deep vadose zone at Hanford.

The panel recognizes that the significant uncertainties associated both with site characterization and the application of the various technologies discussed herein make definitive recommendations on the application of specific technologies difficult. Rather, the panel recommends a structured series of decisions be made following the decision tree shown in Figure 6. Preliminary criteria to be addressed for each go/no-go decision include:

- Will the contaminant flux at the water table remain below a critical threshold within a regulatorily relevant time frame?

- Can uncertainties be adequately reduced with respect to predicting future conditions?

- Can the cost of new technologies be justified in terms of the benefits expected from the technology? 


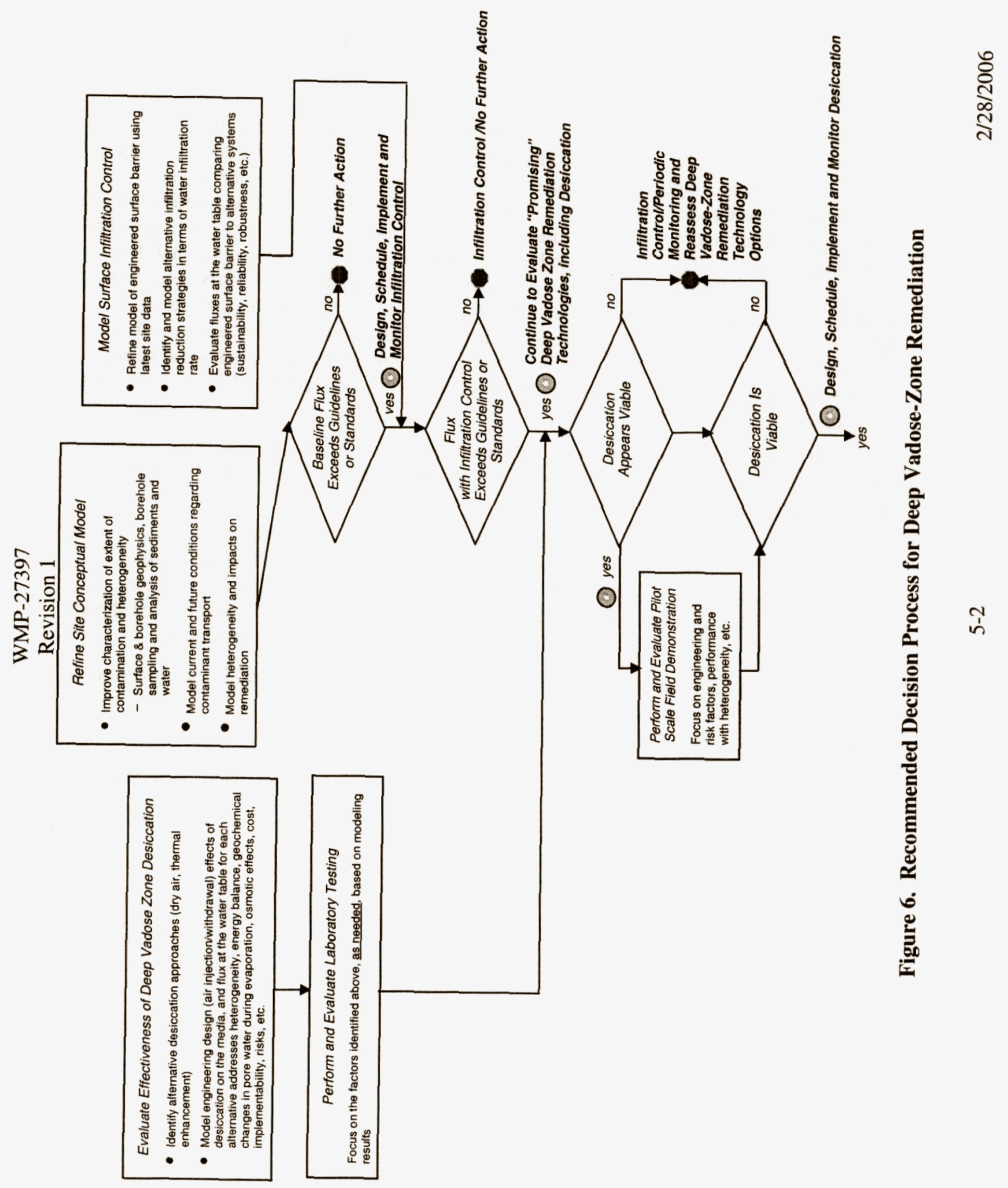


The decision tree depicts three major actions:

1. Evaluation of current conditions with a focus on providing data required for more sophisticated models of current conditions and potential future behavior of the site without further interference either at the surface or in the subsurface. This modeling has two primary goals. First, should the modeling indicate that, under current conditions, the mass flux at the water table is expected to be sufficiently low at all future times of interest, then additional technologies would be considered unnecessary. Second, this modeling will provide substantial insight into the driving forces resulting in contaminant migration, thus allowing future assessments to focus more directly on reduction of the critical driving forces. The panel anticipates that the primary driving force of interest will be the long-term rate of recharge at the surface.

2. Assessment of surface infiltration control as a primary technology, including modeling to determine the degree to which this technology will provide sufficient control over recharge to obviate the need for additional technologies. Once again, this modeling will provide a means for making a go/no-go decision as well as providing insight into additional need for remediation.

3. Assessment of desiccation as a possible enhancement. As outlined in Section 5.4, a number of studies would be required prior to selecting this option.

\subsection{Site Conceptual Model Refinements}

\subsubsection{Delineation of Current Extent of Plume and Its Interaction with Lithology}

Specific activities for delineation of the current extent of the plume and its interaction with lithology at any vadose zone location at Hanford are detailed in Section 6.0 for the BC Cribs

and Trenches example. At any site, traditional methods of drilling, sampling, and analysis of core and downhole geophysical logging are recommended, as well as surface geophysical surveys, such as the HRR survey recently completed at the BC Cribs and Trenches (described in Section 6.1).

\subsubsection{Modeling Based Upon Known Lithologic Structure and Incorporating Random Preferential Pathways}

The panel recommends two types of modeling. The goal of the deterministic modeling is to model, to the greatest precision possible, both current conditions based upon historical knowledge of disposal and the future expected migration of contaminants. This modeling should incorporate new site characterization data such as core samples, geophysical logs, other downhole measurements, groundwater samples, and surface geophysics. This effort will build upon the modeling of Ward et al. (2004) at the BC Cribs and Trenches to provide information on the driving forces that are impacting transport rates (e.g., through sensitivity analysis) and a better baseline for comparison with simulated technology applications.

The panel also recommends numerical modeling to study the potential impact of preferential flow pathways in the vadose zone. It is anticipated that this would be performed using a geological simulation model (rather than a simple random-field approach) and would be based upon analysis of multiple realizations of subsurface geology that are consistent with 
the known lithology. These simulations will provide the opportunity both to explore what significant uncertainties may remain at the site ("invisible" to the currently employed characterization methodologies) and to determine the robustness of proposed remediation technologies to uncertainties in subsurface conditions. Reference to geologically based and fractal-based simulation approaches is encouraged (e.g., Lu et al., 2002).

As indicated in Figure 6, these modeling efforts will lead to the first decision point in the decision tree. The modeling will provide prediction of mass flux of contaminant versus time at the regulatory boundary.

\subsubsection{Linking the Conceptual Model to Evaluate Deep Vadose-Zone Treatment Options}

In abiding with the criteria developed by Truex (2004), recommendations for implementing in-situ treatment options include:

- amount of water introduced to the subsurface;

- impact on water distribution in the subsurface, if the hydraulic conductivity is changed by the in situ technology;

- contrasts in permeability at multiple intervals within the contaminated zone and immediately below this zone; the layers of low-permeability material may be very thin ( $\mathrm{mm}$ to $15 \mathrm{~cm}$ ); layers identified as generally coarse may be laminated by very thin lenses of less permeable material;

- thickness of the contaminated zone; and,

- areal extent of contamination.

\subsection{Modeling of Surface Infiltration Control}

The panel recommends a carefully planned sequence of modeling to evaluate the impacts of surface infiltration control at each specific waste site:

1) refine and upgrade the conceptual model to incorporate new field data (e.g., on heterogeneity, water content, and contamination),

2) model alternative infiltration-control systems in terms of water infiltration rate beneath the root zone (this can be completed in parallel with 1a),

3) model the performance of the selected infiltration-control system in terms of moderating contaminant flux to the water table, using the conceptual model from \#1.

This sequence is described in Figure 6. This modeling will lead to the second decision point, providing a prediction of reduction in mass flux of contaminant versus time at the regulatory boundary based on surface infiltration control. If the results indicate that infiltration control is insufficient, the next step involves evaluation of deep vadose-zone remediation technologies, including desiccation.

Evaluation of infiltration control should be based upon the results of many years' of research on innovative infiltration-control systems at Hanford. This research has identified a variety of infiltration-control options, many of which could be described as alternative or 


\section{Revision 1}

evapotranspiration covers, where precipitation is stored in surface soil layers and then released by plant transpiration and soil evaporation. Other options include more traditional infiltration barriers that include capillary breaks and animal intrusion barriers (Ward and Gee, 2000). Such systems provide "multiple lines of defense" as recommended by the National Academy of Sciences in their reviews of DOE Environmental Management programs. A significant benefit of the research on infiltration-control systems at Hanford is the detailed consideration of local climate, geology, and ecology.

The panel recommends that results from these past studies be used as the basis for design of the infiltration-control system. However, designs must be site specific and robust in terms of construction and aging failure (e.g., edge design), response to extreme climatic conditions, and the like. The primary performance measure for infiltration control should be set in terms of penetration of water through the waste zone.

- In the case of an alternative evapotranspiration cover, water that flows beneath the sustainable root zone of plants, "infiltration rate beneath the root zone," is the same as water that enters the waste zone.

- In the case of more traditional layered cover systems, water flow beneath the root zone is designed to be diverted away from the waste.

A limited set of alternative infiltration-control strategies based on local experience should be evaluated through modeling; specific interrelated issues to be examined include temporal performance (e.g., seasonal response, extreme event response, performance over 100's of years, etc.), and engineering issues (cost, constructability, compatibility with local environmental and ecology, etc.). The modeling of infiltration control is critical to examining the applicability and performance of deep vadose-zone remediation.

\subsection{Evaluation of the Effects of Desiccation}

The panel considers desiccation to have potential benefits for deep vadose zone application. However, because desiccation to minimize contaminant migration in the vadose zone has never been applied to a contaminated site, many uncertainties regarding its effectiveness and long-term performance exist. As a result, the panel has attempted to outline a path forward to reduce uncertainties associated with desiccation (Figure 6). The first activity recommended by the panel is conduct of numerical modeling to better understand the 1) air injection/withdrawal process during desiccation and 2) effects of desiccation on the unsaturated-zone media. After preliminary modeling runs are completed, laboratory testing is recommended as an activity that can proceed concurrently with additional modeling. Field testing is only recommended, if the results of the modeling and laboratory testing find desiccation as a viable alternative.

\subsubsection{Numerical Modeling}

Two types of numerical simulations are needed to evaluate the feasibility of deep vadosezone desiccation treatment: 1) engineering aspects of air injection/exhaust to achieve desiccation, and 2) evaluation of physical and chemical effects of desiccation on long-term vadose-zone flow and transport at the site. Both modeling efforts are important, as either could result in determining whether deep vadose-zone desiccation is a feasible option. If the desiccation system requires too many wells, too long a time frame, or is too costly, 
desiccation treatment will not be feasible. These modeling efforts should be conducted in parallel, as the results of either study could obviate the need for the other.

\subsubsection{Modeling of Engineering Aspects}

Modeling of air injection and withdrawal should concentrate on the effectiveness of active desiccation through simulation of the effects of a pair of air-injection/withdrawal wells located at the diagonal corners of a rectangular area representing a unit cell of a regular or staggered five-spot array. The model should then be extended to include representative heterogeneities and multiple well array design (including infill wells), allowing analysis of volumetric coverage and bypass effects. The panel further recommends that this modeling incorporate combined energy balance and osmotic effects to address the issues raised in Section 4.2.6. This modeling can provide data to support cost estimates of implementation.

Questions have been raised regarding the energy balance during active desiccation, its effect on subsurface temperatures, and whether lower temperatures in the subsurface will compromise the efficacy of this technology. Moreover, osmotic effects, which are additive to the energy-balance effects, may further limit desiccation, particularly within the contaminated zone. The panel recommends that this modeling incorporate combined energy balance and osmotic effects on vapor redistribution and exhaust, as these effects may severely limit the rate at which moisture can be removed from the vadose zone by air extraction. If the injected air is not dried, the panel recommends that the effects of ambient air temperature and humidity be assessed based upon historical or synthesized weather records for an annual weather cycle typical for Hanford.

The model should include representative elements of aquifer heterogeneity, as these may result in significant bypass of intervals in the vadose zone that thus escape treatment and provide a long-term source or a fast pathway for transport through the desiccated zone.

The panel recommends modeling of the implementability of desiccation, including effects of well placement, including staggered arrays, emplacement of infill wells, and other scenarios, on areal coverage. This modeling can provide specific data to be used to estimate costs of implementation.

Achievement of full or nearly full areal coverage will not be easily achieved by well injection/withdrawal. The Truex report infers that such coverage can be achieved by reversing the injection/withdrawal function of the wells. Although this action will result in moisture redistribution, considerable uncertainty exists as to whether the procedure will provide substantially improved areal coverage. Modeling of the effects of flow reversal by swapping injection/withdrawal well functions on vadose-zone water redistribution is also recommended to evaluate that approach.

\subsubsection{Modeling of Desiccation Impacts and Synergies}

The panel recommends numerical flow and transport modeling to respond to the following issues, approaches, and recommendations.

- Chemical/Physical Changes: Evaluation of desiccation must take into account the chemical and physical changes that will occur as the vadose zone is dried. Among these effects are the 1) possible incorporation of contaminants into complex mineralogic forms, reducing the likelihood of dissolution and mobility; 2) 


\section{WMP-27397}

\section{Revision 1}

redistribution of moisture related to rewetting from the air phase of mineral precipitates, and 3) concentration/mass flux profiles to be anticipated under various rewetting scenarios. In addition, predictive modeling needs to examine the potential deleterious effects of desiccation on contaminant fluxes at the water table.

Recommended modeling should include the effects of successive reductions in water content integrated with changes in pore water chemistry. One of the panel members conducted preliminary analytical and numerical modeling to assess whether desiccation could cause a deleterious effect, such as increased pore water concentrations that could later be flushed to greater depths (Appendix D).

- Treatment Synergies: The panel recommends that modeling include treatment combinations to better understand how multiple remediation approaches might yield synergistic effects that a single treatment cannot achieve. This would include (1) infiltration control with no deep vadose-zone treatment; (2) both desiccation and infiltration control, and (3) addition of heat to desiccation. The treatment combinations should augment the analysis already completed by Ward et al. (2004), which showed the differences in contaminant flux as a function of infiltration control.

The numerical modeling should be used as an initial step in the evaluation process leading to a go/no-go decision point (Figure 6). Some preliminary criteria for the go/no-go decision are provided in Section 5.1. This modeling should provide a path forward to reduce uncertainties without committing to a costly field testing program, before the technology can be determined to be viable.

\subsubsection{Laboratory Testing}

Potential laboratory studies to support determination of the feasibility of desiccation fall into two categories: determination of transport properties from undisturbed cores for numerical modeling parameterization, and flow-cell experiments to test concepts and physical processes. While laboratory studies provide for carefully controlled experiments against which to compare predictions derived from numerical models, their greatest value comes in visualizing and studying mechanisms for which mathematical models are currently subject to substantial uncertainty. Therefore, simple laboratory studies demonstrating desiccation in homogeneous or heterogeneous media using clean water as the saturation phase are not considered to provide substantial benefit relative to the cost and time required for these experiments. Much of this work can be completed reliably using existing numerical models and the simplifications required to conduct these experiments in the laboratory are considered extreme.

However, as the modeling described in Section 5.4.1 proceeds, it could definitely benefit from laboratory testing specific to uncertainties identified during the modeling such as:

- magnitude and impact of energy, osmotic, and bypass effects during air injection/withdrawal

- chemical and physical effects, as well as synergistic effects of multiple technology options.

The panel also recommends consideration of flow-cell tests as follows: 
- analysis of the thermodynamic and geochemical effects occurring in the vicinity of a drying front under complex conditions (lab experiment should mimic proposed field operation, with air injected in one corner of a rectangular model, and withdrawn from the opposite comer; such a configuration would result in the representation of the entire sweep area for a unit five-spot cell);

- measurement of permeability to air at prevailing saturation and as the samples are progressively desiccated;

- examination of the effects of rewetting related to chemical precipitation and remobilization and gas-phase migration;

- observations related to hydraulic and pneumatic effects of heterogeneity, including study of low permeability layers;

- measurements related to density effects that occur in the vapor phase during desiccation, and spatial distribution of drying (e.g., Falta et al., 1989);

- analysis of the effects of thermal enhancements for desiccation;

- analysis of the potential for micro-fracturing, particularly in fine-grained intervals, and also during thermal enhancements and other unknown impacts of desiccation.

The results of the numerical modeling and laboratory studies should be used to evaluate the third go/no-go decision. Specifically, the results should be used to answer the question of whether desiccation appears viable for field application.

\subsubsection{Field Testing}

Should the previous analyses indicate that desiccation is both a viable and necessary technology, specific field tests should be pursued prior to and during pilot-scale testing of desiccation technology. To evaluate the effectiveness of desiccation through field testing at the Hanford Site, the panel recommends selection of a site with significant characterization data, so that uncertainties related to the presence and extent of contaminants of concern and the stratigraphy of the vadose-zone sediments are minimized. The presence of some infrastructure, in terms of existing monitoring wells could also be beneficial for monitoring the effectiveness, while minimizing costs.

Specific tests should include the following.

- Knowledge of air permeability of the target treatment zones is critical for determining maximum well injection/exhaust rates and minimum well spacing required to obtain adequate volumetric treatment coverage in a reasonable period of time. Pneumatic tests should be conducted to determine field permeability to air, using existing and installing new wells. This test, listed as Task 5 of the Treatability Test Plan, is critical to support the modeling studies.

In implementing any desiccation scheme, monitoring the actual release of moisture from the subsurface may be important. The panel suggests consideration of stable isotopes to monitor the progression of evaporation in the target zone. Preliminary studies document the value of stable isotopes for the proposed application. The stable isotope composition of hydrogen $\left({ }^{2} \mathrm{H} /{ }^{1} \mathrm{H}\right.$ or $\left.\mathrm{D} / \mathrm{H}\right)$ and oxygen $\left({ }^{18} \mathrm{O} /{ }^{16} \mathrm{O}\right)$ in natural waters provides insights into its origin and evolution over time (Dansgaard, 1964; Craig and Gordon, 1965; Gat, 1971; Sheppard, 1986; 
WMP-27397

Revision 1

Kyser, 1987; Fritz and Fontes 1980; Kendall and McDonnell, 1998; Yurtsever, 1975). The processes of evaporation and condensation impart recognizable signatures in the isotope ratios for both oxygen and hydrogen. Desiccation would result in a quantifiable shift in these ratios. Mapping of these ratios throughout the target zone would provide direct indication of the degree of evaporation.

\subsection{Other Recommendations}

The decision process outlined above cannot be completed without designation of both the point of compliance and the definition of compliance.

The panel recommends that compliance should be defined in terms of the long-term mass flux of contaminants leaving the vadose zone and entering the groundwater. This contrasts with the use of water flux or contaminant concentrations commonly in use for the last thirty or more years. Regardless of how the contaminant fluxes are expressed (point values, averaged across screen length) or regulated (edge of cribs, receptor well), the panel recommends focus on contaminant flux as a key to success. 

WMP-27397

Revision 1

\subsection{RECOMMENDATIONS FOR TESTING, DEMONSTRATING, AND DEPLOYING TECHNOLOGIES AT THE BC CRIBS AND TRENCHES}

Because the BC Cribs and Trenches Site was utilized as an example for the panel to review site data for this evaluation, the panel also provides recommendations specific for testing, demonstrating, and deploying technologies at that site.

\subsection{Conceptual Model of the Vadose Zone Beneath BC Cribs and Trenches}

\subsubsection{Key Elements of the Current Conceptual Model}

The BC Cribs and Trenches in the 200 West Area at the Hanford Site (Figure 7) has a significant historical record related to waste disposal and subsurface characterization. Recent documents and technical presentations summarize and interpret this record. Notable examples include the descriptive conceptual model in Truex (2004), the hydrologic conceptual model in Ward et al. (2004), and recent geophysical field data by Rucker and Sweeney (2005).

The following highlights key elements of the conceptual model for this site; these elements are organized into categories based on the approximate level of certainty or uncertainty.

What We Know

- Liquid wastes, many of which were brines containing radionuclides, were disposed to the subsurface at BC Cribs and Trenches.

- Some mobile contaminants (e.g., ${ }^{99} \mathrm{Tc}$, $\mathrm{NO}_{3}$ ) have migrated to depth (Figure 8).

- Distribution of ${ }^{99} \mathrm{Tc}$ in the vadose zone at $\mathrm{BC}$ Cribs and Trenches has been measured in one borehole (C 4191 in former Trench 26) (Figure 8).

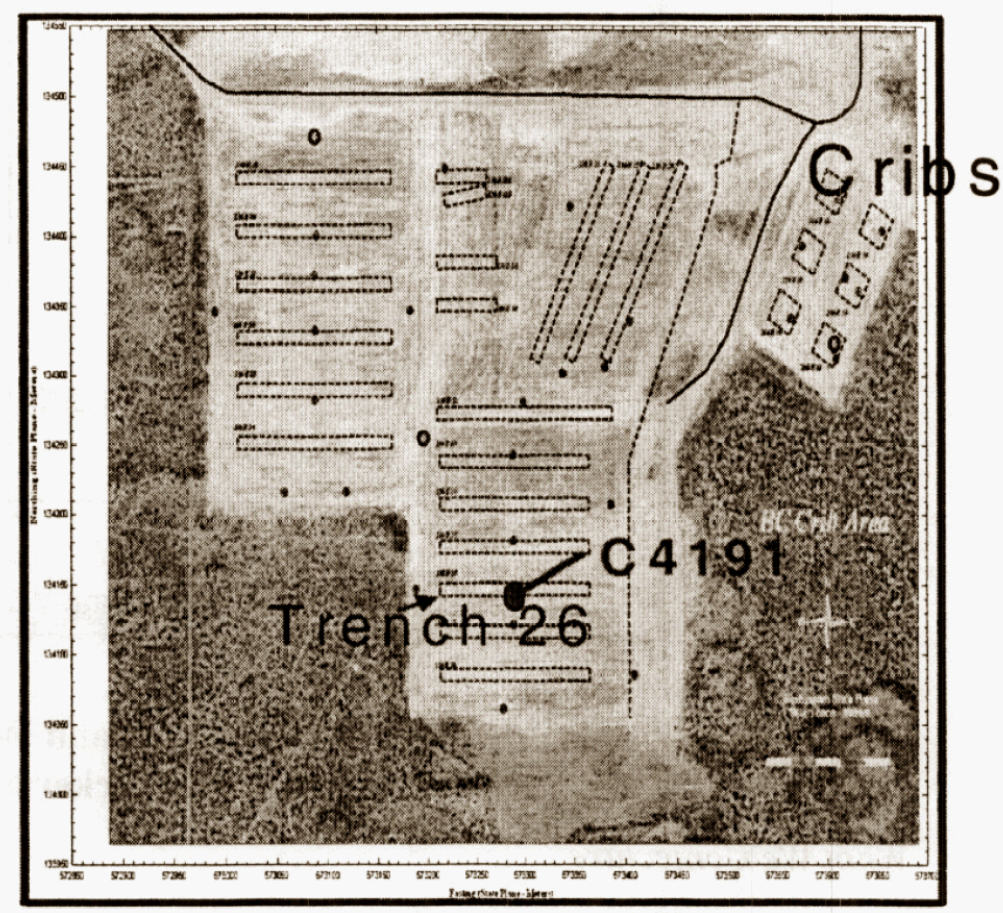

Figure 7. Map of BC Cribs and Trenches (not to scale) (Rucker and Sweeney, 2005)

- At BC Cribs and Trenches, approximately $115,000 \mathrm{~m}^{3}$ (30 million gallons) of aqueous waste were disposed on a 22 -acre parcel. This is equivalent to an average 


\section{Revision 1}

equivalent water column of approximately 1.3 meters. However, BC Cribs received 3 times more volume of waste per square foot of waste facility area than the Trenches, and thus equivalent water column and depth of penetration could likely be much greater for the Cribs than the Trenches.

- The current moisture profile in the vadose zone varies widely from $<2$ to 15 weight $\%$, with higher values associated with finer grained layers between depths of 5 and 65 meters below ground surface (bgs) (Figure 8).

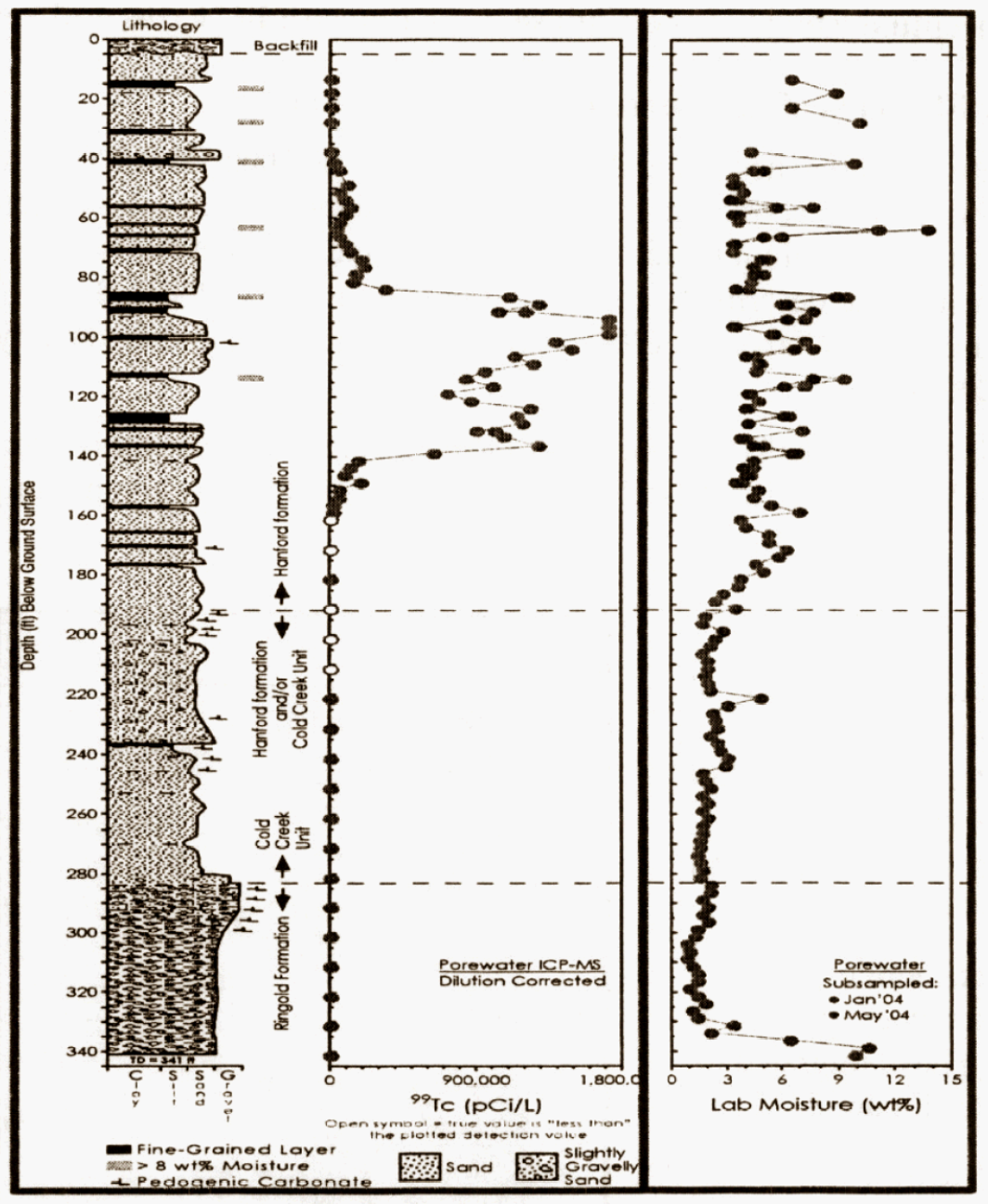

Figure 8. Geologic Profile, ${ }^{99}$ Tc Activity, and Water Content from Borehole C4191, BC Cribs/Trenches (Rucker and Sweeney, 2005)

\section{What We Conjecture}

- New HRR geophysical data provide a two-dimensional visualization of the highconductivity plume in the subsurface (Rucker and Sweeney, 2005) (Figure 9). Below the Trenches, the data show the base of a high-conductivity plume estimated at about 50 meters bgs (Figure 9), which matches the data collected in Borehole C4191 (Figure 8). HRR data in the area of the Cribs show the possibility of deeper contamination (Figure 10). 
WMP-27397

Revision 1

Figure 9. Recent High-Resolution Resistivity Geophysics Indicating the Presence of

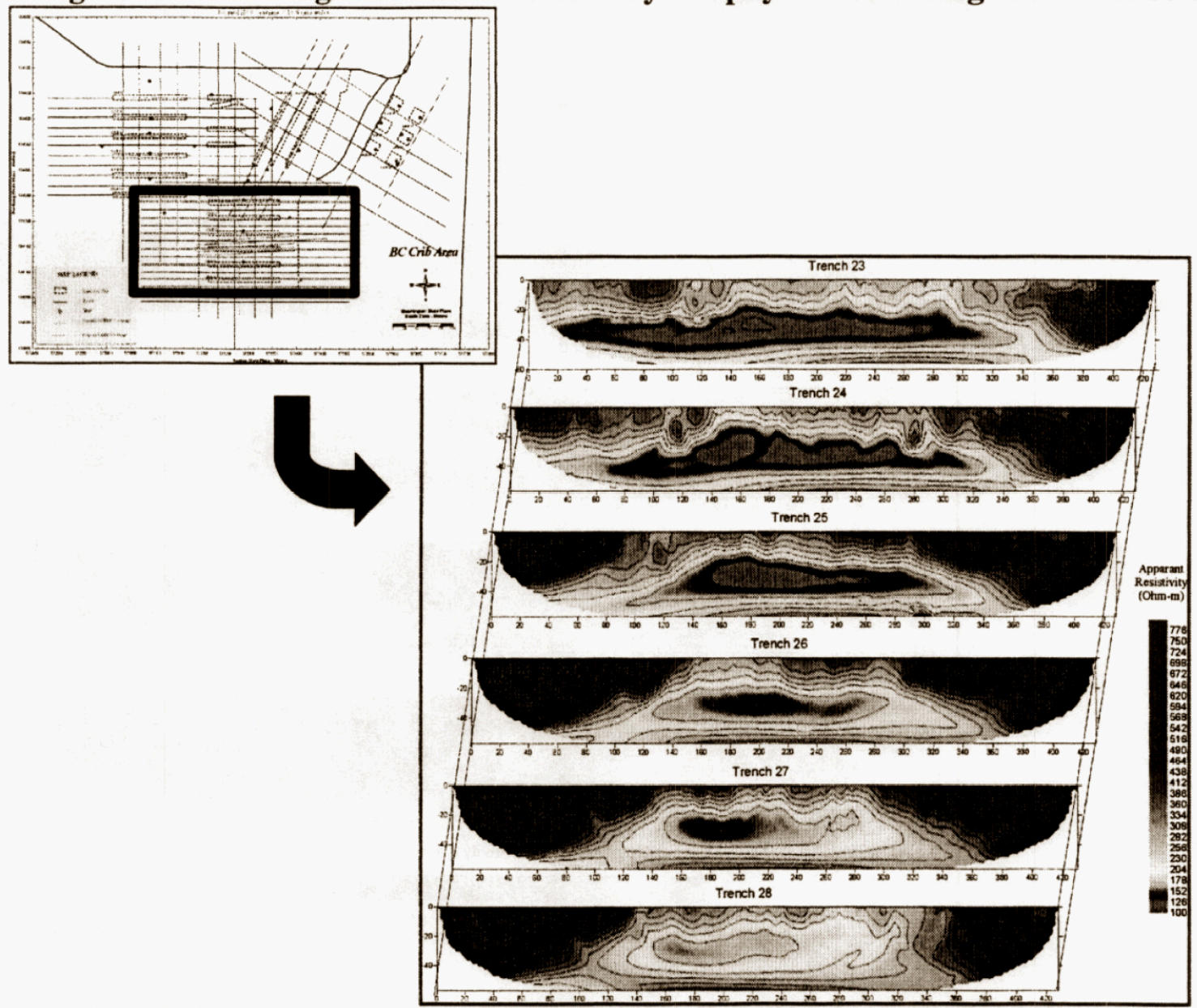

Residual Wastes in the Intermediate Vadose Zone (Rucker and Sweeney, 2005)

- Because the BC Cribs received a higher volume of waste per surface area than the Trenches, excess water could have accumulated through a significant portion of the vadose zone and a greater driving force could have facilitated deeper contaminant penetration below the Cribs.

- Heterogeneity is impacting subsurface migration pathways and rates.

- The current moisture profile is the result of vertical flow impacted by local heterogeneity to promote lateral flow at hydraulic conductivity boundaries and indicates the presence of anthropogenic moisture to a depth of $\sim 65$ meters bgs below the Trenches (Borehole C4191). Between 57 and 65 meters bgs, there is a distinct change in water content, from $\sim 6.5 \%$ to $\sim 2 \%$ by weight. Because most of the decrease appears to occur in a sandy portion of profile, we do not expect that the existence of finer-grained layers to be the cause. 


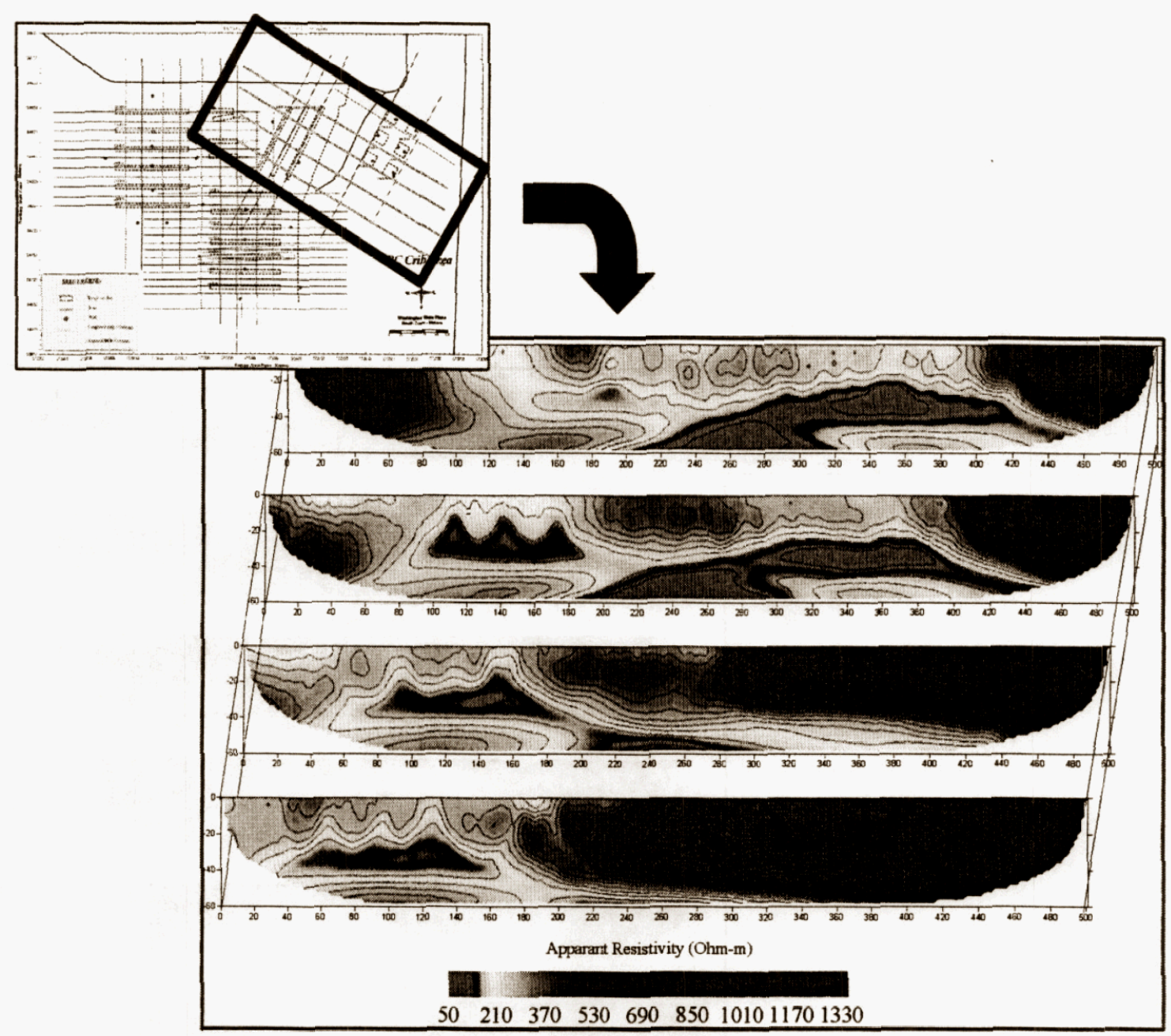

Figure 10. Recent High-Resolution Resistivity Geophysics Indicating Possible Penetration of Wastes Deeper in the Vadose Zone at the BC Cribs (Rucker and Sweeney, 2005)

\section{What Requires Clarification}

- Total depth of migration of mobile contaminants (e.g., ${ }^{99} \mathrm{Tc}, \mathrm{NO}_{3}$ ) at $\mathrm{BC}$ Cribs and Trenches is not known.

- Effectiveness of proposed remedial technologies has significant uncertainties.

- Lithologic controls (e.g., thickness and continuity of silty zones and the role in focusing water flow, and the role of coarse zones in forming capillary barriers or in facilitating waste penetration) are not well understood at this site.

- Geochemical conditions (impact of waste brines and their interaction with subsurface minerals) must be considered during evaluation of remedial alternatives. 
WMP-27397

Revision 1

- Impact of differential wastewater discharge to the Cribs and Trenches may have produced significant variability of contaminant concentrations across the site.

\subsubsection{Vertical Penetration of Contaminants at the BC Cribs and Trenches}

As noted in Figure 8 (based on data from a single borehole), water in the vadose zone reflects past high-volume waste disposal and the current pattern of its redistribution after an extended period of time since disposal was stopped. The "floor" of elevated water content, at approximately 65 meters depth, is believed to be related to geologic heterogeneity, where capillary breaks have induced lateral migration and prevented further downward migration (Ward et al., 2004). This pattern of distribution is similar to that observed at Hanford's Sisson and Lu Site in the 200 East Area after conduct of injection tests (Ward et al., 2002).

Figure 8 also shows the ${ }^{99} \mathrm{Tc}$ distribution beneath the BC Trenches localized at a specific depth interval between approximately 20 and 50 meters bgs. Within this interval, ${ }^{99} \mathrm{Tc}$ activities and water contents vary widely, likely correlating with lithology (with the highest activities and water contents associated with finest grained layers). Below $\sim 65$ meters bgs, the moisture content is low and relatively uniform; the core material from Borehole C4191 indicates relatively coarse sediments prevail. Recent HRR surveys generally confirm the known contaminated interval (Figure 9) (Rucker and Sweeney, 2005), but also suggests deeper penetration in the area of the site near the BC Cribs (Figure 10). Because the original wastes were concentrated brines, the electrical resistivity-based geophysical method appears to provide a clear signature of residual wastewater in the vadose zone, which correlates with intervals of high ${ }^{99} \mathrm{Tc}$ activity in the vicinity of Borehole C4191. However, the HRR survey must be groundtruthed through drilling and sampling to confirm its accuracy.

The geophysics further supports a conceptual model in which residual wastes are associated with the intermediate-depth finer-grained layers and that deeper migration may have been channeled or impeded by the underlying drier and coarser materials. At the Cribs, however, deeper penetration may have occurred as a result of higher waste application rates and/or local geologic heterogeneity, e.g., preferential pathways. The geophysics, however, does not provide a direct indication of what is controlling the apparent deeper penetration in one area of the site, because the surveys were not designed to target greater depths. Additional characterization is critical to the design and potential effectiveness of any deep vadose-zone remediation method.

\subsubsection{Linking the BC Cribs and Trenches Conceptual Model to Evaluate Deep Vadose-Zone Treatment Options}

Recommendations for implementing in situ treatment options at the BC Cribs and Trenches are based upon the criteria identified in Section 2.2. After review of the current knowledge of historical operations and current knowledge of the subsurface, the panel recommends additional investigation to refine the conceptual model regarding: 1) the long-term redistribution of natural water and wastewater in the vadose zone, and 2) heterogeneity in both waste disposal and geology, as influencing the depth of contaminant penetration. 
WMP-27397

Revision 1

\subsection{Recommendations for Site Conceptual Model Refinements, BC Cribs and Trenches Example}

\subsubsection{Delineation of Current Extent of Plume and Its Interaction with Lithology}

As previously described, recent HRR data in the vicinity of the Cribs suggest that a significant portion of the contaminant plume may have migrated below 50 meters bgs. Determination of maximum vertical penetration of the plume and whether the plume has, in fact, reached the water table at any location on the 22-acre site is critical to design and implementation of a remediation plan. Towards this end, a field investigation is recommended.

1. Complete borehole drilling and sampling to validate the HRR survey results presented in this report (Rucker and Sweeney, 2005).

2. Perform an HRR survey to target the deeper portion of the vadose zone, especially in the area below the Cribs, to determine vertical extent of contamination. This, in conjunction with data from the boreholes recommended in \#3, will help to reduce uncertainty regarding the probability that contamination has reached the water table, and may provide greater insight into the relationship between subsurface heterogeneity and contaminant distribution. Additional geophysical methods, such as timedomain electromagnetics, should be considered to provide supplemental information about the subsurface at the BC Cribs and Trenches.

3. Drill three boreholes from which data on subsurface lithology, moisture content, grain size, porosity, bulk density, and contaminant concentrations can be determined and correlated with the results from the geophysics in the vicinity of the $\mathrm{BC}$ Cribs; locations within and down-gradient of the Cribs should be selected based upon the HRR data collected in \#1 (concept depicted in Figure 11); borehole data shall consist of core samples and geophysical logs (e.g., neutron and gamma gamma);

4. Construct water-table monitoring wells at the three borehole locations to sample the upper portion of the saturated zone to determine possible presence or absence of contamination at the water table and to provide a local measure of the hydraulic gradient in the groundwater (for future reference if reduction of mass flux is unsuccessful in the vadose zone). 


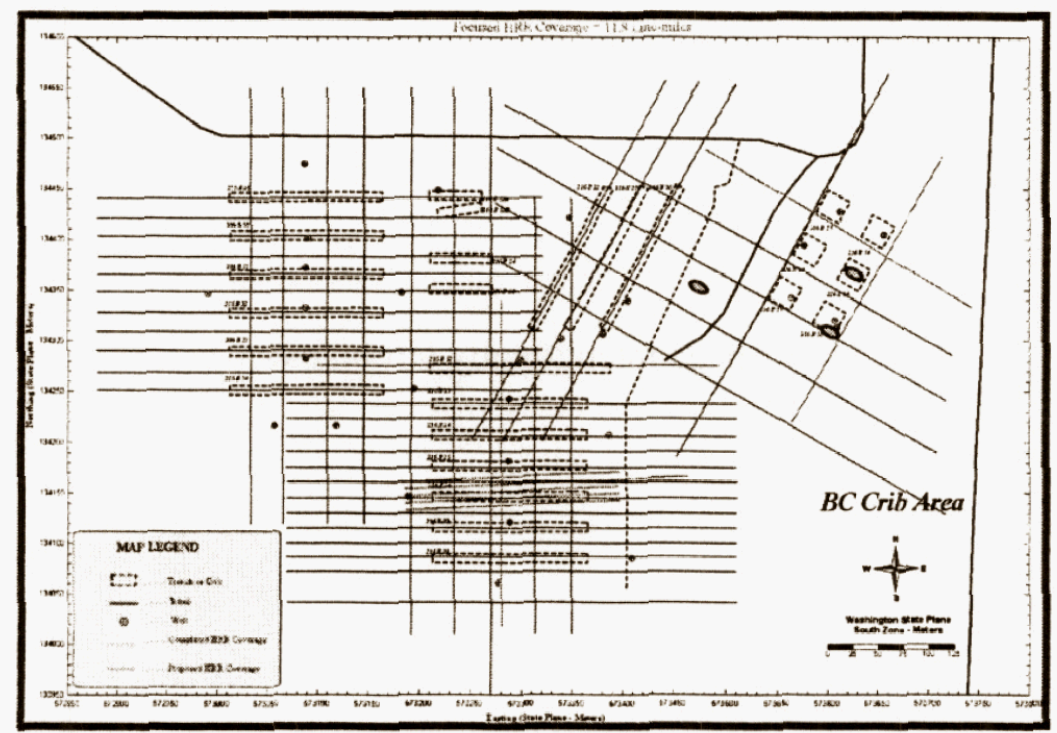

Figure 11. Proposed Borehole/Monitoring Well Locations Near the BC Cribs

\subsubsection{Modeling Based Upon Known Lithologic Structure and Incorporating Random Preferential Pathways}

The panel recommends numerical modeling to include specific Monte Carlo realizations of subsurface geology conditioned on the known lithology, as described in Section 5.2.2, to determine reasonable bounds on sensitivities and to improve understanding of uncertainties.

\subsection{Modeling of Surface Infiltration Control}

Infiltration control is a key component in any response action to ${ }^{99} \mathrm{Tc}$ in the vadose zone beneath the BC Crib and Trenches and is further described in Section 5.3 for general Hanford Site applications.

\subsection{Evaluation of the Effects of Desiccation}

The panel recommends evaluation of the effectiveness of desiccation through a general research study that has application to many Hanford vadose-zone locations. The results of this study should be applicable to the BC Cribs and Trenches and should be assessed within that context. Detailed recommendations for this work are presented in Section 5.4. Specific activities recommended for the study include 1) numerical modeling to evaluate the engineering aspects of air injection/exhaust and physical/chemical effects of desiccation on flow and transport, 2) laboratory testing to determine transport properties and flow-cell experiments to compare model predictions to laboratory results, and 3) field testing. 
WMP-27397

Revision 1

This page intentionally left blank.

6-8 
WMP-27397

Revision 1

\section{REFERENCES}

Amonette J. E., J. E., Szecsody, H. T., Schaef, J. C. Templeton, Y. A. Gorby, and J. S. Fruchter, 1994, Abiotic reduction of aquifer materials by dithionite: a promising insitu remediation technology, PNL-SA-24505, Pacific Northwest National Laboratory, Richland WA.

Armstrong, Aran, Daniel Arrenholz, and Jerry Weidner, 2002, Evaluation of in situ grouting for OU 7-13/14, INEEL /EXT-01-00278 Rev. 0.

Baron D. and C.D. Palmer, 2002, Solid solution aqueous solution reactions between jaarosite and its chromate analog, Geochimica et Cosmochimica Acta, v. 66, No. 16, p. 28412853.

Bethke, C.M., 2004, The Geochemist's Workbench, Hydrogeology Program, University of Illinois.

Cameron, R.J., J.C. Evans, M.D. Johnson, and T.L. Likaka, 2002, Summary of Hanford Subsurface Air Flow and Extraction (SAFE) Activities for Fiscal Year 2001, PNNL13820, Richland, Washington.

Chai, J.C. and M. Miura, 2004, Field vapor extraction test and long-term monitoring at a PCE contaminated site, Journal of Hazardous Materials 110 (1-3): 85-92.

Collins, R.E., 1961, Flow of fluids through porous materials, Reinhold, 270 p.

Craig, H. and L. Gordon, 1965, Deuterium and oxygen-18 variation in the ocean and the marine atmosphere, In Stable Isotopes in Oceanographic Studies and Paleotemperatures, E. Tongiorgi (ed.) Spoleto, 1965 pp. 9-130.

Curti, E., 1999, Coprecipitation of radionuclides with calcite: estimation of partition coefficients based on a review of laboratory investigations and geochemical data, Applied Geochemistry, v. 14, p. 433-445.

Dansgaard, W., 1964, Stable isotopes in precipitation, Tellus, 16, pp. 436-468.

Denham, M. E., 2002, Potential in situ remediation of ${ }^{129} \mathrm{I}$ and ${ }^{99} \mathrm{Tc}$ in groundwater associated with the F-Area Seepage Basins, WSRC-TR-2002-00571, Savannah River National Laboratory, Aiken SC, 29808.

Department of Energy, 2004, Screening level evaluation of remedial alternatives for Pit 9 transuranic waste at Los Alamos National Laboratory, Technical Solutions Report, October 2004, Office of Environmental Management, Washington DC.

Falta, R.W., K. Pruess, 1993, D.A. Chesnut, 1993, Modeling Advective Contaminant Transport During Soil Vapor Extraction, Ground Water 31 (6): 1011-1020.

Fritz, P. and J.C. Fontes, (eds.), 1980, Handbook of Environmental Isotope Geochemistry, Elsevier Sci. Publ. Co., Amsterdam, Netherlands.

Gat, J.R., 1971, Comments on the stable isotope method in regional groundwater investigations, Water Resources Research, 7, pp. 980-993. 
WMP-27397

Revision 1

Gee, G.W., M.K. Rockhold, and J.L. Downs, 1989, Status of the FY 1988 soil-water balance studies on the Hanford Site, PNL-6750, Pacific Northwest Laboratory, Richland, WA.

Hendrickx, J.M.H., G. Rodriguez-Marin, R.T. Hicks, and J. Simunek, 2005, Modeling Study of Produced Water Release Scenarios, API Publication, ed., American Petroleum Institute, volume 4734, American Petroleum Institute Publishing Services, p. 124.

Hendrickx, J.M.H. and M. Flury, 2001, Uniform and preferential flow mechanisms in the vadose zone, in Conceptual models of flow and transport in the fractured vadose zone, National Academy Press, Washington D.C. p. 149-187.

Hillel, D., 1998, Environmental Soil Physics, Academic Press, San Diego, CA.

Jacob, C.E., 1963, Determining the permeability of water-table aquifers, Methods for determining permeability, transmissibility, and drawdown, in Bentall, Ray, compiler: U.S. Geol. Survey Water-Supply Paper 1536-I, p. 245-271.

Jarosch, T. R. and B. B. Looney, 1999, Enhanced recovery of organics using direct energy techniques. In: Innovative Subsurface Remediation: Field Testing of Physical, Chemical and Characterization Technologies, M. L. Brusseau, D. A. Sabatini, J. S. Gierke, and M. D. Annable eds., Americal Chemical Society, Washington DC.

Ju, S.-H. and K.-J.S. Kung, 1993, Simulating funnel-type preferential flow and overall flow properties induced by multiple soil layers, J. Environmental Quality, 22, p. 432-442.

Karberg, N.J., K.S. Pretziger, J.S. King, A.L. Friend, and J.R. Wood, 2005, Soil carbon dioxide partial pressure and dissolved inorganic carbonate chemistry under elevated carbon dioxide and ozone, Oecologia, 142, p. 296-306.

Katz, D.L., 1959, editor, Handbook of Natural Gas Engineering. McGraw-Hill, p. 306.

Kelly, S.F., J.S. Selker, 2001, Osmotically driven water vapor transport in unsaturated soils, Soil Science Society of America Journal, 64 (6): 1634-1641.

Kendall, C. and J. McDonnell (eds.), 1998, Isotope Tracers in Catchment Hydrology, Elsevier, Amsterdam, Netherlands, pp. 839.

Kung, K.-J.S., 1990a, Preferential flow in a sandy vadose zone. I. Field observation. Geoderma.46, p. 51-58.

Kung, K.-J.S., 1990b, Preferential flow in a sandy vadose zone. II. Mechanism and implications. Geoderma.46, p. 59-71.

Kung, K.-J.S., 1993, Laboratory observation of funnel flow mechanism and its influence on solute transport. J. Environmental Quality. 22, p. 91-102.

Kyser, T.K., 1987, Equilibrium fractionation factors for stable isotopes, In Stable Isotope Geochemistry of Low Temperature Processes, T.K. Kyser (ed.), Short Course Handbook, Mineralogical Association of Canada, 13, pp. 1-84.

Liang L., B. Gu, and X.Yin, 1996, Removal of technetium-99 from contaminated groundwater with sorbents and reductive materials, Separations Technology 6, 111122. 
WMP-27397

Revision 1

Lieser K. H. and C. Bauscher, 1987, technetium in the hydrosphere and in the geosphere, Radiochimica Acta 42, 205-213.

Looney, B.B. and R.W. Falta, 2000, Vadose Zone Science and Technology Solutions, Battelle Press, Columbus, Ohio.

Lopez, Steve, William Landman, Don Sebo, and Vivian Schultz, 2005, Summary report of OU7-13/14: early actions beryllium encapsulation project, ICP/EXT-04-00646 Rev. 1.

Lu, S.L., F.J. Molz, G.E. Fogg, et al., 2002, Combining stochastic facies and fractal models for representing natural heterogeneity, Hydrogeology Journal 10 (4): 475-482.

Matthews, C.S. and D.G. Russell, 1967, Pressure buildup and flow tests in wells: Soc. Petrol. Engineers, Monograph v. 1, 167 p.

McCord, J.T., D.B. Stephens, and J.L. Wilson, 1991, Hysteresis and state-dependent anisotropy in modelling unsaturated hillslope processes, Water Resources Research, 27, p. 1501-1518.

Meyer R. E. and W. D. Amold, 1991, The electrode potential of the Tc(IV)-Tc(VII) couple, Radiochimica Acta 55, 19-22.

Mitchell, J. K, 1993, Fundamentals of Soil Science, $2^{\text {nd }}$ Edition, John Wiley and Sons, New York, NY.

Mote, P.W., 2003, Trends in temperature and precipitation in the Pacific northwest during the twentieth century, Northwest Science 77 (4): 271-282.

Mote, P.W. et al., 1999, Impacts of climate variability and change, Pacific Northwest, National Atmospheric and Oceanic Administration, Office of Global Programs, and JSAO/SMA Climate Impacts Group, Seattle, WA, 110 pp, (accessed on-line at http:llwww.usgcrp.gov/usgcrp/Library/nationalassessment/pnw.pdf; co-authors not identified).

Nobre, M..M..M.., R.C..M. Nobre, 2004, Soil vapor extraction of chlorinated solvents at an industrial site in Brazil, Journal of Hazardous Materials 110 (1-3): 119-127.

Palmquist, W.N. and A.I. Johnson, 1962, Vadose flow in layered and non-layered materials, Geological Survey Research, 119, p. c142-143.

Rodríguez-Marín, G., 2001, Water flow through indurated calcic horizons in arid New Mexico, in Earth and Environmental Science, New Mexico Tech, Socorro, NM.

Rodríguez-Marín, G., J.B.J. Harrison, B. Borchers, and J.M.H. Hendrickx, 2005, Dissolution pipes through indurated calcic horizons in southern New Mexico, Vadose Zone J. submitted.

Rodríguez-Marín, G., J.B.J. Harrison, J. Simunek, and J.M.H. Hendrickx, 2003, Simulation of water flow through indurated calcic horizons, in Understanding water in a dry environment. Hydrological processes in arid and semi-arid zones, I. Simmers, Editor, A.A. Balkema Publishers, Lisse, The Netherlands, p. 182-188.

Roote, D.S., 2003, In situ flushing, Vol. Technology Overview Report TO-97-02, GroundWater Remediation Technologies Analysis Center. Pittsburgh, PA 15238, 24. 
WMP-27397

Revision 1

Roote, D.S., 1998, In situ flushing, Technology Status Report TS-98-01, Ground-Water Remediation Technologies Analysis Center, Pittsburgh, PA 15238, 212.

Rucker, D. and M. Sweeney, 2005, Preliminary Geophysics for BC Cribs and Trenches FY2005, Presentation to Technical Panel, April 26, 2005.

Shan, C., R.W. Falta, I. Javandel, 1992, Analytical solutions for steady-state gas-flow to a soil vapor extraction well, Water Resources Research 29 (4): 1105-1120.

Sheppard, S.M.F., 1986, Characterization and isotopic variations in natural waters. In Stable Isotopes in High Temperature Geological Processes. J.W. Valley, H.P. Taylor, Jr., and J.R O'Neil, (eds.), Reviews in Mineralogy, Mineralogical Society of America, 16, pp. 165-183.

Šimünek, J., M. Šejna, and M.T.V. Genuchten, 1998, The HYDRUS-1D software package for simulating the one-dimensional movement of water, heat, and multiple solutes in variably saturated media. Version 2.0. Vol. IGWMC-TPS-70. Golden, Colorado: International Ground Water Modeling Center, Colorado School of Mines, 202.

Spane, F.A., 1999, Effects of barometric fluctuations on well water-level measurements and aquifer test data: PNNL-13078.

Stephens, D.B., 1995, Vadose Zone Hydrology, CRC Press, Boca Raton, FL.

Stephens, D.B. and S.E. Heermann, 1988, Dependence of anisotropy on saturation in a stratified sand, Water Resources Research. 24, p. 770-778.

Tesoriero, A. and J.F. Pankow, 1996, Solid solution partitioning of Sr2+, Ba2+, and Cd2+ to calcite, Geochimica et Cosmochimia Acta, v. 60, No. 6, p. 1-53-1063.

Thornton, E.C., J.T. Giblin, T.J. Gilmore, K.B. Olsen, J.M. Phelan, and R.D. Miller, 1999, In Situ Gaseous Reduction Pilot Demonstration - Final Report, PNNL-12121, Pacific Northwest National Laboratory.

Thomton, E.C., V.L. Gore, and K.B. Olsen, 2003, Immobilization of Chromium, Technetium, and Uranium by Gaseous Reduction in Soil from the Hanford Site. In M.J. Hartman, L.F. Morasch, and W.D. Webber (eds.), Hanford Site Groundwater Monitoring for Fiscal Year 2002, PNNL-14187, Pacific Northwest National Laboratory, p. 3.3-10 3.3-14.

Truex, M. J., 2004, Feasibility Study Evaluation of In Situ Technologies for Immobilization of Technetium Beneath the BC Cribs, Letter Report, Pacific Northwest National Laboratory, Richland WA.

U.S. Environmental Protection Agency, 1990, Development of Electro-Acoustical Soil Decontamination (ESD) Process for In Situ Applications, EPA/540/5-90/004, U. S. Environmental Protection Agency, Washington D.C.

U.S. Environmental Protection Agency, 1997, Technology alternatives for the remediation of soils contaminated with $\mathrm{As}, \mathrm{Cd}, \mathrm{Cr}, \mathrm{Hg}$, and $\mathrm{Pb}$. Office of Research and Development: Cincinnati, OH. p. 20. 


\section{WMP-27397}

\section{Revision 1}

Walton F. B., J. Paquette, J. P. M. Ross, and W. E. Lawrence, 1986, Tc(IV) and Tc(VII) Interactions with Iron Oxyhydroxides. Nuclear Chemistry and Waste Management 6 , 121-126.

Ward, A.L., G.W., Z.F. Zhang, J.M. Keller, 2004, Vadose Zone Contaminant Fate-andTransport Analysis for the 216-B-26 Trench, Pacific Northwest National Laboratory, PNNL-14907.

Ward, A.L. and G.W. Gee, 2000, Hanford Site Barrier Technology, pp. 1415-1423, in B.B. Looney and R.W. Falta (eds), Vadose Zone Science and Technology Solutions, Battelle Press, Columbus, $\mathrm{OH}$.

Weeks, E.P., 1978, Field determination of the vertical permeability to air: U.S. Geol. Survey Prof. Paper 1058, p. 41.

Weisbrod, J., M.R. Niemet, T. McGinnis, J.S. Selker, 2003, Water vapor transport in the vicinity of imbibing saline plumes: Homogeneous and layered unsaturated porous media, Water Resources Research 39 (6).

Wheeting, L.C., 1925, Certain relationships between added salts and the moisture of soils, Soil Science, 19:287-299.

Williams M. D., V. R. Vermeul, J. E. Szecsody, and J. S Fruchter, 2000, 100-D Area In Situ Redox Treatability Test for Chromate-Contaminated Groundwater, PNNL-13349, Pacific Northwest National Laboratory, Richland WA.

Yeh, T.-C.J., L.W. Gelhar, and A.L. Gutjahr, 1985a, Stochastic analysis of unsaturated flow in heterogeneous soils. 2. Statistically anisotropic media with variable $\alpha$. Water Resources Research, 21, p. 457-464.

Yeh, T.-C.J., L.W. Gelhar, and A.L. Gutjahr, 1985b, Stochastic analysis of unsaturated flow in heterogeneous soils. 3. Observations and applications. Water Resources Research. 21, p. 465-471.

Young, M.H., P.J. Wierenga, A.W. Warrick, L.L. Hofmann, S.A. Musil, 1999, Variability of water front velocities during a field-scale infiltration experiment, Water Resources Research, 35, 3079-3087.

Yurtsever, Y., 1975, World survey of stable isotopes in precipitation, In Internal Report, International Atomic Energy Agency, Vienna. 
WMP-27397

Revision 1

This page intentionally left blank. 
WMP-27397

Revision 1

Appendix A: Workshop Agenda

AGENDA

Deep Vadose Zone Treatment Technologies Workshop

Room 1-Cl, 1200 Jadwin Avenue

Richland WA

April 26-28, 2005

Tuesday, April 26

8:00-8:15

$8: 15-8: 30$

8:30-8:45

8:45-9:00

9:00-9:15

9:15-9:30

9:30-10:15

10:15-10:30

10:30-11:00

$11: 00-12: 30$

$12: 30-1: 30$

$1: 30-2: 30$

2:30-3:00

3:00-5:00
Welcome and Introductions

Workshop Objectives and Logistics

Background - Problem Description at

$\mathrm{BC}$ Cribs and Trenches

EPA Perspective on Problem

Ecology Perspective on Problem

Tank Farms Perspective on Problem

In Situ Technology Evaluation

Break

Field Scale Information (SVE, field test)

Laboratory Tour (get site badges on the way)

Lunch

Vadose Zone Modeling at the Hanford Site

High Resolution Resistivity Results

Team Discussions / Workshop Structure
Morse and Wilde

Petersen and Kaback

Mark Benecke

Dennis Faulk

Dib Goswami

Anderson \& Myers

Mike Truex

Rick Cameron

Mart Oostrum

Mark White

Mark Sweeney/

Dale Rucker

Team

Wednesday, April 27 (Room 3-C5; badges required)

8:00-12:00

12:00-1:00

1:00-3:00

3:00-3:30

$3: 30-4: 30$
Brainstorming Solutions

Lunch

Evaluation of Options/Recommendations

U-Plant Waste Sites Issues

Discussion/Questions w/Hanford personnel
Team

Team

Roberta Day

All

\section{Thursday, April 28 (Back to Room 1-C1)}

8:00-12:00

12:00-1:00

1:00-2:30

2:30-4:00

$3: 30-4: 30$
Finalization of Recommendations

Lunch

Preparation of Outbriefing, Assignments

Team Writing

Out-briefing/Discussion w DOE and Fluor
Team

Team

All 
WMP-27397

Revision 1

\section{Panel Members}

Dr. Mark Ankeny - Geosciences Research Manager, INL

Dr. Jan Hendrickx - Professor of Hydrology, New Mexico Institute of Technology

Dr. Brian Looney - Advisory Scientist, Savannah River National Laboratory

Dr. Steve Silliman - Professor and Associate Dean for Educational Programs, University of Notre Dame

Dr. Michael Young - Deputy Directory / Associate Research Professor, Desert Research Institute Ed Weeks - Chief of Unsaturated Zone Field Studies, US Geological Survey, Denver

Dr. Dawn Kaback - Facilitator and Team Lead, Geomatrix Consultants, Inc. 
WMP-27397

Revision 1

\section{Appendix B: ${ }^{99}$ Tc Chemistry}

The relevant chemistry of technetium $\left({ }^{99} \mathrm{Tc}\right)$ and possible in situ treatment options were recently evaluated by Denham (2002). ${ }^{99} \mathrm{Tc}$ can exist in multiple oxidation states that range from -1 to +7 . The most prevalent forms in groundwater are $\mathrm{Tc}(\mathrm{IV})$ and $\mathrm{Tc}(\mathrm{VII})$. The $\mathrm{Tc}(\mathrm{VII})$ form is relatively soluble and dominated by the aqueous complex $\mathrm{TcO}_{4}{ }^{-}$ throughout the $\mathrm{pH}$ range of 2 to 10 . Under reducing conditions, the less soluble $\mathrm{Tc}$ (IV) predominates and forms an oxide, $\mathrm{TcO}_{2}$ or a hydrated solid phase $\mathrm{TcO}_{2} \cdot \mathrm{nH}_{2} \mathrm{O}$, in equilibrium with aqueous complexes of $\mathrm{Tc}(\mathrm{IV})$, such as $\mathrm{TcO}(\mathrm{OH})^{+}$and $\mathrm{TcO}(\mathrm{OH})_{2}{ }^{\circ}$. Figure B.1 shows the predicted aqueous ${ }^{99} \mathrm{Tc}$ species as a function of $\mathrm{pE}$ and $\mathrm{pH}$. It is clear from the stability fields of the reduced complexes that reduction of $\mathrm{Tc}(\mathrm{VII})$ to Tc(IV) occurs at mildly reducing conditions. The most widely proposed approach for in situ remediation of ${ }^{99} \mathrm{Tc}$ is redox manipulation -- reduce $\mathrm{Tc}$ (VII) to the $\mathrm{Tc}(\mathrm{IV})$ state to precipitate the relatively insoluble oxides. Related concepts of co-precipitation with other oxides and hydroxides have also been proposed.

Reduction of ${ }^{99} \mathrm{Tc}$ to levels below the nominal MCL (circa $900 \mathrm{pCi} / \mathrm{L}$ ) by reduction of $\mathrm{Tc}$ (VII) to $\mathrm{Tc}$ (IV) may not be achievable through precipitation alone and may require additional mechanisms (such as increased sorption). In Figure B.2, the solubilities of the predominant $\mathrm{Tc}(\mathrm{IV})$ solids $\left(\mathrm{TcO}_{2}\right.$ and $\left.\mathrm{TcO}_{2} \cdot 1.6 \mathrm{H}_{2} \mathrm{O}\right)$ are shown as a function of $\mathrm{pH}$. Note that the solubility of $\mathrm{TcO}_{2}$ is significantly lower than the solubility of $\mathrm{TcO}_{2} \cdot 1.6 \mathrm{H}_{2} \mathrm{O}$. $\mathrm{TcO}_{2}$ has a solubility below the nominal $\mathrm{MCL}$ and has often been used as the basis of proposals for in situ redox manipulation of ${ }^{99} \mathrm{Tc}$. However, $\mathrm{TcO}_{2}$ does not precipitate readily at low temperatures; instead, the hydrated solid phase is typically observed (Meyer and Arnold, 1991). Nevertheless, if the correct conditions can be created by redox manipulation without generating unjustified collateral environmental impacts, then ${ }^{99} \mathrm{Tc}$ concentrations are likely to decrease as a result of precipitation of the hydrated solid phase and because of enhanced sorption of the aqueous species $\mathrm{TcO}(\mathrm{OH})^{+}$and $\mathrm{TcO}(\mathrm{OH})_{2}{ }^{\circ}$ (see Walton et al., 1986; Lieser and Bauscher, 1987; Liang et al., 1996). Competing electron acceptors (such as nitrate, oxygen, and sulfate) will interfere with the desired reduction. These constituents, if present, will need to be reduced prior to effective treatment of ${ }^{99} \mathrm{Tc}$. 


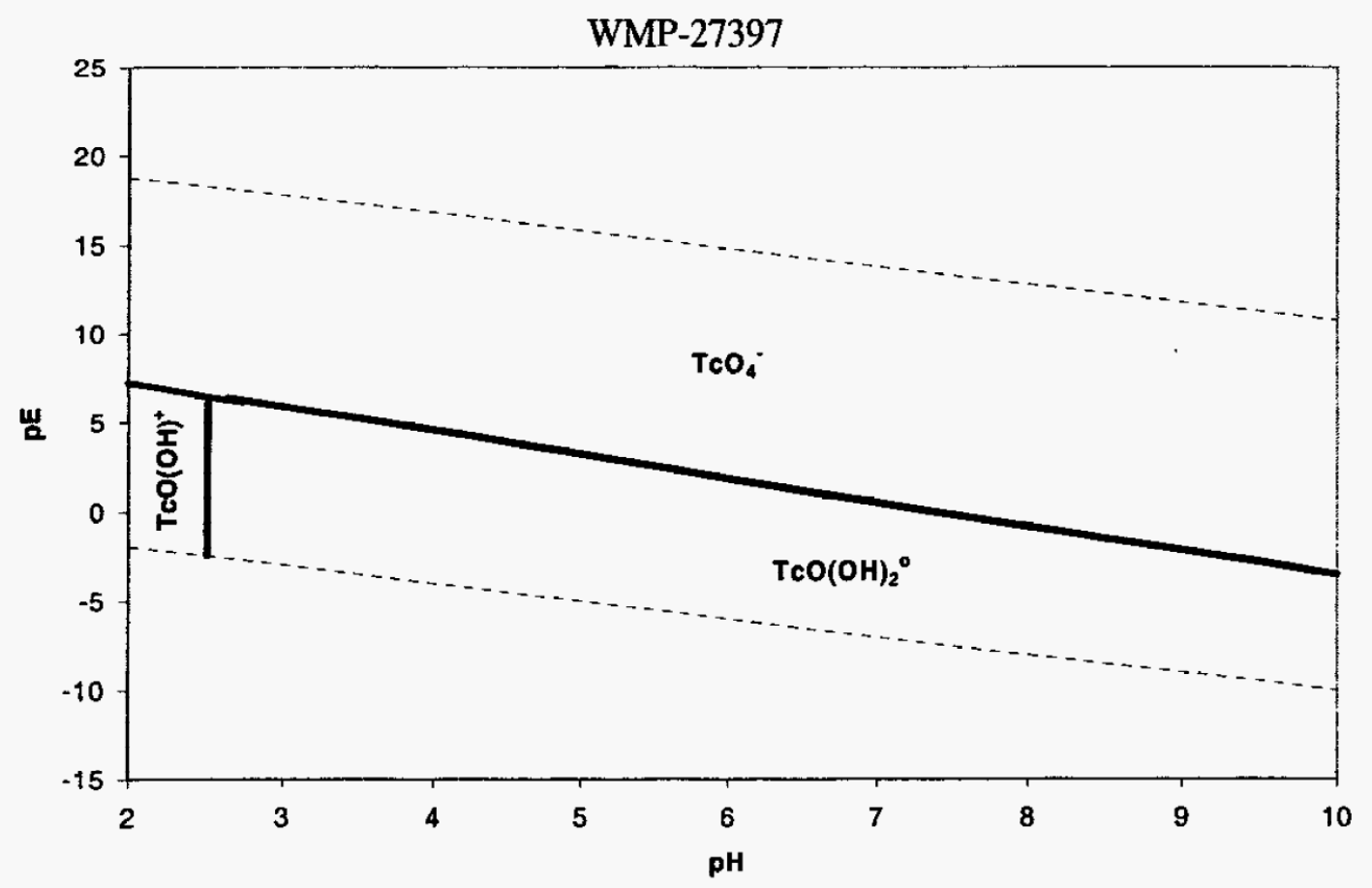

Figure B.1. Speciation (pe-pH) Diagram for Aqueous Complexes of ${ }^{99} \mathrm{Tc}$ at $25^{\circ} \mathrm{C}$

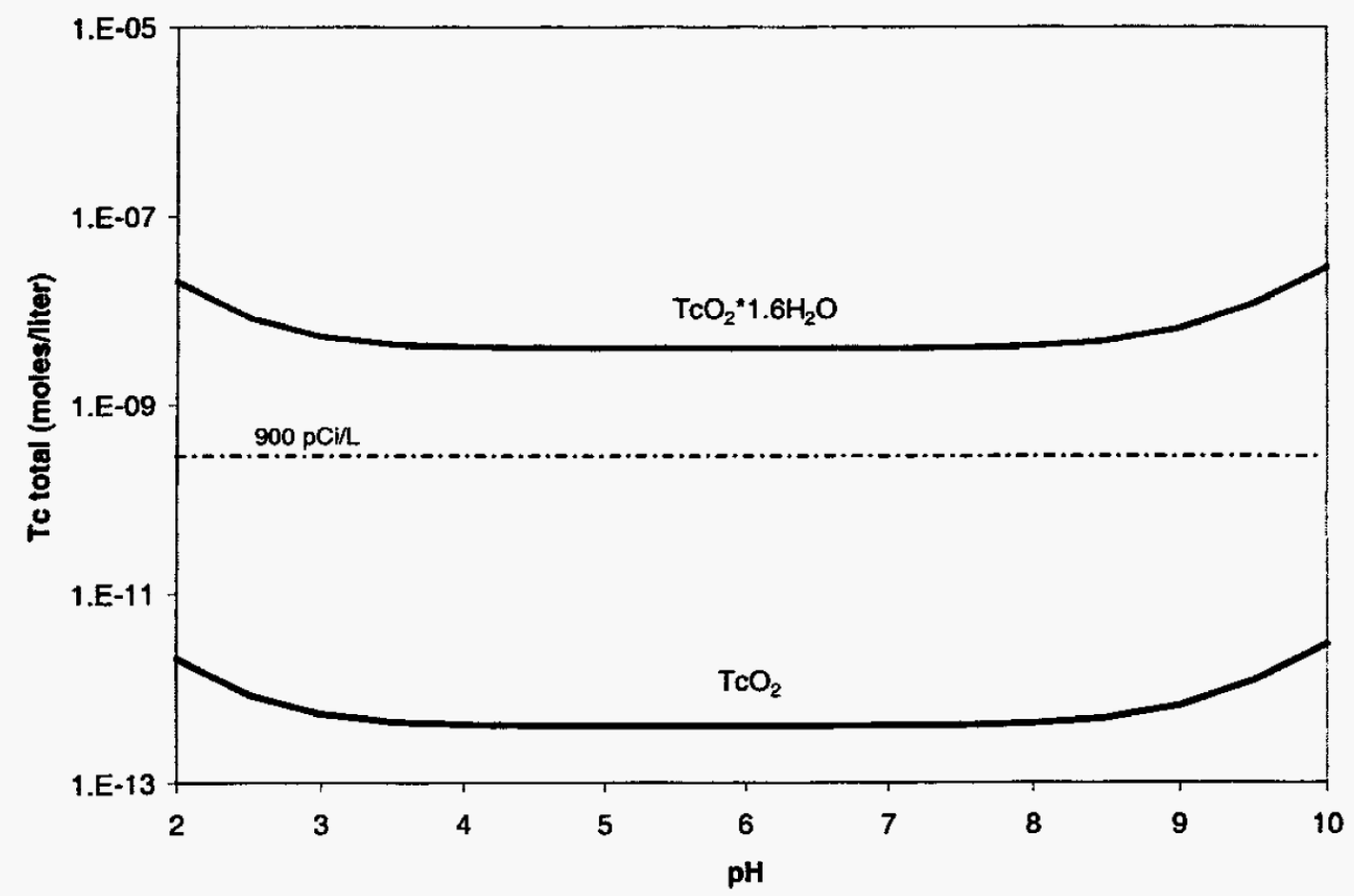

Figure B.2. Solubility Curves for the Phases $\mathrm{TcO}_{2} \cdot 1.6 \mathrm{H}_{2} \mathrm{O}$ and $\mathrm{TcO}_{2}$ at $25^{\circ} \mathrm{C}$ (a nominal MCL of 900 $\mathrm{pCi} / \mathrm{L}$ is shown for reference) 
WMP-27397

Revision 1

\section{Appendix C: Desiccation Calculations}

The maximum rate that air can be extracted from a well in a five-spot injection / withdrawal array is limited by the horizontal permeability to air of the medium. This limitation affects the relationship between well spacing and duration of injection / withdrawal required to achieve desiccation using such an array. This Appendix outlines the equations used to compute the maximum discharge rate as a function of permeability, well spacing, and production well radius, and provides an estimate of an air permeability value for the Hanford vadose zone. This permeability estimate is used to compute a maximum extraction rate that is used in turn to evaluate a base scenario of desiccation operations at the BC Cribs and Trenches site, as given in section 4.2.6.

\section{C.1 Equations Relating Well Discharge to Permeability}

An equation relating well discharge to permeability for noncompressible fluids has been developed for a basic unit five-spot arrangement of alternating injection and withdrawal wells by Matthews and Russell (1967, p. 72-73). This equation can be used to estimate the maximum discharge for wells injecting/extracting air if provision is made for the effects of air compressibility, assumed here to be provided by the Ideal Gas Law.

For incompressible fluids, the well discharge produced by the pressure drop at the withdrawal well below mean pressure in a five-spot unit (assuming no well losses) is determined by computing an effective radius, $\mathrm{r}_{\mathrm{e}}$, equal to the square area of influence of the withdrawal well, or $r_{e}=\sqrt{2 d^{2} / \pi}$, where $d$ is five-spot well spacing. Discharge per unit length of well screen is then given by the Thiem equation,

$$
q=\frac{2 \pi k \Delta P_{n c}}{\mu \ln \left(r_{e} / r_{w}\right)}, \quad \text { Equation } \mathrm{C} 1
$$

where $q$ is well discharge, $\mathrm{m}^{3} / \mathrm{s} / \mathrm{m} ; \mathrm{k}$ is permeability, $\mathrm{m}^{2} ; \Delta \mathrm{P}_{\mathrm{nc}}$ is the pressure drop for a noncompressible fluid, equal to $\left(P_{e}-P_{w}\right) ; P_{e}$ is pressure at the effective radius, $\mathrm{Pa} ; P_{w}$ is pressure at the well screen, $\mathrm{Pa} ; \mu$ is dynamic viscosity of the fluid, $\mathrm{Pa} \cdot \mathrm{s}$; and $\mathrm{r}_{\mathrm{w}}$ is the withdrawal well radius. For a compressible gas, the equation becomes:

$$
q=\frac{2 \pi k\left(P_{e}^{2}-P_{w}^{2}\right)}{\mu P_{0} \ln \left(r_{e} / r_{w}\right)}, \quad \text { Equation } \mathrm{C} 2
$$

where $P_{0}$ is ambient (atmospheric) pressure, in this case equal to $P_{e}$. Equation $C 2$ is analogous to the Dupuit-Forchheimer equation for discharge to a well fully penetrating an unconfined aquifer (Jacob, 1963, p. 247). Based on this analogy, it can be shown that observed pressure drop, $\Delta \mathbf{P}_{c}$, in a gas reservoir can be corrected to that for an equivalent noncompressible fluid as $\Delta P_{n c}=\Delta P_{c}-\frac{\Delta P_{c}^{2}}{2 P_{0}}$ or, inversely, $\Delta P_{n c}$ from equation $\mathrm{Cl}$ can be 
WMP-27397

Revision 1

used to compute $\Delta \mathrm{P}_{\mathrm{c}}$ by the equation

$\Delta P_{c}=P_{o}\left(1-\sqrt{1-\frac{2 \Delta P_{n c}}{P_{o}}}\right) . \quad$ Equation C3

The significance of Equation $\mathrm{C} 3$ is that the actual pressure drop would be that to a complete vacuum when the computed pressure drop from equation $\mathrm{Cl}$ is half the ambient pressure. Such a pressure drop is impossible, indicating that the computed $q$ would exceed that available from the formation. However, the correction for effects of compressibilty diminishes quickly as the pressure drop decreases from $\mathrm{P}_{0} / 2$. A safety margin to allow for well losses and barometric fluctuations limits the allowable computed pressure drop, $\Delta \mathrm{P}_{\mathrm{nc}}$, to be no more than about $0.4 \mathrm{P}_{0}$, or about $40,000 \mathrm{~Pa}$.

With that constraint on $\Delta \mathbf{P}_{\mathrm{nc}}$, a maximum air $\mathrm{q}$ can be solved for as a function of $\mathrm{k}$ (adjusted to be the permeability to air of the medium at its ambient moisture content, $\left.\mathrm{K}_{\mathrm{air}} \mathrm{k}_{\mathrm{h}}\right)$. For an assumed well radius of $0.1 \mathrm{~m}$, a well spacing of $40 \mathrm{~m}$, a k of $1 \times 10^{-12} \mathrm{~m}^{2}(1$ Darcy), and an air viscosity of $1.8 \times 10^{-5} \mathrm{~Pa} \cdot \mathrm{s}, \mathrm{q}_{\max }=0.0025 \mathrm{~m}^{3} / \mathrm{m} / \mathrm{s}$, or $\mathrm{q}_{\max } / \mathrm{k}=0.0025$ $\mathrm{m}^{3} / \mathrm{s} / \mathrm{m} / \mathrm{Darcy}$. For units of days, $q_{\max } / \mathrm{k}=200 \mathrm{~m}^{3} / \mathrm{s} / \mathrm{m} / \mathrm{Darcy}$.

\section{C.2 Permeability Estimate}

Permeability values (k) computed from hydraulic conductivities $(K)$ given by the SAFE report (Cameron et al., 2004, p. 3-15) and by Gee et al. (1989) appear to be too low to allow air withdrawal rates at values even closely matching the rates used in the SAFE experiments or in other Hanford area vapor extraction operations. However, an estimate of vadose zone permeability to air at its prevailing moisture content can be obtained from field-scale estimates of $D_{\mathrm{a}}$ (pneumatic diffusivity). Values of $D_{\mathrm{a}}$ of 0.15 and $0.20 \mathrm{~m}^{2} / \mathrm{s}$ are given for the sites of Hanford area monitoring wells 699-43-42 and 299-E33-41 (Spane, 1999). Values of $K_{a i r} k_{v}$, the effective vertical permeability to air at the prevailing moisture content, may be determined from the formula (Weeks, 1978, p. 1): $K_{\text {air }} k_{\mathrm{v}}=\frac{D_{a} \mu_{a} \theta_{a}}{P}$, where $\mu_{\mathrm{a}}$ is air dynamic viscosity, $\mathrm{Pa} \cdot \mathrm{s} ; \theta_{\mathrm{a}}$ is air-filled porosity, and $\mathrm{P}$ is station pressure, $\mathrm{Pa}$. Assuming $\mu_{\mathrm{a}}$ of $1.8 \times 10-5 \mathrm{~Pa} \cdot \mathrm{s}, \theta_{\mathrm{a}}$ of 0.3 , and $\mathrm{P}$ of $100,000 \mathrm{~Pa}$, $\mathrm{K}_{\mathrm{air}} \mathrm{k}_{\mathrm{v}}=8.1$ to $10.8 \times 10^{-12} \mathrm{~m}^{2}$. Due to the effects of bedding, the vertical permeability to air is undoubtedly lower than the horizontal permeability. Assuming the general rule of thumb of $\mathrm{k}_{\mathrm{h}} / \mathrm{k}_{\mathrm{v}}=10, \mathrm{~K}_{\mathrm{air}} \mathrm{k}_{\mathrm{h}} \approx 10^{-10} \mathrm{~m}^{2}$, or about 100 Darcies. For this $\mathrm{k}, \mathrm{q}_{\max }=0.25$ $\mathrm{m}^{3} / \mathrm{m} / \mathrm{s}$, or about $20,000 \mathrm{~m}^{3} / \mathrm{d} / \mathrm{m}$. This rate is about 15 times larger than that used for the SAFE desiccation test. 


\section{Appendix D: Further Desiccation Analysis}

The purpose of this appendix is to present a preliminary analysis of under what general conditions, if any, desiccation might increase risk related to groundwater contamination. It is not our intention to present a final judgment on the merits or problems of desiccation in the deep vadose zone at the Hanford Site. In general, desiccation seems to work quite well in delaying solute velocity. However, the case study on transient flow conditions in section D.3 demonstrates that desiccation might lead to increased solute fluxes at the water table.

\section{D.1 Motivation for Desiccation in the Deep Vadose Zone}

In deep vadose zones, gravity forces dominate water flow and as a result an (almost) steady downward flux develops below the root zone ${ }^{1}$. This long-term flux $q(L / T)$ determines the water content $\theta\left(\mathrm{L}^{3} / \mathrm{L}^{3}\right)$ in the vadose zone and in the absence of capillary forces

$q=K(\theta)$

where $K(\theta)$ is the unsaturated hydraulic conductivity $(\mathrm{L} / \mathrm{T})$ at water content $\theta$.

The convective flux of solutes $J(M / T)$ is

$J=q C=K(\theta) * C(\theta)$

where $C$ is the concentration of the solutes $\left(M / L^{3}\right)$.

As shown in Eq. [3], both the downward flux $q$ and concentration $C$ depend on the volumetric water content $\theta$. If the water content decreases due to desiccation, the flux will decrease and the solute concentration will increase. The increase of the solute concentration is a linear function of the decrease in water content, while the decrease of the unsaturated hydraulic conductivity and downward flux is a strongly non-linear function of the decrease in water content. Therefore, it is expected that the convective solute flux will decrease after desiccation in a deep homogeneous vadose zone where gravity-driven steady-state flow dominates. For example, the solute flux in loamy sand ${ }^{1}$ is calculated using Eq. [2] assuming a solute concentration at saturation of $1000 \mathrm{ppm}$. The logarithm of the solute flux is plotted against volumetric water content (Figure 1). If the media becomes drier, the solute flux dramatically decreases, because the decrease of the water flux is much larger than the increase in solute concentration. These theoretical results, based on steady-state flow in the deep vadose zone, make desiccation an attractive remediation strategy.

\footnotetext{
${ }^{1}$ The Van Genuchten parameters used to derive the hydraulic properties are: residual water content $=0.057$, saturated water content $=0.41$, alpha $=1.24, \mathrm{n}=2.28$, saturated hydraulic conductivity $=350.2 \mathrm{~cm} /$ day.
} 


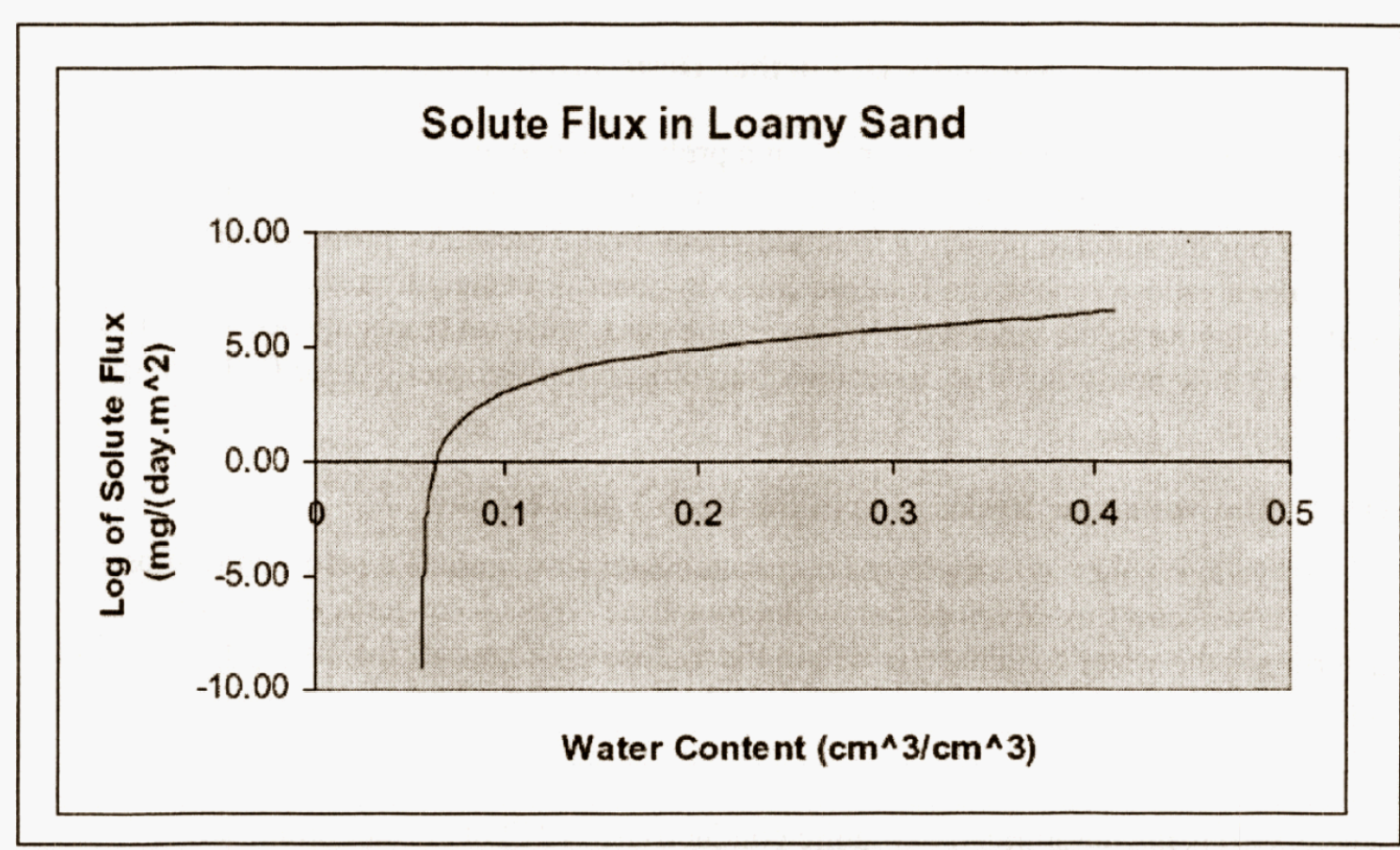

Figure D.1. Logarithm of Solute Flux through Deep Vadose Zone of Loamy Sand with Gravity-driven Steady-state Flow as a Function of Volumetric Water Content.

\section{D.2 How Much Water Must be Removed for Desiccation to Work?}

Figure D.1 demonstrates that the solute flux decreases non-linearly with decreasing water content. Due to the non-linear relationship between unsaturated hydraulic conductivity and volumetric water content decreasing the volumetric water content by one volume percent in a relatively dry soil has a much bigger impact than in a relatively wet soil. For example, a decrease in water content from 0.41 to 0.40 decreases the solute flux from 3.5 $\mathrm{x} 10^{6}$ to $2.8 \times 10^{6} \mathrm{mg} /$ day. $\mathrm{m}^{2}$, which is a decrease of 20 percent. However, a decrease in water content from 0.072 to 0.062 decreases the solute flux from 23.7 to 0.221 $\mathrm{mg} /$ day. $\mathrm{m}^{2}$, which is a decrease of two orders of magnitude. This means that the removal of a small amount of water in a relatively dry soil may have a big impact on the solute flux.

\section{D.3 Desiccation under Transient Flow Conditions}

Data from the BC Cribs and Trenches at Hanford showed an interval of elevated moisture and ${ }^{99} \mathrm{Tc}$ in the deep vadose zone, believed to occur as a result of liquid releases during waste operations in the cribs and trenches. This moisture is likely redistributing into deeper drier layers under transient flow and transport conditions. Previously, we have examined the effects of desiccation under steady flow conditions; in this section, we examine desiccation under transient flow conditions using a simple one-dimensional model HYDRUS1D ${ }^{2}$. HYDRUS-1D is a Microsoft Windows-based modeling environment for analysis of water flow and solute transport in variably saturated porous media. The latest version of this program can be downloaded at no charge from http://www.ussl.ars.usda.gov. The HYDRUS program is a finite-element model for 


\section{Revision 1}

simulating the one-dimensional movement of water, heat, and multiple solutes in variably saturated media (Simunek et al., 1998). The program numerically solves the Richards' equation for saturated-unsaturated water flow and Fickian-based advection dispersion equations for heat and solute transport.

Two simulations were conducted in a homogeneous ten-meter deep profile of loamy sand with the hydraulic properties presented in footnote 1 . The top boundary condition is a steady infiltration rate of $0.5 \mathrm{~mm} /$ year; the bottom boundary condition is a constant pressure head of $0 \mathrm{~cm}$, i.e. the water table. The initial conditions of Simulation One are presented in Figure D.2. In the top $400 \mathrm{~cm}$, is a "bulge" of water and solutes; the water content is 0.139 and the solute concentration is $0.5 \mathrm{mg} / \mathrm{cm}^{3}$ or $500 \mathrm{ppm}$. Simulation Two mimics desiccation where the top $400 \mathrm{~cm}$ has been dried from 13.9 to 6.85 volume percent water content; as a consequence the solute concentration increased from 0.5 to $1.0 \mathrm{mg} / \mathrm{cm}^{3}$ (Figure D.3).

Figures D.4 and D.5 present the solute fluxes entering the table at a depth of $10 \mathrm{~m}$ without and with desiccation. Simulation One results in a peak solute flux of about $7 \mathrm{x}$ $10^{-5} \mathrm{mg} /$ day. $\mathrm{cm}^{2}$, while Simulation Two mimicking the effects of desiccation in a peak solute bottom flux of $12 \times 10^{-5} \mathrm{mg} /$ day. $\mathrm{cm}^{2}$. Soil desiccation clearly would have an adverse effect on peak solute bottom flux. However, it is quite effective in delaying the arrival of the peak concentration as well as the time where the first solutes enter the water table. These simulations demonstrate that under transient flow conditions, desiccation is effective in delaying solute arrival at the water table, but might cause an increase of the solute flux in the groundwater.
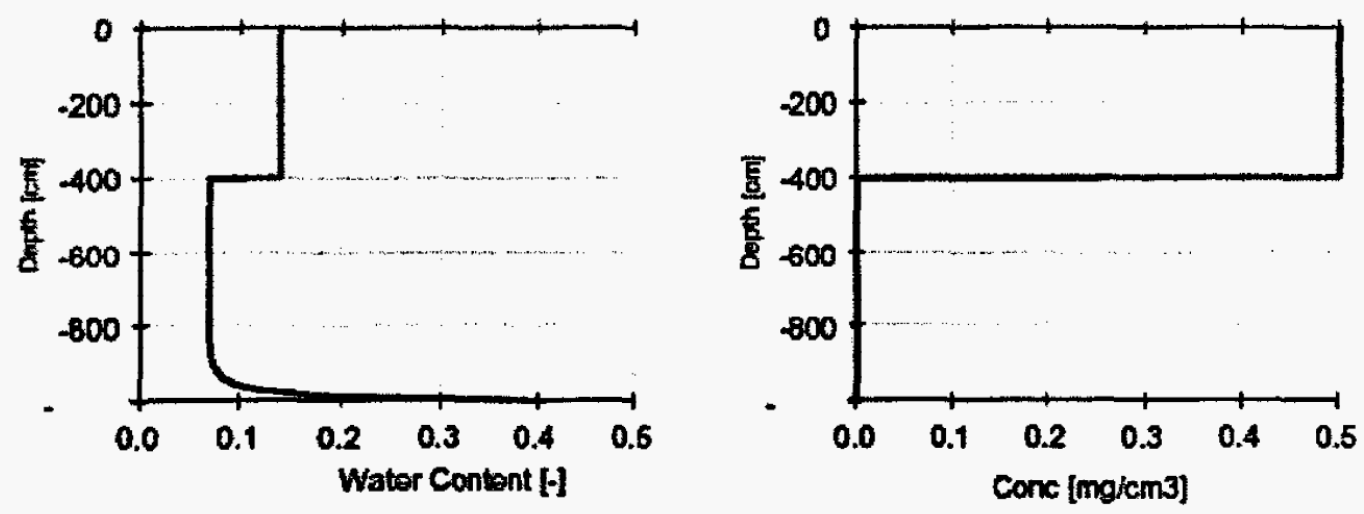

Figure D.2. Initial Profiles of Water Content and Solute Concentration with Depth for Simulation One 

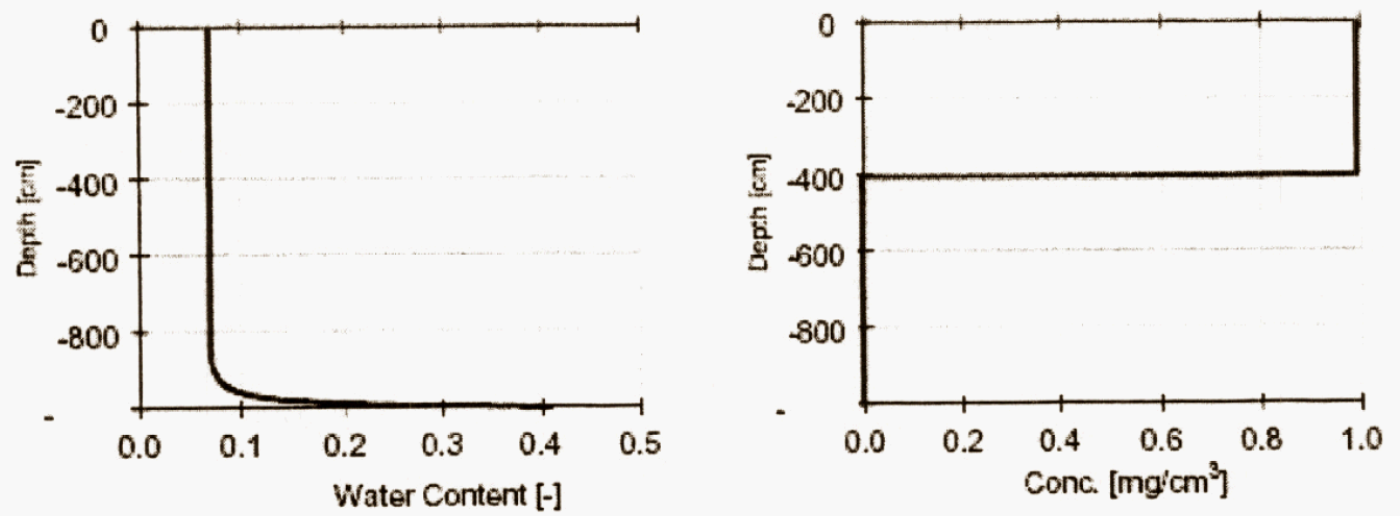

Figure D.3. Initial Profiles of Water Content and Solute Concentration with Depth for Simulation Two after Desiccation

[Note length scale of concentration is different from Figure D.2.]

\section{Solute Bottom Flux Simulation One}

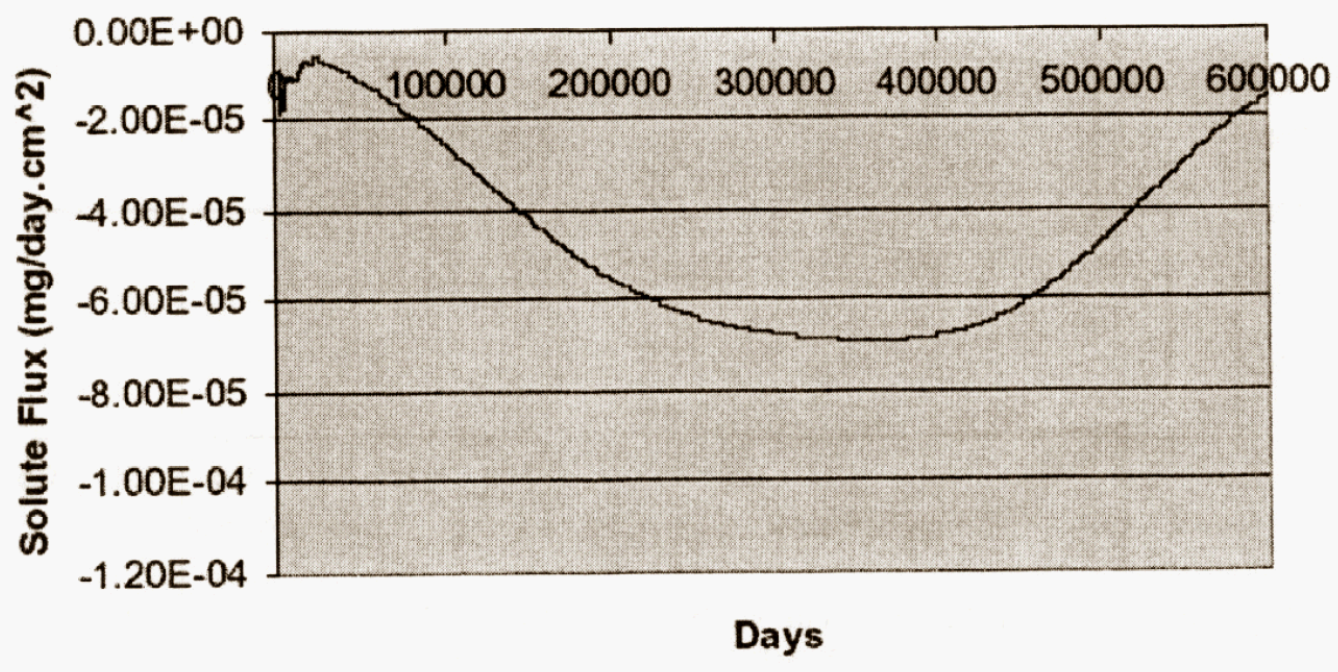

Figure D.4. Solute Bottom Flux for Simulation One with Water and Solute "Bulge" in Top Four Meters of the Profile 




Figure D.5. Solute Bottom Flux for Simulation Two after Desiccating the Water

\section{"Bulge" in the Top Four Meters of the Profile \\ "Bulge" in the Top Four Meters of the Profile}

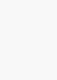

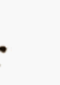

\section{WMP-27397
Revision 1 \\ WMP-27397
Revision 1 \\ Revision 1}

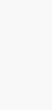

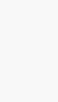




\section{Appendix E: Perturbation Geochemistry}

Perturbation geochemistry, as described in Section 4.2.9, is currently being researched at INL. Some of the key questions being pursued are discussed below. Most contaminated subsurface systems are not at equilibrium. Diffusion of the contaminants into the interior of the crystallites is a slow process. Some of the chemical reactions are slow. One can change the nature of these systems by geochemically perturbing them by changing the $\mathrm{Eh}, \mathrm{pH}$, and/or the concentrations of certain ions in the system. Such perturbations can take the system far from the ambient condition and result in conditions that maintain contaminant concentrations in the subsurface water at much lower concentrations. For example, by dissolving a mineral phase and rapidly precipitating it, contaminants that were previously on the surface of the crystal will be distributed over a greater depth resulting in lower concentrations on the surface of the crystal and hence lower aqueous concentrations. Further, because of the kinetics of the precipitation, it is likely that the concentrations of the contaminants will be higher in the interior of the crystal than on the exterior surface (Doerner-Hoskins model). Such phenomena would lower the aqueous concentrations even further. The contaminants in the interior of the crystal will most likely reach mobile water only by solid-state diffusion which is a very slow process. Infiltrating water will be equilibrated with naturally existing calcite in the system before it reaches the treated zone, so little or no mineral dissolution will occur.

Contaminants may also be co-precipitated in metastable phases that can sequester a contaminant for long periods of time and control release rates to values that maintain their aqueous concentrations below the MCL. The concept of geochemically perturbing subsurface systems to achieve longer and better sequestration of contaminants may prove to be a fast and cost-effective means of controlling the release of contaminants from many waste sites. These processes can be manipulated to jointly decrease the concentrations of the contaminants in the pore water and increase their retardation in the vadose zone.

The key issue is delivering the amendments capable of producing the appropriate biogeochemical perturbations without mobilizing the contaminants in the vadose zone.

\section{E.1 Perturbation of Carbonate Systems}

Methods are needed to inhibit the transport of contaminants, such as ${ }^{90} \mathrm{Sr}$, through the vadose zone to the water table and thereby decrease the risk of exposure to the environment. For select contaminants, co-precipitation with natural mineral phases is one approach to retarding metal contaminant migration. Because of their low concentrations, most contaminant metal ions generally do not precipitate as pure phases; rather they are co-precipitated in common mineral phases such as calcite, forming solid solutions. Coprecipitation of metals (Tesoriero and Pankow, 1996) and radionuclides (Curti, 1999) into calcite is well established. Co-precipitation with calcite is expected to be important at many arid western sites that have sediments with significant amounts of calcite. The concentration of metal ions in pore water equilibrated with such solid solutions is often much lower than the concentrations in waters equilibrated with the pure phases, and apparent retardation factors can be greatly increased (Tesoriero and Pankow, 1996). The amount of co-precipitated metal in the phase depends on the thermodynamics 
WMP-27397

\section{Revision 1}

of solid solutions as well as the rate of precipitation. For example, Tesoriero and Pankow (1996) report increases in apparent retardation factors for Sr by factors of 8 to 9 at higher precipitation rates when compared to lower precipitation rates. This additional retardation means that the contaminants will remain in the vadose zone for a longer period of time. For ${ }^{90} \mathrm{Sr}$, which has a half life of $29.2 \pm 0.1$ years, more of the ${ }^{90} \mathrm{Sr}$ can decay before reaching the water table.

In many cases, the existing vadose-zone contamination is associated with cation exchange sites at, or very near, the surface of naturally existing crystallites, such as calcite. By perturbing the geochemistry of the system so as to increase the solubility of calcite, the contaminated surfaces and the underlying uncontaminated calcite will dissolve, increasing $\mathrm{Ca}^{2+}$ concentrations in the pore water, which will compete for sites with many of the contaminants as well as with other cations in the exchange sites. After this initial dissolution step, the system returns to the ambient chemical conditions resulting in the re-precipitation of calcite and the co-precipitation of solubilized radionuclides and metal contaminants.

Using the gas phase for geochemical perturbation of the vadose zone offers advantages over liquid phase additions. Introduction of liquid solutions into the vadose zone generally runs the risk of mobilizing contaminants. Further, small-scale preferential flow in the physically and chemically heterogeneous media results in liquid phase amendments being inadequately distributed. For example, with addition of $\mathrm{CO}_{2}$ gas, we can decrease the $\mathrm{pH}$ of the soil water and increase the solubility of calcite:

$$
\mathrm{CaCO}_{3}+\mathrm{H}_{2} \mathrm{O}+\mathrm{CO}_{2(\mathrm{~g})}=\mathrm{Ca}^{2+}+2 \mathrm{HCO}_{3}^{-}
$$

The additional $\mathrm{Ca}^{2+}$ in the soil water solubilizes sorbed radionuclides and metals, such as $\mathrm{Sr}$, on an exchanger $(\equiv \mathrm{Sr})$ via:

$$
\equiv \mathrm{Sr}+\mathrm{Ca}^{2+}=\equiv \mathrm{Ca}+\mathrm{Sr}^{2+}
$$

If the $\mathrm{Ca}^{2+}$ concentration is insufficient to remove the $\mathrm{Sr}$ from the exchanger, a small amount of ammonia can be added to the gas mixture to generate $\mathrm{NH}_{4}{ }^{+}$in the soil water to displace the Sr. Purging with another gas, such as air or $\mathrm{N}_{2}$, will then increase the $\mathrm{pH}$, inducing precipitation of a calcite solid solution with a mole fraction, $\mathrm{X}, \mathrm{of} \mathrm{Ca}^{2+}$ and a mole fraction, $(1-\mathrm{X})$ of $\mathrm{Sr}^{2+}$ :

$$
\mathrm{XCa}^{2+}+(1-\mathrm{X}) \mathrm{Sr}^{2+}+2 \mathrm{HCO}_{3}^{-}=\left(\mathrm{CaXSr}_{1-\mathrm{X}}\right) \mathrm{CO}_{3}+\mathrm{CO}_{2(\mathrm{~g})}+\mathrm{H}_{2} \mathrm{O}
$$

The thermodynamic and kinetic considerations of such solid solutions are outlined in the technical literature (Barron and Palmer, 2002;Tesoriero and Pankow, 1996).

The potential benefits of gas-phase amendments over liquid-phase manipulation for the co-precipitation of metals and radionuclides include

- the cost of delivering gases to the vadose zone is relatively low,

- large diffusion coefficients of gases in the vadose zone allow treatment of unsaturated sediments in spite of subsurface heterogeneity,

- gases are less likely to mobilize soil water and their associated contaminants,

- gas-delivery systems will have minimal effect on other activities at the site, and 
WMP-27397

\section{Revision 1}

- co-precipitation of radionuclides with the calcite will increase their retardation in the vadose zone allowing more of time for them to decay before reaching the water table (Curti, 1999).

\section{E.2 Perturbation of Silicate Systems}

Ammonia is highly soluble in water with a solubility of almost $300 \mathrm{~g} / \mathrm{L}$ of ammonia at a $15^{\circ} \mathrm{C}$ at a partial pressure of 1 . Thus, if gaseous ammonia is injected into the vadose zone, a large portion of it will partition into the soil water:

$$
\mathrm{NH}_{3} \text { gas } \leftrightarrows \mathrm{NH}_{3} \text { aqueous }
$$

At $\mathrm{pH}$ values less than about 9 , ammonia reacts with water to form ammonium $\left(\mathrm{NH}_{4}{ }^{+}\right)$and hydroxyl ions $(\mathrm{OH})$ :

$$
\mathrm{NH}_{3}+\mathrm{H}_{2} \mathrm{O} \leftrightarrows \mathrm{NH}_{4}^{+}+\mathrm{OH}^{-}
$$

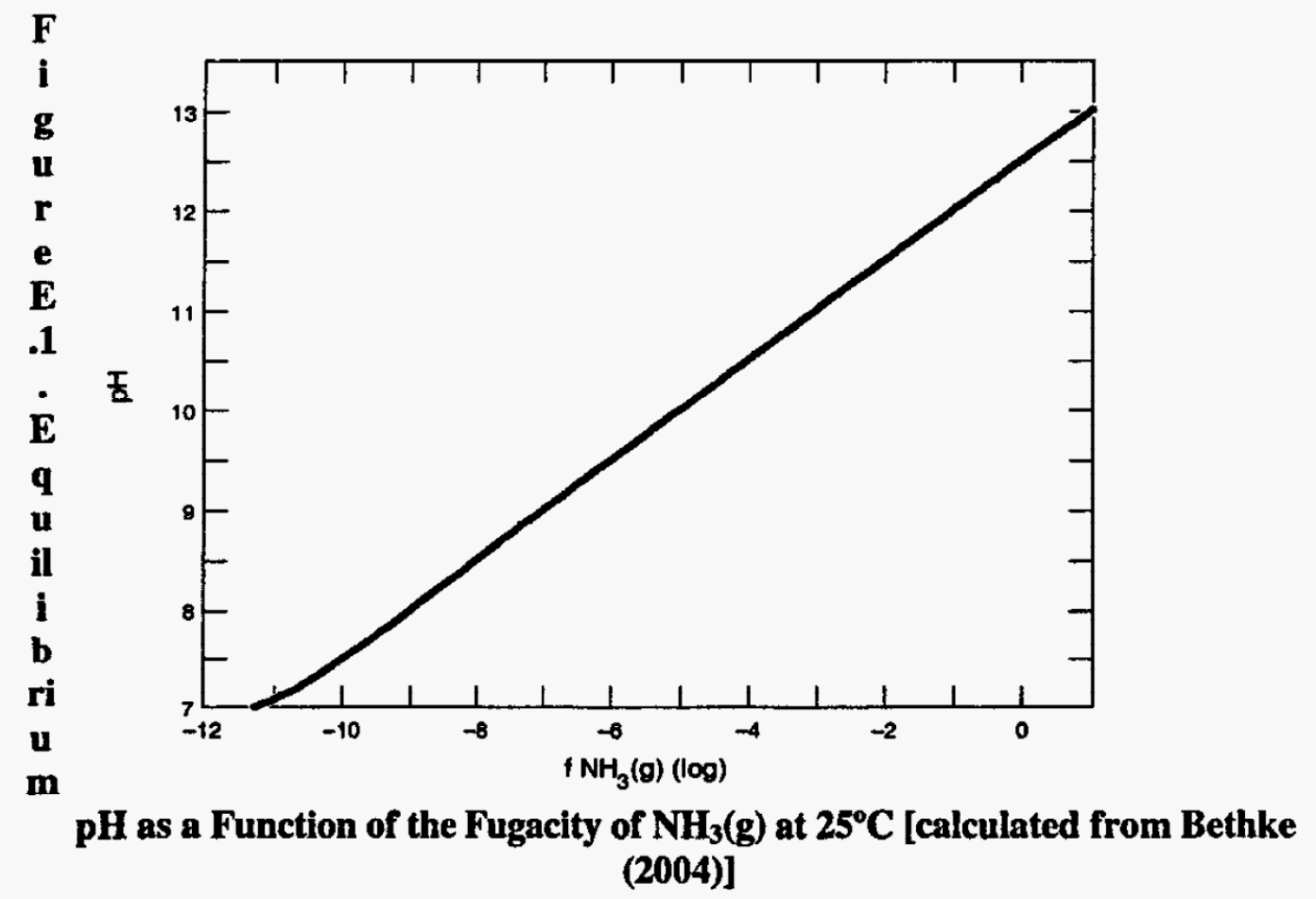

Generating hydroxyl ions increase the $\mathrm{pH}$ of the solution to values greater than 13 as the fugacity approaches 1 . At these high $\mathrm{pH}$ values, silica concentrations can become very high (Figure E.2). The elevated $\mathrm{pH}$ values also promote the dissolution of $\mathrm{Al}$ and $\mathrm{Fe}$ oxides as well as aluminosilicate minerals. These conditions can result in the formation of various aluminosilicate phases that have the potential of co-precipitating metal contaminants and radionuclides. For example, C.D. Palmer of INL (unpublished data) observed the formation of bertherine (a mixed $\mathrm{Fe}(\mathrm{II}) / \mathrm{Fe}(\mathrm{III})$ aluminosilicate), nontronite (an iron-rich smectite clay), annite (an Fe-rich mica), and perhaps a zeolite downgradient 
from a zero-valent iron permeable reactive barrier in which the $\mathrm{pH}$ approached 11 .

Precipitates have been observed to form in sediments at Hanford where solutions with pH $>13$ have leaked into the subsurface. There are a large number of precipitates that can form in Portland cement systems where the $\mathrm{pH}$ is about 12.5. Many of these are known to sequester metals and radionuclides. If the newly formed phases remain metastable as the fugacity of carbon dioxide and other gases return to ambient state, then the contaminants may remain sequestered in the vadose zone for long periods of time.

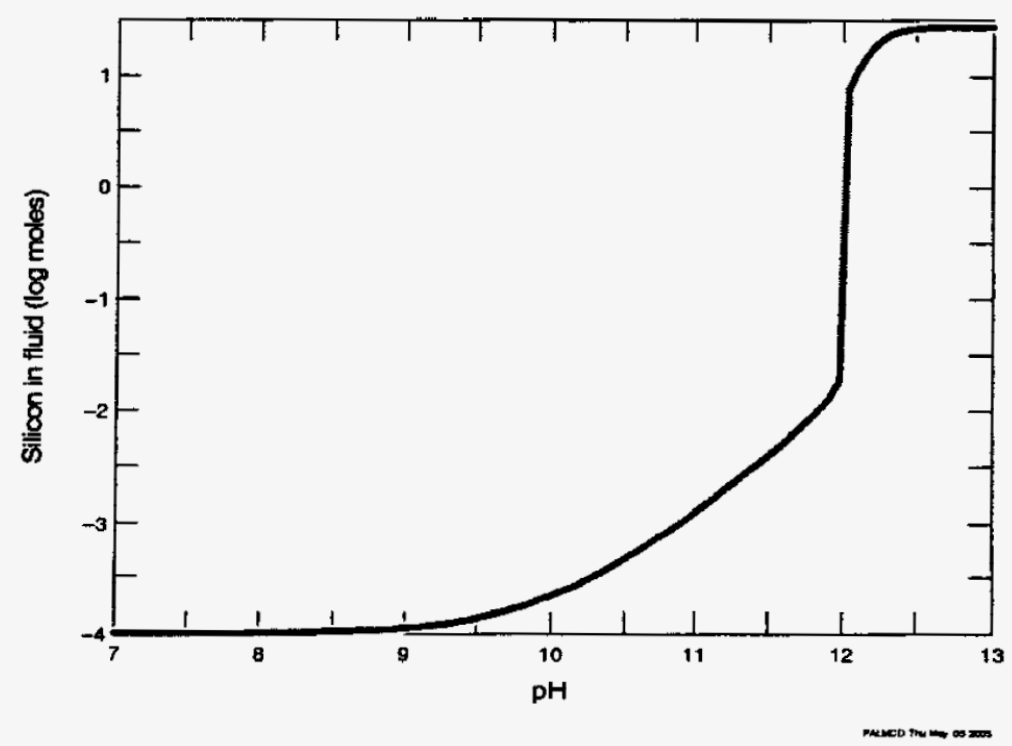

Figure E.2. Concentration of $\mathrm{SiO}_{2}$ as a Function of pH in a Quartz-Water System 
WMP-27397

Revision 1

\section{DISTRIBUTION}

Onsite

5

Fluor Hanford

M. W. Benecke

E6-35

T. W. Fogwell

E6-35

S. W. Petersen

E6-35

K. S. Schneider (2)

E6-35

1

Pacific Northwest National Laboratory

Hanford Technical Library

P8-55

2

Lockheed Martin Information Technology

Document Processing Center

H6-08

EDMC

H6-08

Distr.-1 